Universidade de São Paulo

Instituto de Astronomia, Geofísica e Ciências Atmosféricas

Departamento de Geofísica

Túlio Cordeiro Bicudo

\title{
Caracterização de contaminação por hidrocarboneto creosoto utilizando os métodos GPR e Eletrorresistividade
}

São Paulo 



\section{Túlio Cordeiro Bicudo}

\section{Caracterização de contaminação por hidrocarboneto creosoto utilizando os métodos GPR e Eletrorresistividade}

Dissertação apresentada ao Departamento de Geofísica do Instituto de Astronomia, Geofísica e Ciências Atmosféricas da Universidade de São Paulo como requisito parcial para obtenção do título de Mestre em Ciências.

Área de Concentração: Geofísica Aplicada. Orientador: Prof. Dr. Jorge Luís Porsani (IAG/USP).

Versão Corrigida. O original encontra-se disponível na Unidade.

São Paulo 
“Nós somos uma maneira para o cosmos se autoconhecer."

- Carl Sagan 


\section{Agradecimentos}

Agradeço aos meus pais, Marta e Zílcio por me ensinarem o valor dos estudos e do trabalho duro, me incentivando sempre a dar o meu melhor.

Dedico este trabalho a minha amada namorada Caroline Costa Nunes por todo o amor, apoio e ajuda durante esses 11 anos de companheirismo e principalmente durante os 2 anos de curso de mestrado que não foram nada fáceis.

Aos meus irmãos Tales, Tácio e Silvana por todo amor e suporte durante toda minha vida.

Aos meus sogros Valdir e Rita por todo apoio e incentivo durante todos os anos que estamos juntos.

Aos meus tios José, Inailda e Mara pelo incentivo durante minha vida, desde criança. Eles fazem parte diretamente do meu desenvolvimento estudantil.

À minha querida e amada avó, Dona Maria, que hoje já não está mais presente, mas a levo sempre em meu coração. Obrigado por todo amor e carinho.

Ao meu falecido Tio Eduardo, uma pessoa muito boa a qual sempre me lembrarei com muito carinho.

Ao meu orientador Prof. Dr. Jorge Luís Porsani por todo apoio durante mais de 4 anos de orientação.

Aos professores do IAG/USP por todo o conhecimento passado durante a minha graduação e pós graduação, em especial professores Chiquinho, Vagner e Victor.

Aos funcionários do IAG por toda a estrutura disponibilizada para formar um ambiente ótimo para meu trabalho, muito obrigado.

Aos meus colegas do IAG, em especial os amigos Dr. Vinicius, Felipe, Dr. Marcelo, Prof. Emerson, Giovanni e Matheus.

Aos técnicos Marcelo e Ernande por todo o apoio durante a minha pesquisa.

À CAPES pela bolsa de mestrado.

À todos que contribuíram para que eu chegasse até aqui.

Muito Obrigado! 


\section{Sumário}

Lista de Abreviações e Símbolos................................................................................................

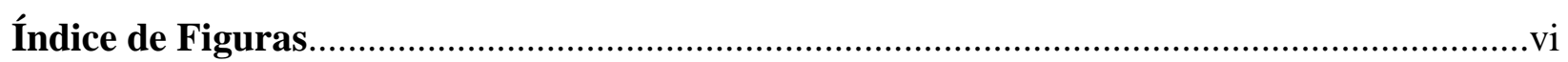

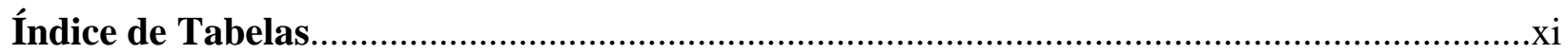

Resumo

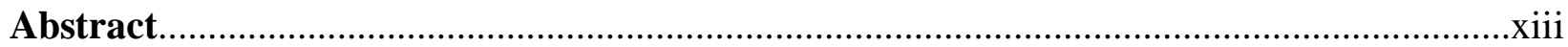

\section{CAPÍTULO 1}

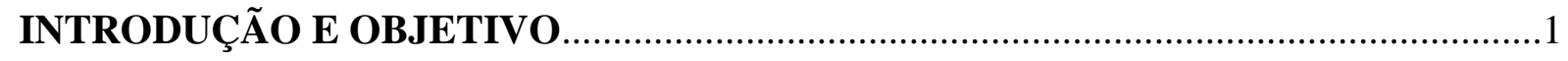

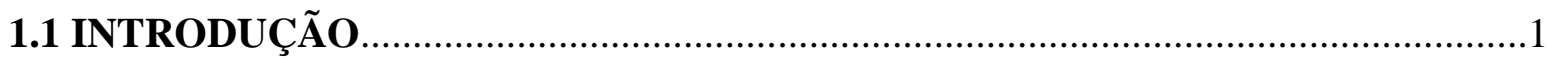

1.2 OBJETIVO.

\section{CAPÍTULO 2}

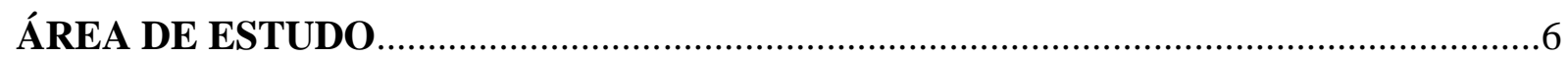

2.1 HISTÓRICO

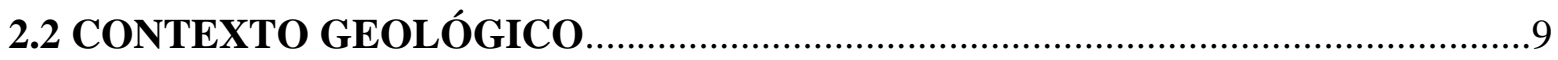

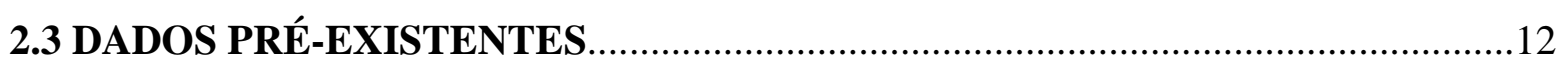

\section{CAPÍTULO 3}

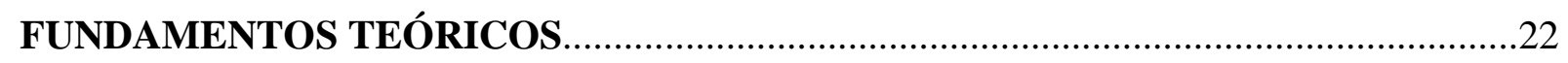

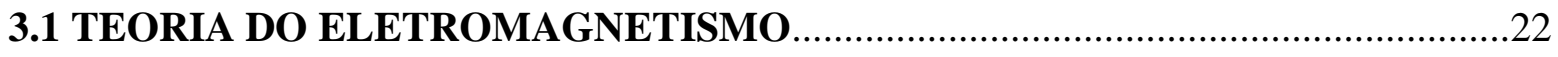

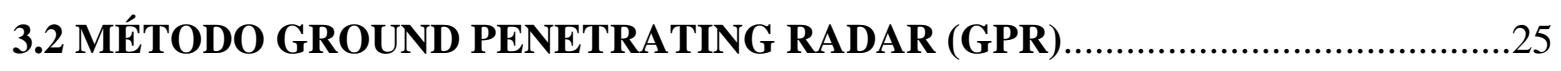

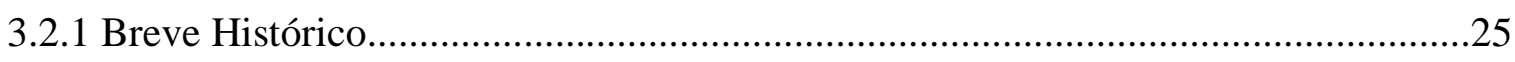

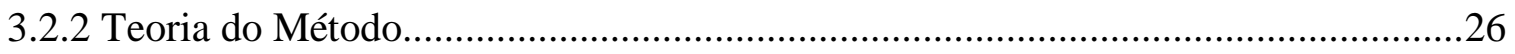

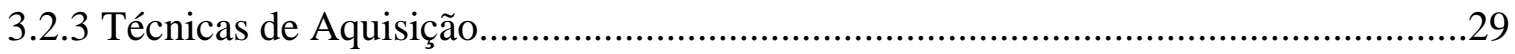

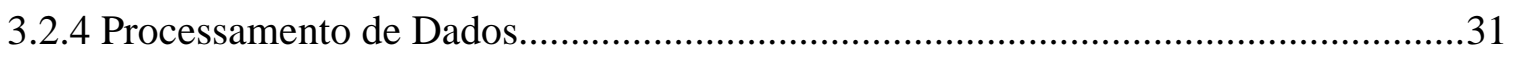

3.2.4.1 Processamento de Dados no ReflexWin...............................................................32

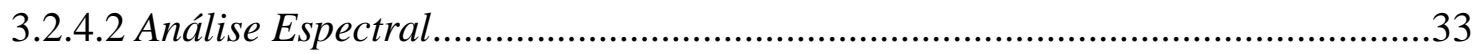

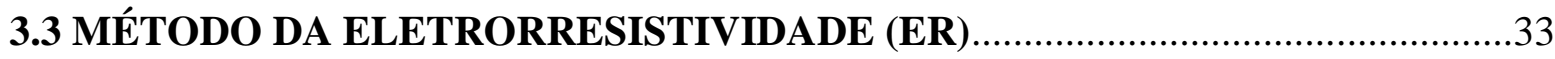




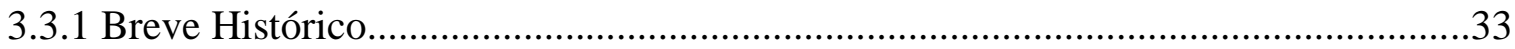

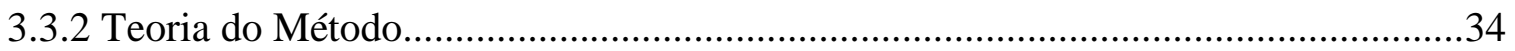

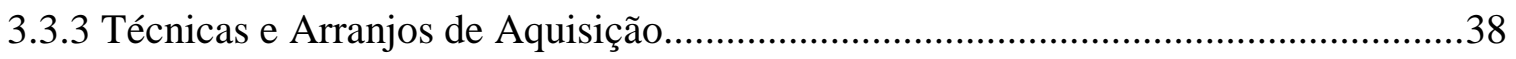

3.3.4 Eletrorresistividade com Acoplamento Capacitivo (RC)..........................................41

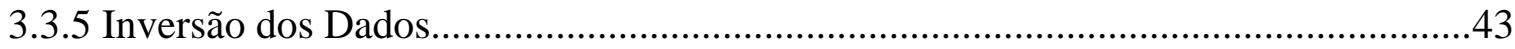

\section{CAPÍTULO 4}

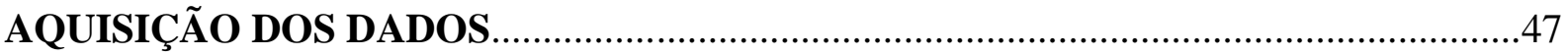

4.1 COLETA DE AMOSTRAS DE SOLOS...................................................................4

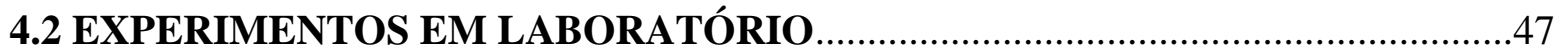

4.2.1 Medidas de Resistividade das Amostras de Solos......................................................47

4.2.2 Aquisições GPR..................................................................................................... 51

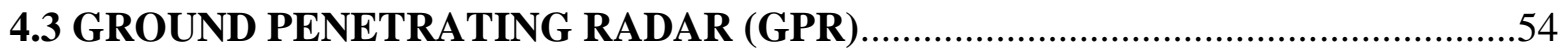

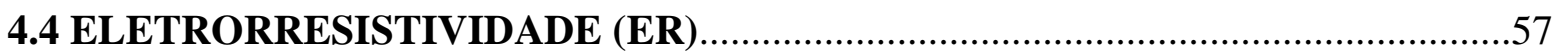

4.5 ELETRORRESISTIVIDADE COM ACOPLAMENTO CAPACITIVO (RC).......58

\section{CAPÍtULO 5}

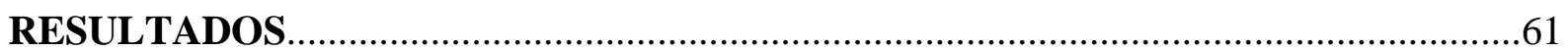

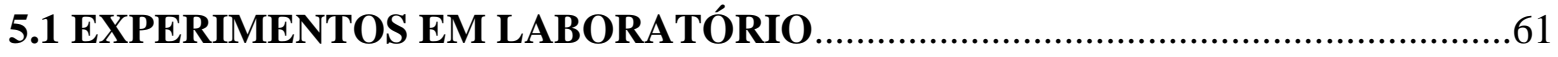

5.1.1 Medidas de Resistividade das Amostras de Solos.......................................................61

5.1.2 Aquisições e Análise Espectral GPR.....................................................................65

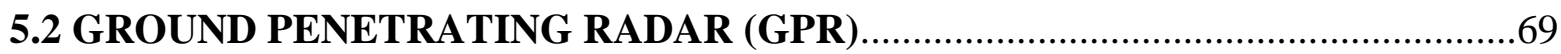

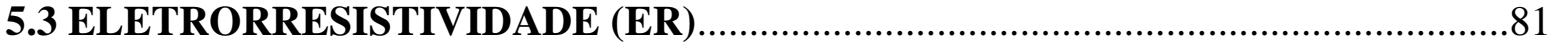

5.4 ELETRORRESISTIVIDADE COM ACOPLAMENTO CAPACITIVO (RC).......84

\section{CAPÍTULO 6}

DISCUSSÃO

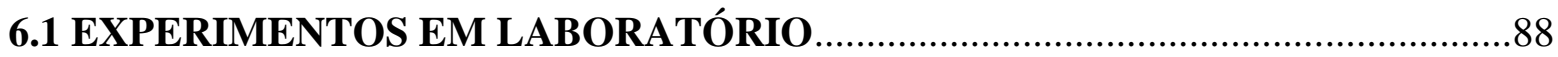

6.1.1 Medidas de Resistividade das Amostras de Solos......................................................8

5.1.2 Aquisições e Análise Espectral GPR........................................................................ 89

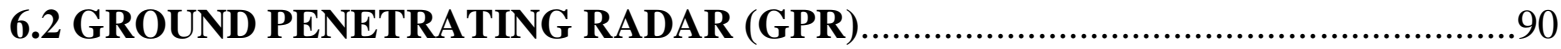




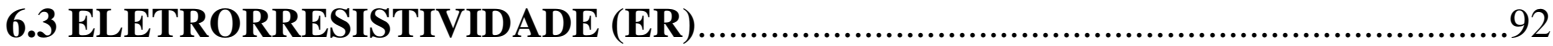

6.4 ELETRORRESISTIVIDADE COM ACOPLAMENTO CAPACITIVO (RC).......93

\section{CAPÍTULO 7}

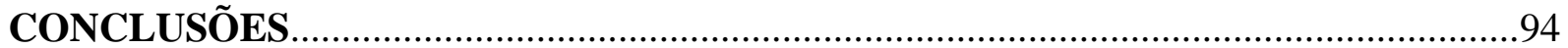

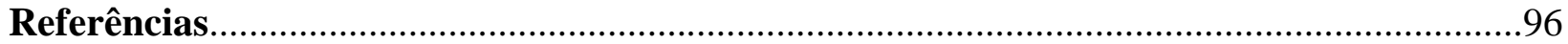




\section{Lista de Abreviações e Símbolos}

GPR - Ground Penetrating Radar

ER - Eletrorresistividade

RC - Eletrorresistividade com Acoplamento Capacitivo

LNAPL - Light Non Aqueous Fase Liquid

DNAPL - Dense Non Aqueous Fase Liquid

IPT - Instituto de Pesquisas Tecnológicas

$\boldsymbol{E}$ - Vetor Intensidade do Campo Elétrico (V/m)

$\boldsymbol{H}$ - Vetor Intensidade do Campo Magnético (A/m)

$\boldsymbol{D}$ - Vetor Densidade de Fluxo Elétrico $\left(\mathrm{C} / \mathrm{m}^{2}\right)$

$\boldsymbol{B}$ - Vetor Densidade de Fluxo Magnético (T)

$J_{C}$ - Vetor Densidade de Corrente de Condução Elétrica $\left(\mathrm{A} / \mathrm{m}^{2}\right)$

$\nabla \cdot-$ Operador Divergente

$\nabla \times$ - Operador Rotacional

$\frac{\partial}{\partial t}$ - Operador de Derivação com Relação ao Tempo

$\boldsymbol{J}_{D}$ - Vetor Densidade de Corrente de Deslocamento $\left(\mathrm{A} / \mathrm{m}^{2}\right)$

$\sigma$ - Condutividade Elétrica (S/m)

$\mu$ - Permeabilidade Magnética $(\mathrm{H} / \mathrm{m})$

$\varepsilon$ - Permissividade Dielétrica $(\mathrm{F} / \mathrm{m})$

$\mu_{0}$ - Permeabilidade Magnética do Vácuo (H/m)

$\varepsilon_{0}-$ Permissividade Dielétrica do Vácuo $(\mathrm{F} / \mathrm{m})$

$E_{0}$ - Amplitude do Campo Elétrica

$\omega$ - Frequência Angular (rad/s)

$i$ - Unidade Imaginária

$H_{0}$ - Amplitude do Campo Magnético

$f$ - Frequência $(\mathrm{Hz})$

$\overrightarrow{\mathrm{A}}-$ Vetor Arbitrário 
$\nabla$ - Operador Gradiente

$\nabla^{2}-$ Laplaciano

$\varepsilon_{r}$ - Constante Dielétrica

$k$ - Número de Onda Complexo

$\alpha$ - Coeficiente de Atenuação $(\mathrm{dB} / \mathrm{m})$

$\beta$ - Coeficiente de Propagação ( $\mathrm{rad} / \mathrm{m})$

$v$ - Velocidade de Propagação

$c$ - Velocidade da Luz no Vácuo

$c r$ - Coeficiente de Reflexão

Tx - Antena Transmissora

$\mathrm{Rx}$ - Antena Receptora

STFT - Transformada de Fourier no Tempo Curto

$\int$ - Operador de Integração

$R$ - Resistência (Ohm)

$\rho$ - Resistividade Elétrica $(\mathrm{Ohm} \cdot \mathrm{m})$

$S$ - Área da Secção Transversal de um Cilindro $\left(\mathrm{m}^{2}\right)$

$L$ - Comprimento Arbitrário de um Cilindro (m)

$\Delta V$ - Diferença de Potencial (V)

I - Corrente Elétrica (A)

$\Omega-\mathrm{Ohm}$

FC - Frequência Central

STFT - Short Time Fourier Transform (Transformada de Fourier no Tempo Curto) 


\section{Índice de Figuras}

Figura 1. Mapa de localização da área de estudo no Bairro do Jaguaré, cidade de São Paulo - SP, Brasil...... .6

Figura 2. Foto do setor de tratamento químico de dormentes de madeira na parte sul do terreno (foto da década de 90). Fonte: Relatório do IPT do ano de 2010. 7

Figura 3. Mapa do setor de tratamento químico de madeiras com as posições dos tanques aéreos e das autoclaves. Informações retiradas da planta disponibilizada pelo IPT. 8

Figura 4. Mapa das localizações dos furos para caracterização da estratigrafia. .10

Figura 5. Perfis estratigráficos observados nos furos de sondagem.

Figura 6. Fotos de alguns dos tipos de solos encontrados durante a perfuração. a) Solo argiloso vermelho. b) Solo argiloso preto. c) Solo argiloso cinza escuro.

Figura 7. Mapa das posições das coletas de amostras de solo e de água para a análise química......14

Figura 8. Resultado da análise química de algumas amostras de solo quanto a concentração de diversos compostos químicos. Dados disponibilizados pelo IPT.

Figura 9. Resultado da análise química de algumas amostras de solo quanto ao número de carbono das cadeias carbônicas e concentrações de TPH. Dados disponibilizados pelo IPT.

Figura 10. Resultado da análise química de algumas amostras de água quanto a concentração de diversos compostos químicos. Dados disponibilizados pelo IPT.

Figura 11. Resultado da análise química de algumas amostras de água quanto ao número de carbono das cadeias carbônicas e concentrações de TPH. Dados disponibilizados pelo IPT.

Figura 12. Croqui das linhas de aquisição com métodos geofísicos indiretos e com a sonda MIP. Modificado de (Netto, 2020).

Figura 13. Perfis de resistividade elétrica obtidos com a sonda MIP e a interpretação estratigráfica. Perfis disponibilizados pelo IPT através de relatórios da área.

Figura 14. Croqui de uma aquisição GPR com a técnica Common Offset ou Perfil de Reflexão com Afastamento Constante. a) Aquisição de A-scans nos pontos de 1 a 6. b) B-scan da aquisição.

Figura 15. Croqui de uma aquisição GPR com a técnica Common Mid Point. a) Aquisição de Ascans nos pontos de 1 a 6. b) B-scan da aquisição 
Figura 16. Cilindro com resistência R, área de secção transversal S e comprimento L...................34

Figura 17. Fluxo de corrente elétrica e linhas equipotenciais devido a um eletrodo acoplado a Terra. $\mathrm{O}$ circuito é fechado por um segundo eletrodo de corrente a uma distância muito grande......35

Figura 18. Dois eletrodos acoplados na superfície da Terra..................................................36

Figura 19. Arranjo de quatro eletrodos acoplados na superfície da Terra. A e B são eletrodos de corrente e M e N são eletrodos de potencial........................................................................37

Figura 20. Movimentação dos eletrodos para as técnicas de Sondagem Elétrica Vertical (SEV) e

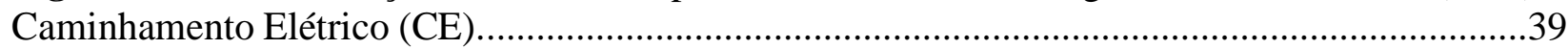

Figura 21. Principais arranjos de eletrodos usados em aquisições de Eletrorresistividade.............40

Figura 22. Arranjo Dipolo-Dipolo e as sequências de medidas para se obter a tomografia elétrica (Borges, 2007).

Figura 23. Modelo do acoplamento capacitivo no método da Eletrorresistividade com acoplamento capacitivo (Yamashita et al, 2004).

Figura 24. Croqui do funcionamento do acoplamento capacitivo através da utilização de cabos dipolares (Cavenaghi, 2017).

Figura 25. Modelo sintético de distribuição de resistividade (Ohm.m) simulando uma pluma de contaminação por DNAPL com décadas de existência.

Figura 26. Distribuição de resistividade aparente, com $1 \%$ de ruído, calculado sobre o modelo da Figura 1

Figura 27. Resultado do processo de inversão dos dados sintéticos gerados a partir do modelo da

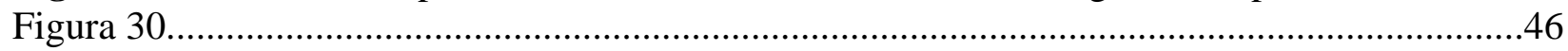

Figura 28. Croqui do arranjo dos eletrodos e das amostras de solos durante o experimento..........48

Figura 29. Experimento de medida de resistividade das amostras. a) Sistema desenvolvido para medição. b) Processo de adição de creosoto nas amostras.

Figura 30. Croqui da caixa de solo argiloso vermelho utilizada para a aquisição com antena GPR de alta frequência. a) Visão em planta do experimento. b) Visão lateral do experimento.

Figura 31. Croqui da caixa de areia utilizada para a aquisição com antena GPR de alta frequência. a) Visão em planta do experimento. b) Visão lateral do experimento. .53

Figura 32. Aquisição sobre a caixa de areia utilizando a antena GPR GSSI de $2600 \mathrm{MHz}$ .54 
Figura 33. Mapa das localizações das linhas de aquisição de perfis de reflexão com afastamento constante (common offset) e da malha GPR pseudo-3D... .55

Figura 34. Aquisições GPR na área de estudo. a) Antena de 200 MHz. b) Antena de 900 MHz.....56

Figura 35. Mapa das localizações das aquisições CMP (common mid point) e da malha de interpolação das CMPs.

Figura 36. Mapa das localizações das linhas de aquisição de Eletrorresistividade (ER) DipoloDipolo. .58

Figura 37. Mapa das localizações das linhas de aquisição e da malha 3D de Eletrorresistividade Capacitiva (RC) 59

Figura 38. Aquisições com o equipamento OhmMapper sobre a área de estudo. .60

Figura 39. Curva de resistividade pela concentração de creosoto obtida a partir do ajuste aos dados da medição sobre as amostras do solo argiloso vermelho.

Figura 40. Curva de resistividade pela concentração de creosoto obtida a partir do ajuste aos dados da medição sobre as amostras do solo argiloso cinza intermediário.

Figura 41. Curva de resistividade pela concentração de creosoto obtida a partir do ajuste aos dados da medição sobre as amostras da areia.

Figura 42. Perfil GPR de $2600 \mathrm{MHz}$ sobre a caixa de argila vermelha. .66

Figura 43. Perfil GPR de $2600 \mathrm{MHz}$ sobre a caixa de argila vermelha com o recipiente preenchido por creosoto enterrado. .66

Figura 44. Perfil GPR de $2600 \mathrm{MHz}$ sobre a caixa de areia .67

Figura 45. Perfil GPR de $2600 \mathrm{MHz}$ sobre a caixa de areia com o recipiente preenchido por creosoto enterrado.

Figura 46. Espectrograma dos dados de $2600 \mathrm{MHz}$ sobre a caixa de argila vermelha. a) Sem contaminação. b) Com recipiente preenchido com creosoto.

Figura 47. Espectrograma dos dados de $2600 \mathrm{MHz}$ sobre a caixa de areia. a) Sem contaminação.

b) Com recipiente de preenchido com creosoto.

Figura 48. Perfil GPR de $200 \mathrm{MHz}$ sobre a linha de background...........................................70

Figura 49. Perfil GPR de $270 \mathrm{MHz}$ sobre a linha de background.............................................71

Figura 50. Perfil GPR de $400 \mathrm{MHz}$ sobre a linha de background...........................................71 
Figura 51. Perfil GPR de $900 \mathrm{MHz}$ sobre a linha de background.........................................71

Figura 52. Perfil GPR de $200 \mathrm{MHz}$ sobre a linha central................................................73

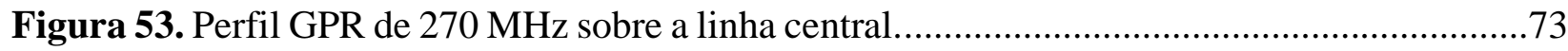

Figura 54. Perfil GPR de $400 \mathrm{MHz}$ sobre a linha central...................................................73

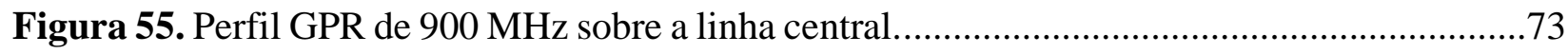

Figura 56. Perfil GPR de $200 \mathrm{MHz}$ sobre a linha lateral......................................................74

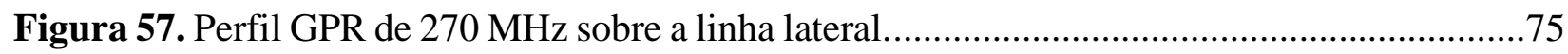

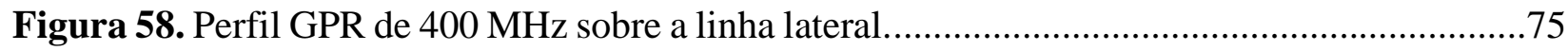

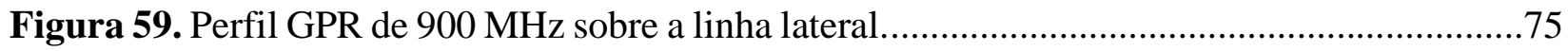

Figura 60. Espectrograma dos dados de frequência central (FC) $200 \mathrm{MHz}$. a) Linha background.

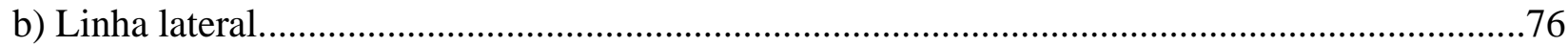

Figura 61. Espectrograma dos dados de frequência central (FC) $200 \mathrm{MHz}$. a) Linha background.

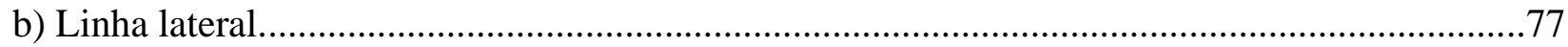

Figura 62. Corte a $20 \mathrm{~cm}$ de profundidade do modelo GPR pseudo-3D de $900 \mathrm{MHz}$ resultado da

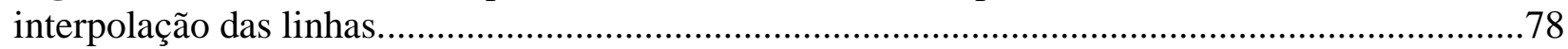

Figura 63. Corte a $20 \mathrm{~cm}$ de profundidade do modelo GPR pseudo-3D de $900 \mathrm{MHz}$ com transformada de Hilbert (Envelope) .............................................................................

Figura 64. Modelo pseudo-3D de constante dielétrica a partir de processamento CMP................80

Figura 65. Modelo pseudo-3D de isovalor de constante dielétrica de 20 obtido através do

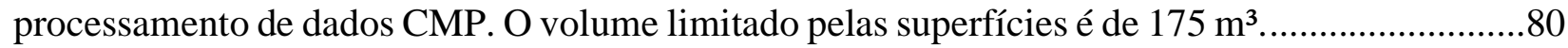

Figura 66. Perfil tomografia elétrica obtida com o método ER sobre a linha de background..........81

Figura 67. Perfil tomografia elétrica obtida com o método ER sobre a linha central....................82

Figura 68. Perfil tomografia elétrica obtida com o método ER sobre a linha lateral....................83

Figura 69. Perfil de tomografia elétrica obtido com o método RC sobre a linha de background....84

Figura 70. Perfil de tomografia elétrica obtido com o método RC sobre a linha central................85

Figura 71. Perfil de tomografia elétrica obtido com o método RC sobre a linha lateral................86 
Figura 72. Modelo de resistividade elétrica pseudo-3D obtido com a interpolação dos perfis de

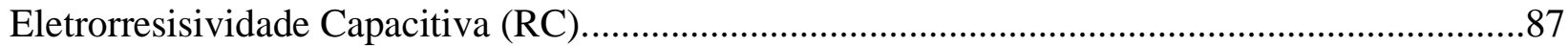

Figura 73. Modelo pseudo-3D de isovalor 1000 Ohm.m obtido com interpolação dos perfis de Eletrorresisividade Capacitiva (RC). O volume limitado pelas superfícies é de $80 \mathrm{~m}^{3}$. 


\section{Índice de Tabelas}

Tabela 1. Compostos do creosoto de acordo com os resultados da espectroscopia de massa. Em negrito estão os compostos com maior porcentagem na composição do creosoto. Modificado de (Aranha et al, 2020).

Tabela 2. Porcentagem da distribuição do creosoto em diferentes fases em subsuperfície. Modificado de (Aranha et al, 2020).

Tabela 3. Propriedades elétricas de alguns materiais. (Annan, 1992; Craig, 1998) .28

Tabela 4. Parâmetros de aquisição dos dados GPR para cada uma das antenas utilizadas. .55

Tabela 5. Resultados dos valores de resistividade (Ohm.m) das amostras calculados a partir das medidas de diferença de potencial e de corrente elétrica durante o experimento. 


\section{Resumo}

Nesta pesquisa foi feita a detecção e caracterização de uma contaminação por hidrocarboneto creosoto através da utilização dos métodos Ground Penetrating Radar (GPR), Eletrorresistividade (ER) e Eletrorresistividade com Acoplamento Capacitivo (RC). Os dados foram coletados sobre uma área contaminada onde funcionou por décadas uma usina de preservação de madeiras que utilizada como produto químico principal o óleo creosoto. O óleo creosoto era utilizado nos dormentes de madeira por causa do seu poder inseticida e fungicida que aumenta muito a durabilidade dos dormentes que eram usados para a construção de linhas férreas no estado de São Paulo. O óleo era armazenado em tanques aéreos e o processo de impregnação dos dormentes era feito dentro de grandes autoclaves no próprio local. Os levantamentos GPR foram feitos com antenas de 200, 270, 400 e $900 \mathrm{MHz}$ de maneira a se produzir tanto perfis únicos caracterizando um imageamento 2D quanto um modelo GPR pseudo-3D. Aquisições GPR com a técnica CMP foram feitas para a geração de um modelo pseudo-3D de constante dielétrica de uma região em específico que engloba a posição de uma das antigas autoclaves. Uma análise espectral dos dados GPR foi feita, baseada na aplicação da Transformada de Fourier no Tempo Curto, para que os resultados pudessem auxiliar na detecção das plumas de contaminação. Tanto com o método GPR quanto para os métodos ER e RC foram feitas as aquisições sobre três linhas pré-definidas chamadas de linha de background, linha central e linha lateral. A utilização dos métodos GPR, ER e RC permitiu tanto a detecção como a estimativa da forma e do volume das plumas de contaminação. Os levantamentos com o método RC foram feitos não só sobre as três linhas mencionadas, mas também sobre uma malha, os quais proporcionaram a geração de um modelo de resistividade elétrica pseudo-3D para estimativa de forma e volume das plumas de contaminação. Todos os dados dos métodos geofísicos foram acompanhados de experimentos em laboratório para dar maior confiabilidade nas interpretações. Os resultados sugerem que a contaminação está passando por um processo de biodegradação por bactérias que se alimentam de hidrocarbonetos.

Palavras-chave: Contaminação, GPR, Eletrorresistividade (ER), Resistividade Capacitiva, Creosoto 


\begin{abstract}
The primary objective of the present research is to characterize a hydrocarbon contamination using three geophysical methods: (1) the Ground Penetrating Radar (GPR), (2) Electrorresistivity (ER), and (3) Electrorresistivity with Capacitive Coupling (RC). The data were collected over the contaminated area, which is located in a wood preservation plant that operated for decades, and creosote oil was the main chemical contamination product at the site. Creosote oil was used in wooden sleepers because of its insecticidal and fungicidal power that greatly increases the durability of sleepers. The creosote oil was stored in overhead tanks and the process of impregnating the sleepers was carried out inside large autoclaves on the spot. The GPR surveys were made with 200, 270, 400, and $900 \mathrm{MHz}$ antennas to produce both unique profiles featuring 2D and a pseudo-3D GPR model. Acquisitions were made using the CMP technique to generate a dielectric constant pseudo-3D model of a specific region that encompasses the position of one of the old autoclaves. Spectral analysis of the GPR data was made so that the results could assist in the detection of contamination plumes. Both with the GPR method and for the ER and RC methods, acquisitions were made on three predefined lines called the background line, center line, and lateral line. The GPR, ER, and RC methods allowed both the detection and the estimation of the shape and volume of the contamination plumes. The surveys with the RC method took place not only on the three lines mentioned but also on a grid, which provided the generation of a pseudo-3D electrical resistivity model to estimate the shape and volume of the contamination plumes. All data from the geophysical methods were accompanied by laboratory experiments to provide greater reliability in the interpretations. The results suggest that the contamination undergoes a process of biodegradation by bacterias.
\end{abstract}

Keyword: Contamination, GPR, Electrorresistivity (ER), Capacitive Resistivity, Creosote 


\section{CAPÍTULO 1}

\section{INTRODUÇÃO E OBJETIVO}

\subsection{INTRODUÇÃO}

As contaminações por hidrocarbonetos são grandes causas de poluição da água subterrânea ao redor do mundo. Este tipo de problema pode ser causado, por exemplo, por vazamentos em tanques de armazenamento ou por derramamentos acidentais durante o transporte e distribuição desses produtos. Os impactos dessas contaminações nos recursos hídricos do subsolo incluem um grande risco direto a saúde e a vida dos humanos e outros animais (Lee et al, 2003; Kuppusamy et $a l$, 2020). Entretanto, a manipulação de hidrocarbonetos se faz necessária pela sua grande importância econômica e seu importante papel no desenvolvimento social tanto de países desenvolvidos como de países subdesenvolvidos. Portanto, são necessários estudos para aprimorar os processos de caracterização e remediação de contaminações.

Apesar de ser uma preocupação mundial, localizar e quantificar os contaminantes em subsuperfície ainda são desafios para cientistas e engenheiros devido à alta complexidade da distribuição e movimentação desses contaminantes em subsuperfície. A complexidade da distribuição se deve ao fato dos hidrocarbonetos em subsuperfície se dividirem em diferentes fases, sendo elas a fase em vapor resultado da evaporação parcial do contaminante, a fase livre com mobilidade, a fase residual sem mobilidade aprisionada na porosidade do solo, a fase adsorvida sem mobilidade resultado da retenção do contaminante pelas partículas do solo e a fase dissolvida resultado da interação entre o contaminante e a água subterrânea (Yong, 2001; Lago, 2009).

Os hidrocarbonetos contaminantes podem ser divididos em dois tipos, os menos densos que a água (Light Non-Aqueous Phase Liquids - LNAPL's) e os mais densos que a água (Dense NonAqueous Phase Liquids - DNAPL's). Hidrocarbonetos do tipo LNAPL são encontrados em grandes quantidades em refinarias e aeroportos e em menores quantidades em postos de gasolina. Por outro lado, hidrocarbonetos do tipo DNAPL são encontrados em pequenas e médias quantidades próximos às regiões industriais (Daniels, 1992). O tipo de hidrocarboneto controla o seu comportamento com relação ao nível freático, sendo os LNAPL's aqueles que migram por ação da gravidade até que sua fase livre se acumule sobre o nível d'agua. Os DNAPL's, entretanto, 
ultrapassam o nível d'agua e continuam migrando até que sua fase livre se acumule sobre uma camada impermeável ou com baixa condutividade hidráulica.

A geofísica se apresenta como uma ferramenta útil em casos de contaminação do subsolo devido ao seu caráter não destrutivo, a possibilidade de cobrir grandes áreas e sua capacidade de gerar dados indiretos de maneira rápida e contínua, sendo muitas vezes mais interessante do que sondagens de medições direta que são mais custosas e geram apenas informações pontuais. A geofísica geralmente é utilizada na fase inicial de estudo de uma área contaminada, direcionando a perfuração de poços e processos de remediação. Alguns métodos geofísicos são de particular importância no estudo de áreas contaminadas, sendo eles o Método Ground Penetrating Radar (GPR), o Método da Eletrorresistividade (ER), o Método da Polarização Induzida (IP) e os Métodos Eletromagnéticos (EM) (Atekwana, 2000; Ustra, 2008).

Estudos utilizando o GPR mostram que este método é muito útil no mapeamento de contaminações por hidrocarbonetos. Pesquisadores ao redor do mundo produziram ótimos trabalhos que serviram de base para esta pesquisa. Pode-se citar estudos de experimentos controlados em laboratório (Campbell et al, 1996; Bertolla et al, 2014), aplicações reais em campo (Daniels, 1992; Castro e Branco, 2003) e modelos numéricos (Carcione et al, 2000).

Daniels (1992) mostrou os resultados GPR de um estudo sobre um derrame de gasolina no norte do estado de Indiana, Estados Unidos. Os resultados de modelos computacionais da contaminação e os resultados do levantamento de campo foram aparentemente contraditórios. Enquanto os modelos computacionais mostraram altas amplitudes das anomalias relacionadas a contaminação, os resultados de campo mostram mais baixas amplitudes das anomalias se comparado com áreas sem contaminação. Segundo o autor isso pode ser explicado como o resultado de uma alta perda anômala de amplitude devido aos produtos dos hidrocarbonetos. Caso esses produtos apresentem uma alta perda no intervalo de frequência das ondas do GPR, as ondas eletromagnéticas sofreriam uma atenuação durante a propagação através do meio.

Campbell et al (1996) apresentaram um estudo utilizando o método GPR-4D para detectar um derrame controlado de gasolina. O resultado mostrou uma maior amplitude nas reflexões sob o ponto do derrame, o que indicou que a presença da gasolina pode ser detectada pelo GPR. As reflexões anômalas foram relacionadas com o maior contraste de permissividade dielétrica entre a gasolina e a água. 
Carcione et al (2000) apresentaram um estudo de simulações de dados GPR de uma contaminação em uma antiga base aérea soviética na Polônia, onde o solo foi contaminado por combustível de aviões. Nesta simulação computacional foram avaliadas a mínima concentração de hidrocarboneto que é capaz de ser detectada pelo GPR e a frequência da antena requerida para tal finalidade. Os resultados mostraram que para uma saturação de 0,1\% de contaminante e uma condutividade de $0,5 \mathrm{mS} / \mathrm{m}$ para o meio de propagação, a antena de $200 \mathrm{MHz}$ é capaz de detectar a zona contaminada. Entretanto, para uma condutividade de $5 \mathrm{mS} / \mathrm{m}$ é necessário a utilização de uma antena de $50 \mathrm{MHz}$ cujo a penetração do sinal é maior.

Castro e Branco (2003) apresentaram uma aplicação do método GPR-4D em uma situação real de contaminação por LNAPL devido a um vazamento em um posto de gasolina em Fortaleza, Brasil. Os resultados mostraram diferentes assinaturas do sinal GPR de acordo com a sua interação com as várias fases do contaminante. Foi observada uma zona de sombra relacionada a fase em vapor do contaminante. Reflexões acentuadas acima do nível freático foram relacionadas a fase livre e residual. Abaixo do nível freático as reflexões acentuadas foram relacionadas a fase dissolvida. Estes resultados mostraram como a distribuição das fases do contaminante geram diferentes assinaturas geofísicas.

Bertolla et al (2014) apresentaram um estudo utilizando o método GPR-4D para mapear um derrame controlado de LNAPL conforme este migrava através da areia. Para este estudo foram utilizados um tanque de alvenaria para aquisição dos dados reais e simulações numéricas para geração de dados sintéticos. Os resultados mostraram uma atenuação do sinal de reflexão do GPR conforme o contaminante se espalhava até se estabelecer sobre o nível d'agua. As atenuações observadas são chamadas de "zonas de sombra" (shadow zones).

Os métodos da Eletrorresistividade e Eletrorresistividade com Acoplamento Capacitivo são amplamente utilizados para estudos de contaminação (Nash, 1997; Sauck, 2000; Kress and Teeple, 2005; Ortega, 2007; Atekwana and Atekwana, 2010). Geralmente as contaminações por hidrocarbonetos são tratadas com modelos intuitivos que admitem uma pluma com alta resistividade, porém, através de levantamento geofísicos e informações diretas de outras ciências, foi constatado que as contaminações também podem ser caracterizadas por zonas com baixa resistividade. A baixa resistividade pode ser resultado da modificação do hidrocarboneto devido à interações geoquímicas ou pela ação de bactérias que geralmente surgem em locais contaminados à muitas décadas. 
Nash (1997) apresentou um estudo geofísico utilizando os métodos GPR, ER, EM e Potencial Espontâneo (SP) sobre um local contaminado em uma base aérea em Michigan, Estados Unidos. Os resultados da aplicação do método de Eletrorresistividade foram capazes de identificar o aquífero contaminado como uma feição mais condutiva. A contaminação acima do nível freático também foi identificada como uma feição mais condutiva. Este resultado mostra que um modelo intuitivo, onde o contaminante em subsuperfície é considerado uma anomalia de alta resistividade, nem sempre é aplicável.

Sauck (2000) apresentou um modelo de resistividade para plumas de contaminação em ambientes arenosos. O autor explica que a característica mais condutiva da contaminação em subsuperfície pode ser proveniente da ação de micro-organismos que degradam o contaminante. Esses processos de biodegradação geram, além de outros subprodutos, os ácidos orgânicos. A presença de ácidos orgânicos que não faziam parte da composição inicial do contaminante leva a reações que aumentam a condutividade da subsuperfície, como por exemplo, a lixiviação agressiva do próprio grão mineral.

Kress and Teeple (2005) apresentaram um estudo com o método da Eletrorresistividade sobre uma área contaminada no estado do Texas, Estados Unidos, onde funcionava uma usina de preservação de madeira. Nesse estudo os autores usaram diferentes maneiras de se injetar corrente em subsuperfície, os chamados acoplamento galvânico e acoplamento capacitivo. Também foi usado modelagem computacional para validar as interpretações e definir um modelo representativo do local. Os resultados mostraram que a presença do contaminante gerou uma zona mais resistiva que o solo local intacto.

Ortega (2007) apresentou um estudo com o método de Eletrorresistividade sobre um centro de abastecimento de locomotivas na cidade de Paulínia, Estado de São Paulo. O estudo visou duas áreas em particular. Foram encontradas anomalias condutivas nas duas áreas. Em uma delas a alta concentração de contaminante foi comprovado por coletas de amostras de solo. Na área onde foi comprovada a contaminação a anomalia condutiva foi relacionada com a presença do contaminante (óleo diesel). O autor indica a possível ação de micro-organismo para explicar os resultados.

Atekwana \& Atekwana (2010) apresentaram um estudo que discute as assinaturas geofísicas provenientes de atividades microbianas em áreas contaminadas por hidrocarbonetos e seus derivados. Foram apresentadas diversas áreas, estudos e métodos. Perfis de Eletrorresistividade, adquiridos sobre uma contaminação em uma base aérea, foram discutidos e 
os resultados mostraram que em diferentes localizações das aquisições, são observadas diferentes assinaturas geofísicas. Os autores destacam que muitos fatores, gerados por ação de bactérias, podem contribuir para as assinaturas geofísicas. Alguns exemplos são as alterações nas propriedades do aquífero causadas por um crescimento na população de micróbios, como o fechamento dos poros pelas células microbianas e biofilme, a alteração das superfícies dos minerais por ação de bactérias ou seus subprodutos, a diminuição da concentração do contaminante pelo consumo do carbono e outros fatores.

Esta pesquisa é de grande importância para a sociedade pois trata da caracterização de plumas de contaminação por hidrocarboneto, o que configura um sério problema ambiental devido ao forte impacto negativo dessas contaminações ao meio ambiente e a saúde humana. Com uma rápida remediação das áreas contaminadas este impacto pode ser minimizado. Esta pesquisa utilizou como área de estudos um local onde a contaminação ocorreu a muitas décadas, configurando uma área chamada de "Long Term Contaminated Site". Esse tipo de local é de difícil caracterização devido aos processos que ocorrem em subsuperfície ao longo das décadas. Mesmo diante deste desafio, esta pesquisa gerou ótimos resultados e pode contribuir tanto para futuras pesquisas acadêmicas quanto para atividades profissionais que exigem um rápido resultado.

\subsection{OBJETIVO}

No sentido de contribuir para a ciência de estudos ambientais em áreas contaminadas por hidrocarbonetos, esta pesquisa tem como objetivo a caracterização de plumas de contaminação por creosoto* utilizando os métodos geofísicos Ground Penetrating Radar (GPR) e Eletrorresistividade (ER). Foram adquiridos dados sobre uma área contaminada, na cidade de São Paulo, onde por décadas funcionava uma usina de preservação de madeira. Na usina eram utilizados produtos para a impermeabilização de madeiras, sendo o mais utilizado o óleo creosoto. Espera-se que as plumas de contaminação possam ser caracterizadas através da aplicação dos métodos geofísicos e com o auxílio de experimentos em laboratório.

\footnotetext{
* Creosoto é um composto químico derivado do destilado de alquitranos procedentes da combustão de carbonos graxos (hulha). A principal propriedade é sua propriedade biocida para os agentes causadores da deterioração da madeira, a qual se protege impregnando-a com o produto mediante o processo que habitualmente se realiza em uma auto-clave.
} 


\section{CAPÍTULO 2}

\section{ÁREA DE ESTUDO}

A área de estudo está situada na região metropolitana de São Paulo, bairro Jaguaré, próximo ao Rio Pinheiros. Trata-se de um terreno com área total de $15,338 \mathrm{~m}^{2}$ e formato estreito alongado na direção noroeste-sudeste (Figura 1). No local ainda existem galpões construídos, abrangendo uma área de 2,532 $\mathrm{m}^{2}$, onde foram manipulados produtos químicos e principalmente um composto chamado creosoto, para o tratamento de madeiras utilizadas na construção de linhas ferroviárias do estado de São Paulo. A manipulação de creosoto aconteceu entre 1974 e 1997, resultando em pontos de contaminação do solo, principalmente próximos as localizações das antigas autoclaves onde eram feitos os procedimentos de impregnação da madeira.
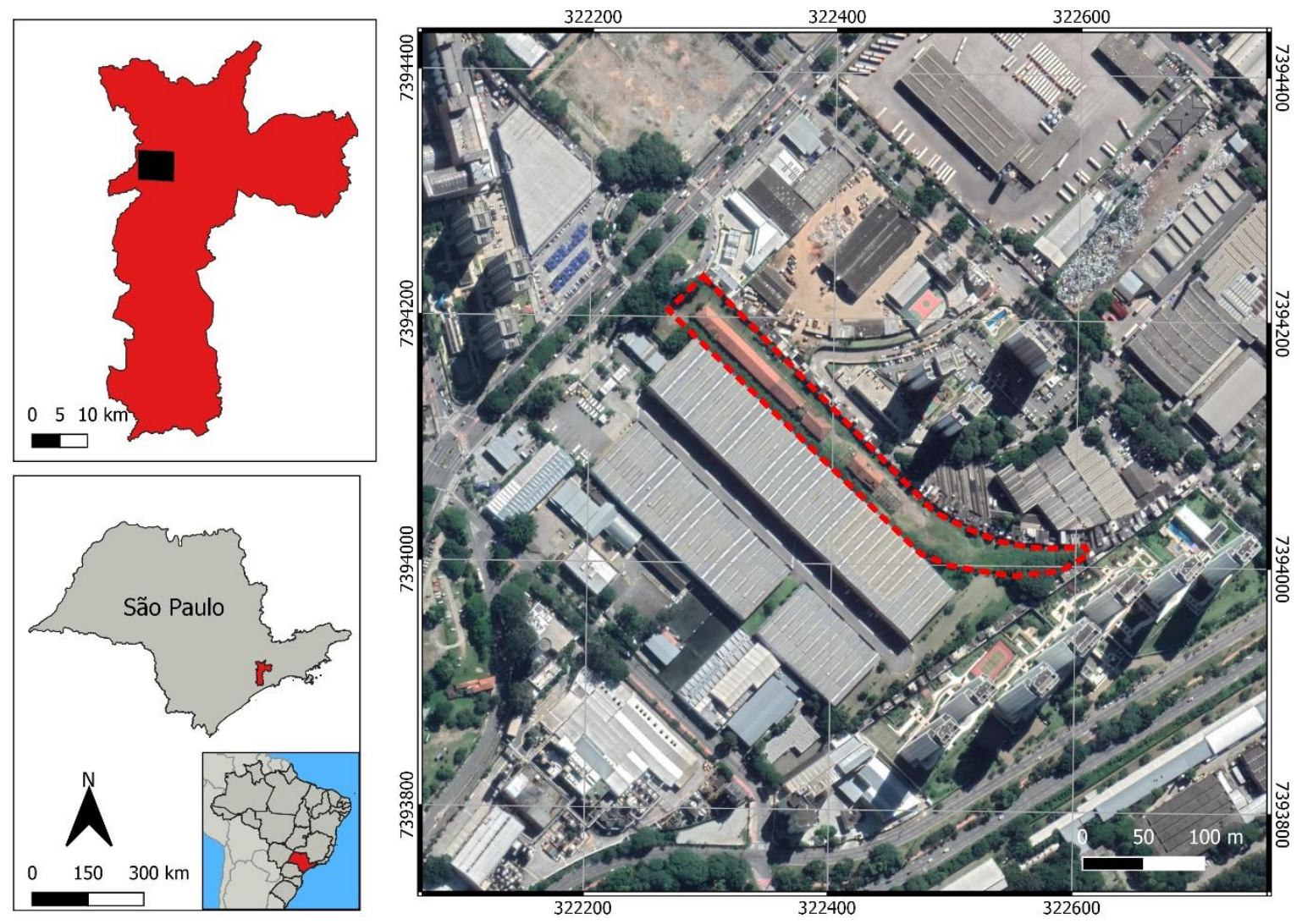

Figura 1. Mapa de localização da área de estudo no Bairro do Jaguaré, cidade de São Paulo - SP, Brasil. 


\subsection{HISTÓRICO}

Anteriormente à década de 1970, o local foi sede do Instituto Brasileiro de Desenvolvimento Florestal (IBDF), o antigo Instituto Nacional do Pinho. Já na década de 1970, com o fim do IBDF, o terreno passou a ser de responsabilidade do Instituto Brasileiro do Meio Ambiente e dos Recursos Naturais Renováveis (IBAMA). Ainda na década de 70 o terreno foi concedido para o Instituto de Pesquisas Tecnológicas (IPT) para que fosse instalada a Usina de Tratamento de Madeiras do Jaguaré (UTM-Jaguaré). A UTM-Jaguaré foi operada pela antiga Divisão de Madeiras do IPT, entre os anos de 1974 e 1997, que instalou na área um setor administrativo, um setor de serraria e marcenaria, um setor de prensas e um setor de tratamento químico de madeiras.

O setor de tratamento químico era composto por duas autoclaves, uma cilíndrica com volume de $15 \mathrm{~m}^{3}$ e uma retangular, seis tanques aéreos de armazenamento do creosoto, sendo quatro deles com capacidade para $10 \mathrm{~m}^{3}$ e dois deles com capacidade de $15 \mathrm{~m}^{3}$, além de mais três tanques aéreos que armazenavam outros produtos químicos como o arseniato de cobre cromado (CCA - Chromated Copper Arsenate). Após o processo de corte e de prensagem os dormentes de madeira eram encaminhados para o setor de tratamento químico, localizado no galpão da parte sul do terreno (Figura 2).

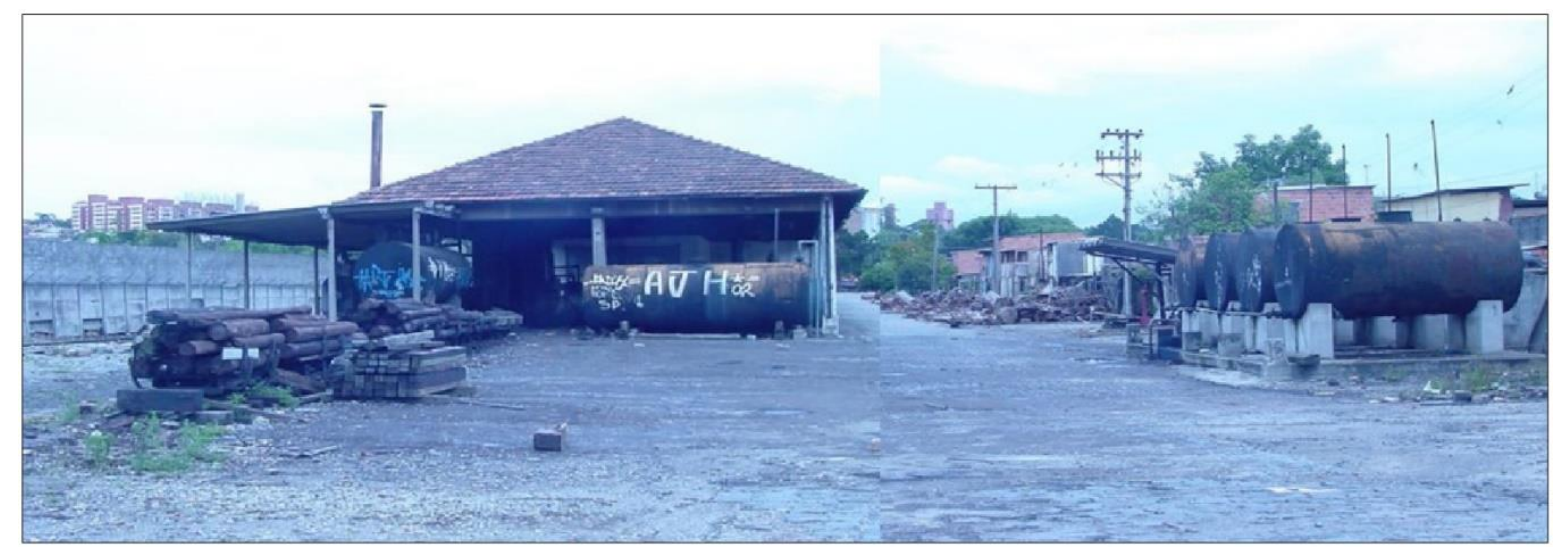

Figura 2. Foto do setor de tratamento químico de dormentes de madeira na parte sul do terreno (foto da década de 90). Fonte: Relatório do IPT do ano de 2010.

O tratamento químico da madeira com creosoto era feito nas autoclaves, onde sob pressão era injetada a solução preservativa na madeira, sendo o material preservativo que não era absorvido pela madeira reutilizado no processo. Segundo informações provenientes dos antigos funcionários, 
apesar das atividades na usina seguirem todas as normas de segurança e qualidade vigentes na época, os derramamentos acidentais de produtos no chão eram comuns, principalmente nas áreas próximas às autoclaves no momento da retirada dos dormentes (Fonte: Relatório do IPT). As posições das autoclaves e dos tanques aéreos com creosoto e outros produtos estão disponíveis na planta da área (Figura 3).

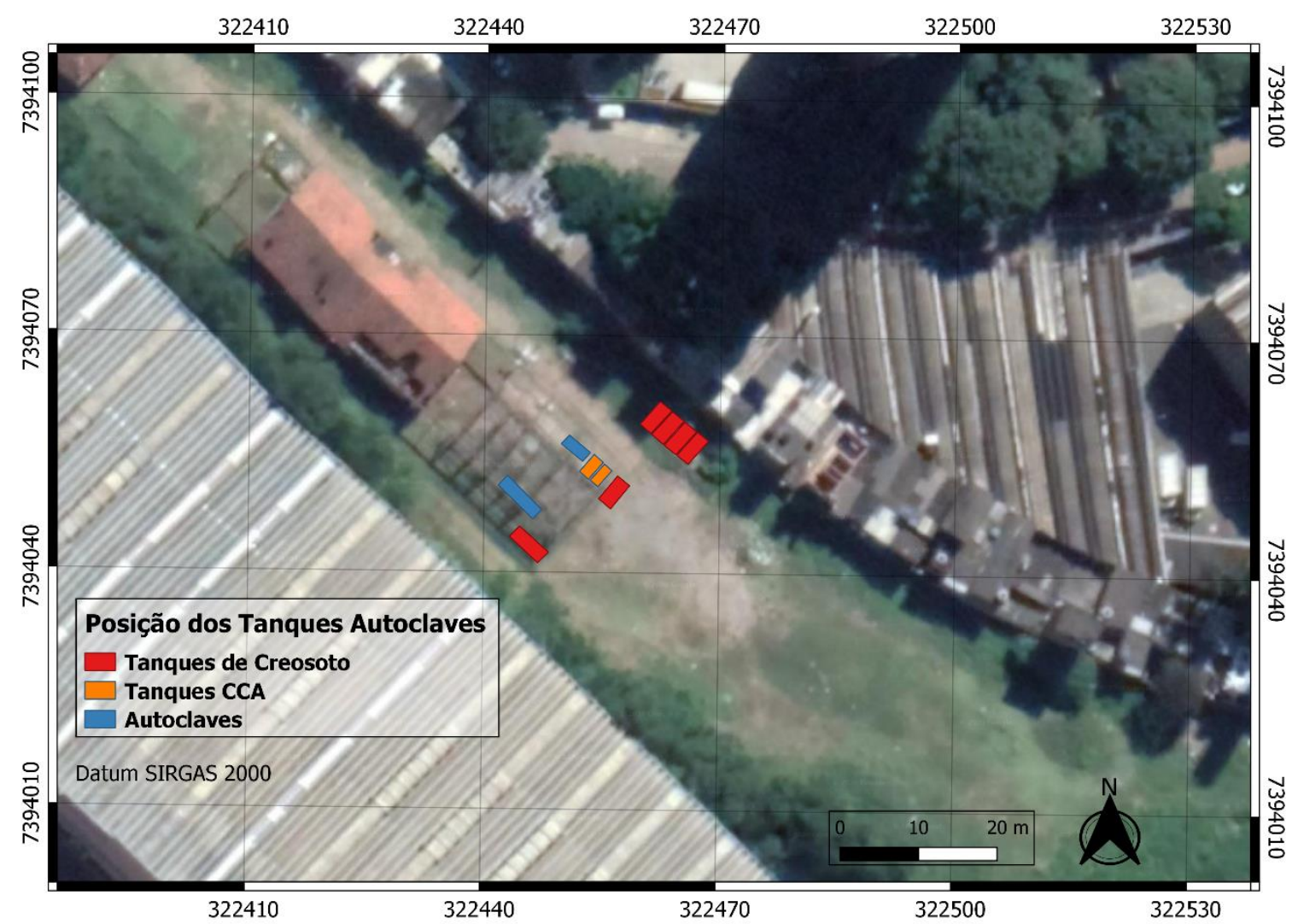

Figura 3. Mapa do setor de tratamento químico de madeiras com as posições dos tanques aéreos e das autoclaves. Informações retiradas da planta disponibilizada pelo IPT.

As atividades relacionadas ao tratamento de madeira desta usina terminaram em 1997 quando iniciou-se a desmobilização progressiva das atividades no local, sendo em 2003 feita a retirada dos tanques aéreos e encerrada a utilização da área. Atualmente a área está desativada e sob responsabilidade do IPT. Apesar da construção de um muro na lateral norte do terreno para conter o acesso de pessoas devido ao crescimento da ocupação irregular, a área é constantemente acessada de maneira irregular. Foi constatado pelo próprio IPT a existência de hortas e lançamento de esgoto, no solo e na galeria de captação de água, da comunidade vizinha ao terreno. 


\subsection{CONTEXTO GEOLÓGICO}

Em um contexto regional, a área de estudo está situada na Bacia de São Paulo, na região da várzea do Rio Pinheiros. A camada mais superficial trata-se de um aterro argiloso/arenoso de aproximadamente 2 metros de espessura. Sob este aterro encontra-se uma camada de 2 metros de espessura, em média, com os sedimentos aluviares quaternários constituídos por camadas de argila, areia e cascalho. Os grãos desses sedimentos quaternários aumentam de tamanho com a profundidade, caracterizando uma granocrescência descendente. A camada mais profunda trata-se de sedimentos dos depósitos terciários da Bacia de São Paulo constituídos por argila, areia (grossa a fina) e cascalhos. O embasamento cristalino é constituído por gnaisses e migmatitos (Coutinho, 1980).

Para a caracterização do contexto geológico local foram perfurados alguns locais do terreno com os objetivos de se caracterizar a estratigrafia com precisão e coleta de amostras. As posições dos furos na área de estudo foram escolhidas com base nas antigas posições das fontes potenciais e em dados pré-existentes (Figura 4). As perfurações e retiradas de amostras foram feitas através de coleta com amostrador de cravação direta usando Geoprobe (equipamento de cravação).

A estratigrafia rasa nas posições das perfurações pode ser observada (Figura 5). A maior parte da área é coberta por uma camada de paralelepípedo de granito de $14 \mathrm{~cm}$ de espessura, exceto alguns pontos dentro do galpão onde se encontram pisos concretados. Os paralelepípedos e os pisos concretados encontram-se sobrepostos a um aterro de espessura variável composto por argila e cascalhos mal selecionados. Abaixo do aterro se inicia uma sequência de diferentes tipos de solos argilosos que compõem o deposito de sedimentos aluviares. As espessuras de cada tipo de solo argiloso variam de um ponto a outro. O aspecto visual de alguns dos tipos de solos argilosos encontrados na área pode ser observado (Figura 6). 


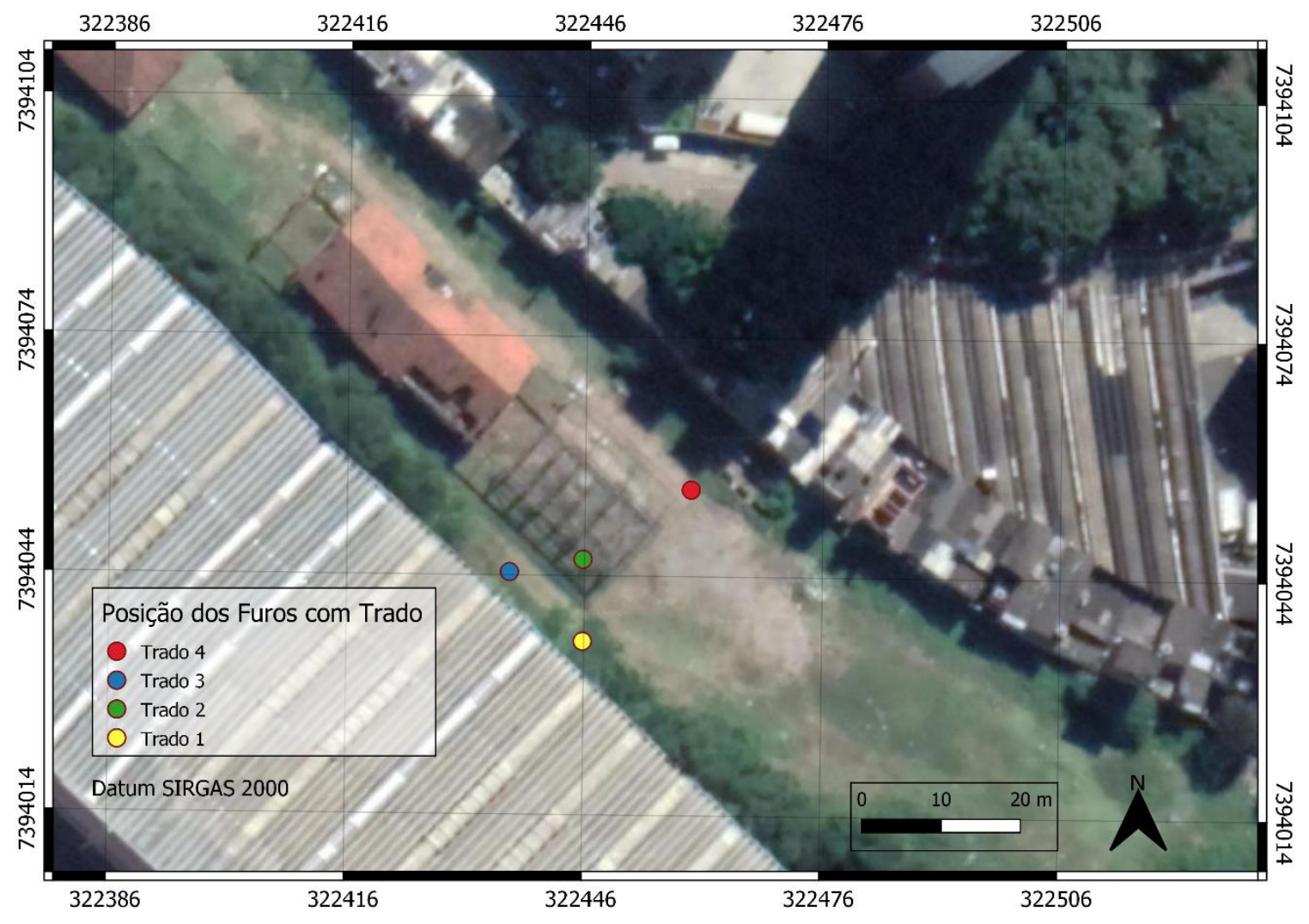

Figura 4. Mapa das localizações dos furos para caracterização da estratigrafia.

O nível d'agua (lençol freático) foi observado a aproximadamente 4 metros de profundidade, o que está de acordo com a informações obtidas através de sondagens geofísicas anteriores e mencionadas nos relatórios do IPT. De acordo com os relatórios, o nível d'agua ocorre entre 4 e 5 metros de profundidade. O fluxo subterrâneo tem sentido NE, influenciado pelos córregos no entorno (Fonte: Relatório do IPT). 


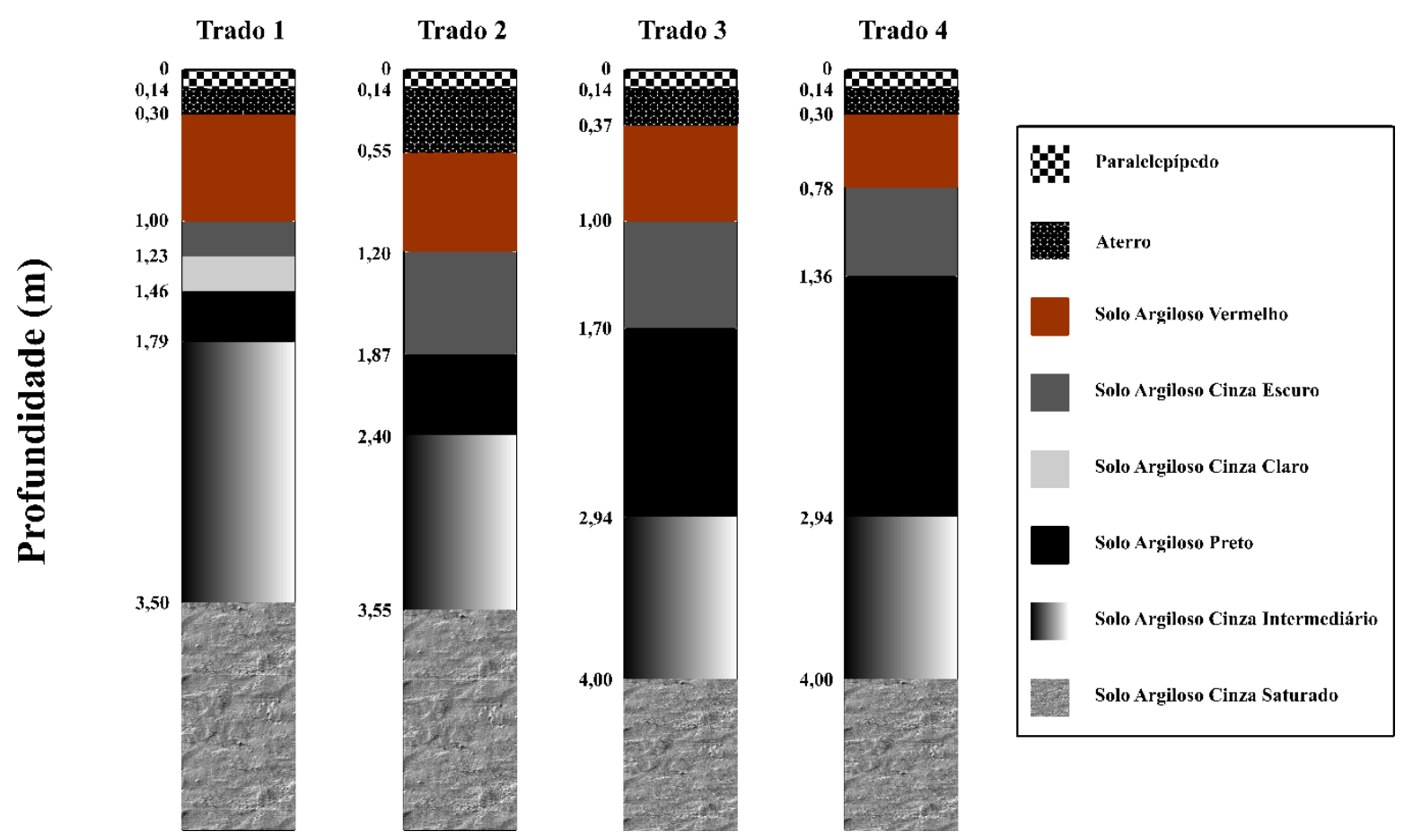

Figura 5. Perfis estratigráficos observados nos furos de sondagem.

a)

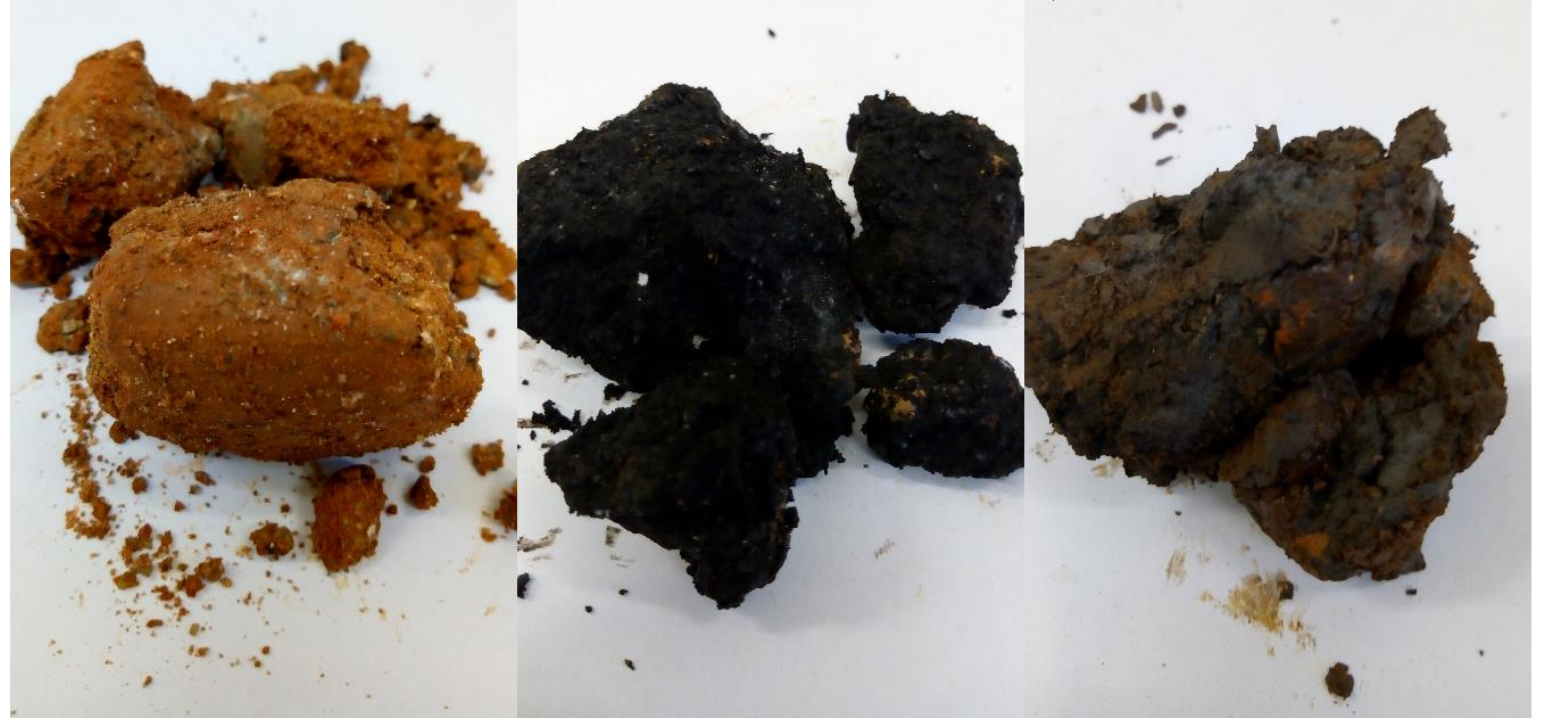

Figura 6. Fotos de alguns dos tipos de solos encontrados durante a perfuração. a) Solo argiloso vermelho. b) Solo argiloso preto. c) Solo argiloso cinza escuro. 


\subsection{DADOS PRÉ-EXISTENTES}

O IPT realizou estudos na área com as finalidades de avaliar o risco a saúde humana e definir um plano de intervenção para remediação das contaminações. Os estudos consistiram em caracterizar o meio físico da subsuperfície, caracterizar as fontes das contaminações, definir as dimensões das plumas de contaminação (principalmente na água subterrânea), determinar as concentrações de contaminantes e definir um modelo geológico representativo da área.

Em 2011 o IPT confirmou a contaminação da subsuperfície pelos hidrocarbonetos utilizados na preservação de madeira. O principal contaminante no local é o óleo creosoto constituído por uma mistura complexa de hidrocarbonetos aromáticos e outros compostos. O óleo creosoto é mais denso que a água, portanto é um DNAPL, com densidade entre 1,01 e 1,13 g/cm². É formado a partir da destilação de alcatrão de carvão mineral (coal tar). Foram bombeados da área aproximadamente 50 litros desse contaminante para a análise composicional através da técnica amplamente utilizada de espectrometria de massa por cromatografia em fase gasosa (GC-MS - Gas Chromatrography-Mass Espectrometry). Os resultados do estudo GC-MS são apresentados na Tabela 1.

\begin{tabular}{lll}
\hline Naftaleno & Heptadecano & 9-Metilantraceno \\
\hline Benzo[b]tiofeno & 9-Metil-9H-fluorência & 2-Fenilnaftaleno \\
Isoquinolina & 1,2-Dimetilbenzo[e][1]benzofurano & Fluoranteno \\
2-Metilbenzotiofeno & 4-(2-feniletenil)fenol & Dimetill-4-nitrofitalato \\
Indol & 9-Fluorenona & Pireno \\
2-Metilnaftaleno & 1,2,3,4-Tetrahidroantraceno & Benzonaftofurano \\
1-Etilnaftaleno & Dibenzotiofeno & 4-Azapireno \\
2,6-Dimetilnaftaleno & Pentadecano & 2,3-Benzofluorência \\
Acenafteno & Fenantreno & 1-Metilpireno \\
2-Metilbifenil & Antraceno & 9-(2-Propenil)antraceno \\
1-Isopropeninaftaleno & Benzo[c]quinolina & Benzantrenona \\
Dibenzofurano & N-Nitrosocarbazol & Benzo[b]nafto[2,1-d]tiofeno \\
2,3,6-Trimetilnaftaleno & 9-Vinilantraceno & Benzo[c]fenantreno \\
Fluoreno & 2-Metilhexadecano & Benz[a]antraceno \\
4-Metildibenzofurano & 2-Metilfenantreno & Trifenileno \\
9H-fluoren-9-ol & 1a,9b-Dihidro-1H0ciclopropa[1]fenantreno & Perileno \\
9,10-Dihidroantraceno & 4H-Ciclopenta[def]fenantreno & \\
\hline
\end{tabular}

Tabela 1. Compostos do creosoto de acordo com os resultados da espectroscopia de massa. Em negrito estão os compostos com maior porcentagem na composição do creosoto. Modificado de (Aranha et al, 2020). 
Foram selecionados os 9 compostos com maior porcentagem na composição do creosoto para uma análise quantitativa que buscou definir a proporção da divisão dos contaminantes em diferentes fases em subsuperfície. O resultado desta análise é apresentado na Tabela 2 a seguir.

\begin{tabular}{lcccc}
\hline Compostos & \multicolumn{4}{l}{ Fases } \\
\cline { 2 - 5 } & Adsorvida/Residual (\%) & Livre (\%) & Vapor (\%) & Dissolvida (\%) \\
\hline Naftaleno & 32,98 & 1,50 & 3,39 & 0,15 \\
2-Metilnaftaleno & 42,80 & 4,21 & 0,96 & 0,21 \\
Acenafteno & 53,44 & 5,28 & 0,54 & 0,00 \\
Fluoreno & 42,12 & 3,56 & 0,37 & 0,00 \\
Fenantreno & 51,24 & 4,71 & 0,16 & 0,00 \\
Antraceno & 14,63 & 4,41 & 0,08 & 0,00 \\
Fluoranteno & 27,74 & 3,75 & 0,03 & 0,00 \\
Pireno & 38,71 & 3,10 & 0,04 & 0,00 \\
Benz[a]antraceno & 81,54 & 7,23 & 0,01 & 0,00 \\
\hline
\end{tabular}

Tabela 2. Porcentagem da distribuição do creosoto em diferentes fases em subsuperfície. Modificado de (Aranha et $a l, 2020)$.

Após a análise do creosoto, foram feitas análises químicas de amostras de solo e de água. Estas análises foram feitas com o objetivo de se constatar a contaminação do solo e da água subterrânea. A escolha da localização das coletas de amostras foi feita levando-se em consideração as posições das fontes potenciais indicadas no mapa da Figura 7. A posição das coletas de amostras de solo e de água nos poços de monitoramento são apresentadas no mapa da Figura 4. 


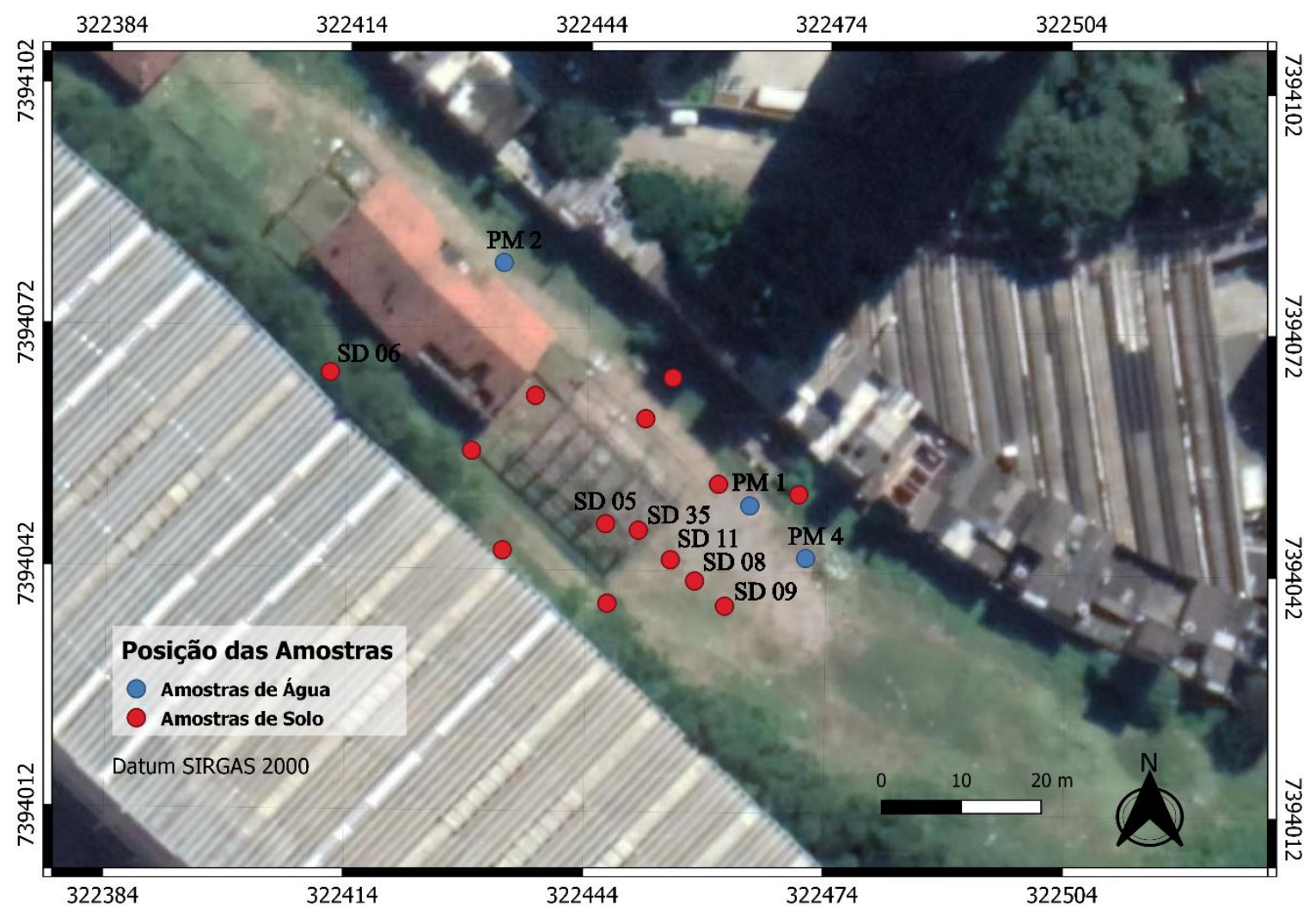

Figura 7. Mapa das posições das coletas de amostras de solo e de água para a análise química.

A seguir são apresentados os resultados das análises químicas de amostras de solo (Figuras 8 e 9) e de amostras de água (Figuras 10 e 11). Nas Figuras 8 e 10 são apresentadas as concentrações de diversos compostos químicos observados nas amostras, como por exemplo o naftaleno $\left(\mathrm{C}_{10} \mathrm{H}_{8}\right)$, um hidrocarboneto aromático potencialmente cancerígeno. Além dos vários tipos de compostos químicos, essas figuras apresentam também a concentração de hidrocarbonetos totais de petróleo (TPH - Total Petroleum Hydrocarbon). As Figuras 9 e 11 apresentam as concentrações de cadeias carbônicas com diferentes números de átomos de carbono, cadeias com 12 a 15, 16 a 20 e 21 a 40 carbonos. Segundo a Companhia Ambiental do Estado de São Paulo (CETESB), o nível de intervenção industrial para a concentração de TPH no solo é de $1000 \mathrm{mg} / \mathrm{kg}$ (miligramas por quilograma) e na água é de $600 \mu \mathrm{g} / \mathrm{L}$ (microgramas por litro). 


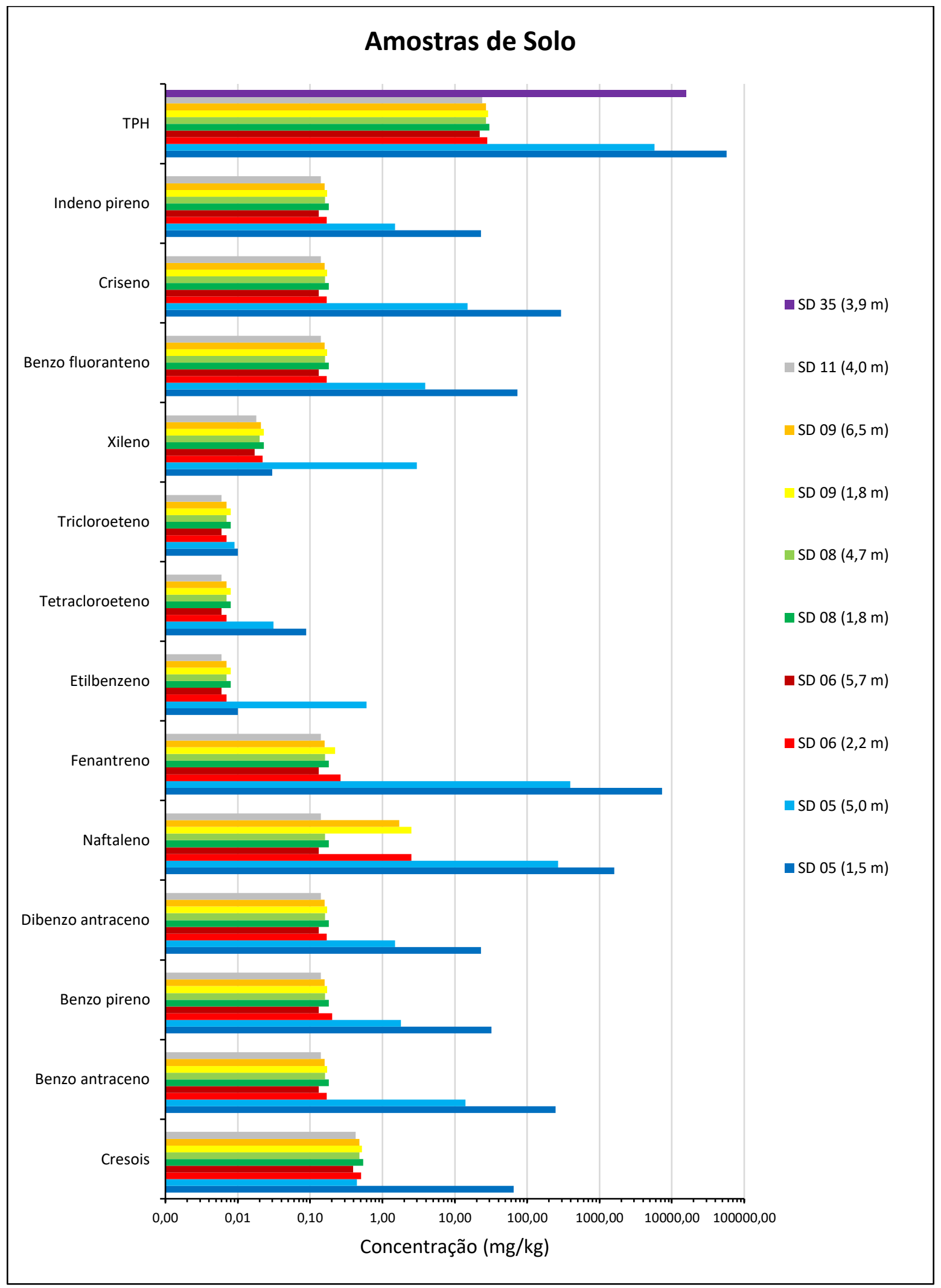

Figura 8. Resultado da análise química de algumas amostras de solo quanto a concentração de diversos compostos químicos. Dados disponibilizados pelo IPT. 


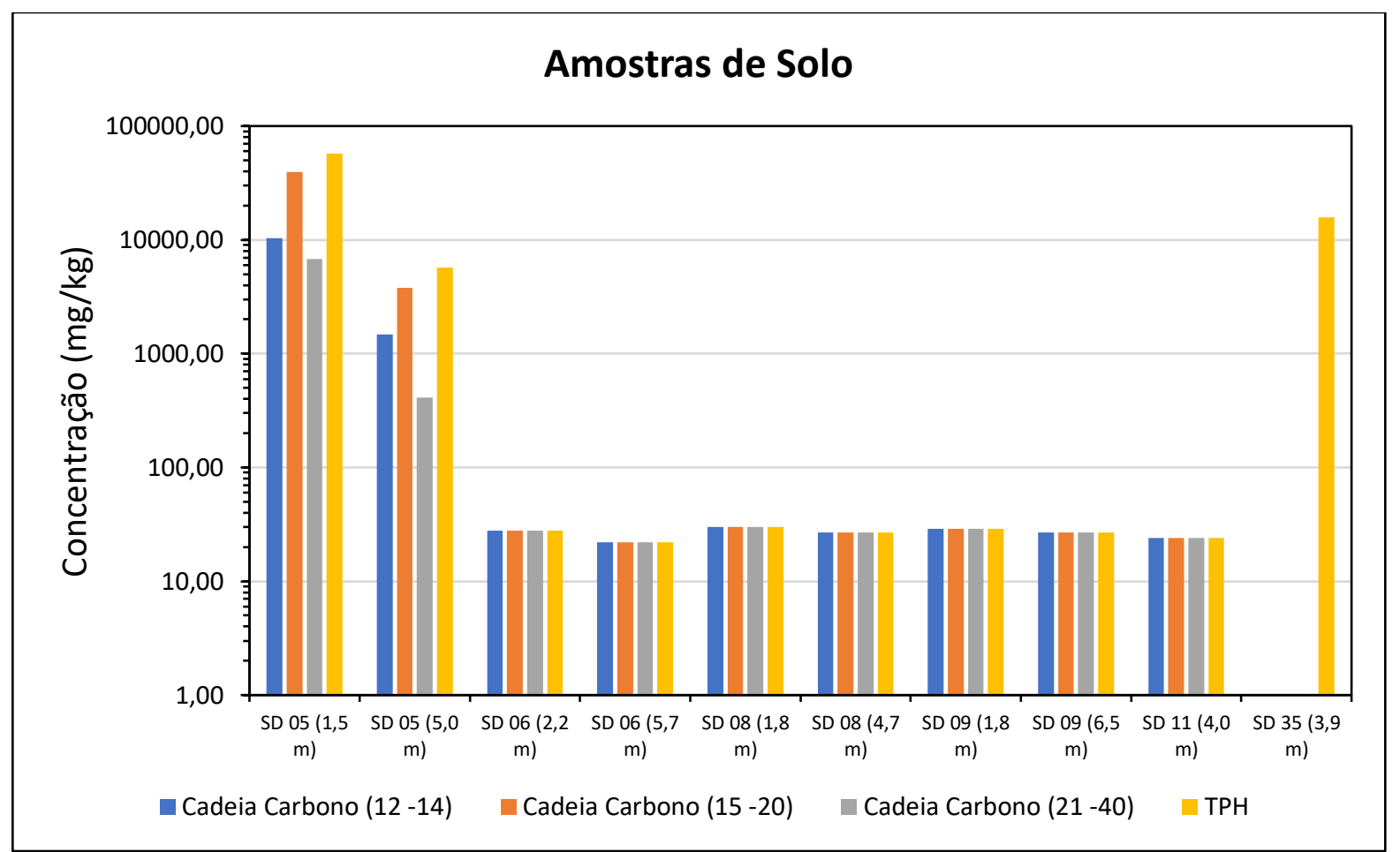

Figura 9. Resultado da análise química de algumas amostras de solo quanto ao número de carbono das cadeias carbônicas e concentrações de TPH. Dados disponibilizados pelo IPT.

Nota-se pela Figura 8 que as concentrações de hidrocarbonetos estão acima do nível máximo estipulado pela CETESB (1000 mg/kg) nas amostras SD 05 e SD 35 que correspondem a posição da antiga autoclave cilíndrica. Pode-se verificar que, apesar das amostras SD 05 à diferentes profundidades apresentarem altas concentrações, uma maior concentração ocorre na amostra da profundidade de 1,5 m. A Figura 9 mostra que as altas concentrações nas amostras SD 05 são geradas principalmente por cadeias carbônicas intermediárias, entre 15 e 20 carbonos.

No caso das amostras de água, nota-se pela Figura 10 que nas amostras PM 2 e PM 4 as concentrações estão acima do nível máximo estipulado pela CETESB. Da mesma maneira que as amostras de solo, nota-se pela Figura 11 que nas amostras de água, as altas concentrações são geradas principalmente por cadeias carbônicas intermediárias, entre 15 e 20 carbonos. Tanto nas amostras PM 2 quanto nas PM 4, pode-se observar que as concentrações são maiores nas amostras coletadas em menores profundidades.

De maneira geral, tanto para as amostras de solo quanto para as amostras de água, as concentrações de THP são maiores em profundidades menores. Isso pode indicar que na parte mais superficial o solo tem maior capacidade de retenção dos contaminantes ou que a transmissividade 
hidráulica é baixa e o contaminante não percolou em profundidades maiores. Este aspecto será discutido mais adiante. Observa-se que, apesar do produto contaminante (creosoto) ser constituído principalmente por hidrocarbonetos de cadeias carbônicas menores (naftaleno, fenantreno, fluoreno, acenafteno, entre outros), os hidrocarbonetos responsáveis pelas altas concentrações observadas nas análises químicas das amostras, como pode ser visto nas figuras 6 e 8, são aqueles com cadeias carbônicas intermediárias (benzopireno, benzoantraceno, criseno, benzofluoranteno, entre outros). Este resultado pode indicar algum processo de degradação das cadeias carbônicas menores. 


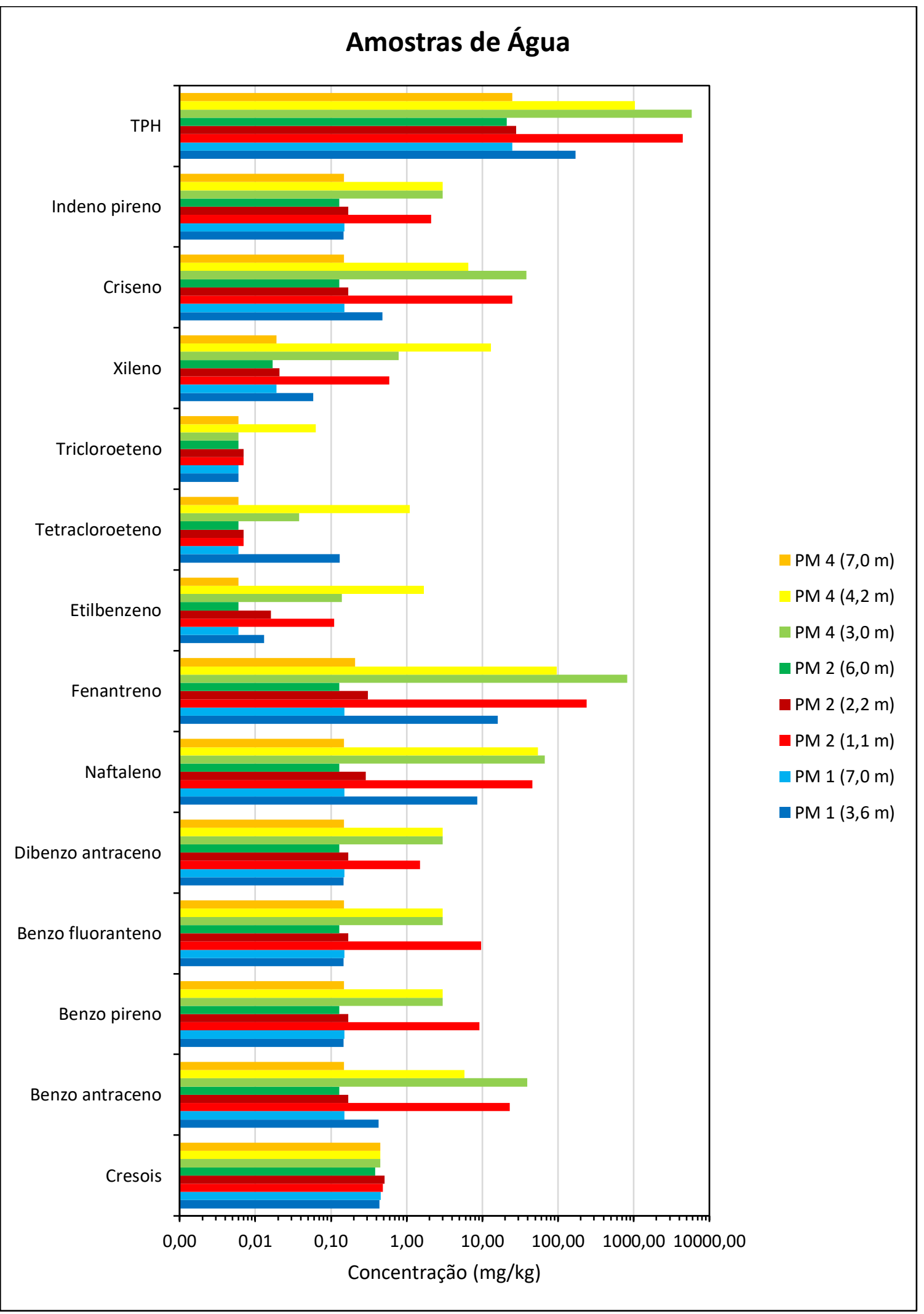

Figura 10. Resultado da análise química de algumas amostras de água quanto a concentração de diversos compostos químicos. Dados disponibilizados pelo IPT. 


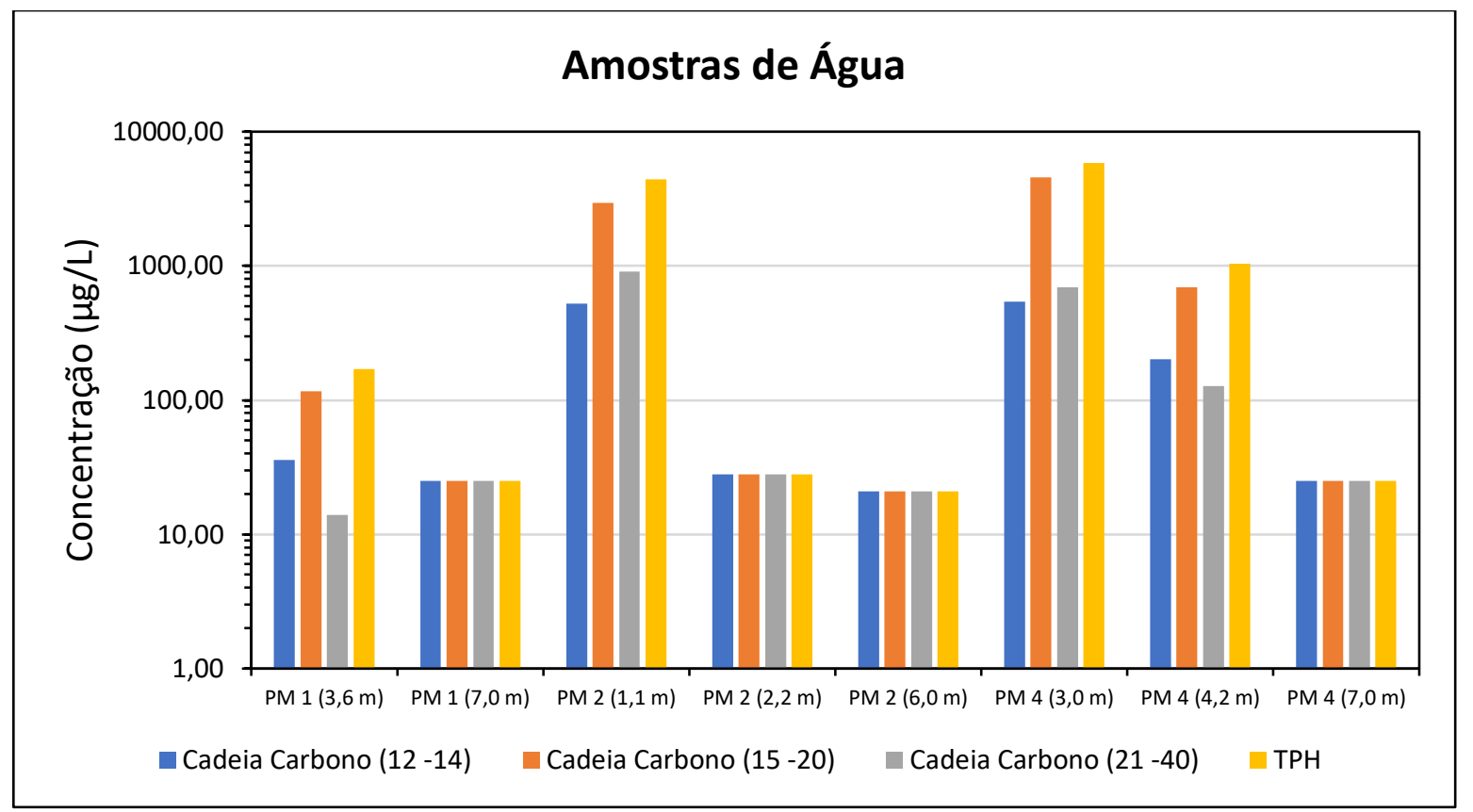

Figura 11. Resultado da análise química de algumas amostras de água quanto ao número de carbono das cadeias carbônicas e concentrações de TPH. Dados disponibilizados pelo IPT.

Após a análise química das amostras e a constatação da contaminação, o IPT iniciou o processo de aquisição de dados geofísicos, dados de Fluorescência de Raios x (XRF - X-Ray Fluorescence) e dados invasivos com sonda (Netto, 2020). Na aquisição geofísica, foram adquiridos dados com os métodos de ER, GPR e Sísmico com a técnica de Análise Multicanal de Ondas de Superfície (MASW - Multi-Channel Analysis Surface Waves). Após a aquisição de dados geofísicos indiretos, foi utilizada uma sonda Membrane Interface Probe (MIP) em pontos estratégicos baseados nos resultados desses métodos e das análises de solo e de água (Figura 12).

Segundo (Netto, 2020) a distribuição 3D de resistividade da área baseada na interpolação de linhas de tomografia elétrica mostra uma anomalia de alta resistividade que coincide com o local do galpão do antigo setor de tratamento químico onde se localizavam as fontes potencias de contaminação. Esta anomalia resistiva se estende até 30 metros pela saída sul do galpão. Ainda segundo este autor, o modelo pseudo-3D de amplitudes de sinais GPR mostra que anomalias nas amplitudes dos sinais GPR coincidem com a localização das antigas fontes potenciais do galpão e também se estendem a aproximadamente 30 metros pela saída sul. 


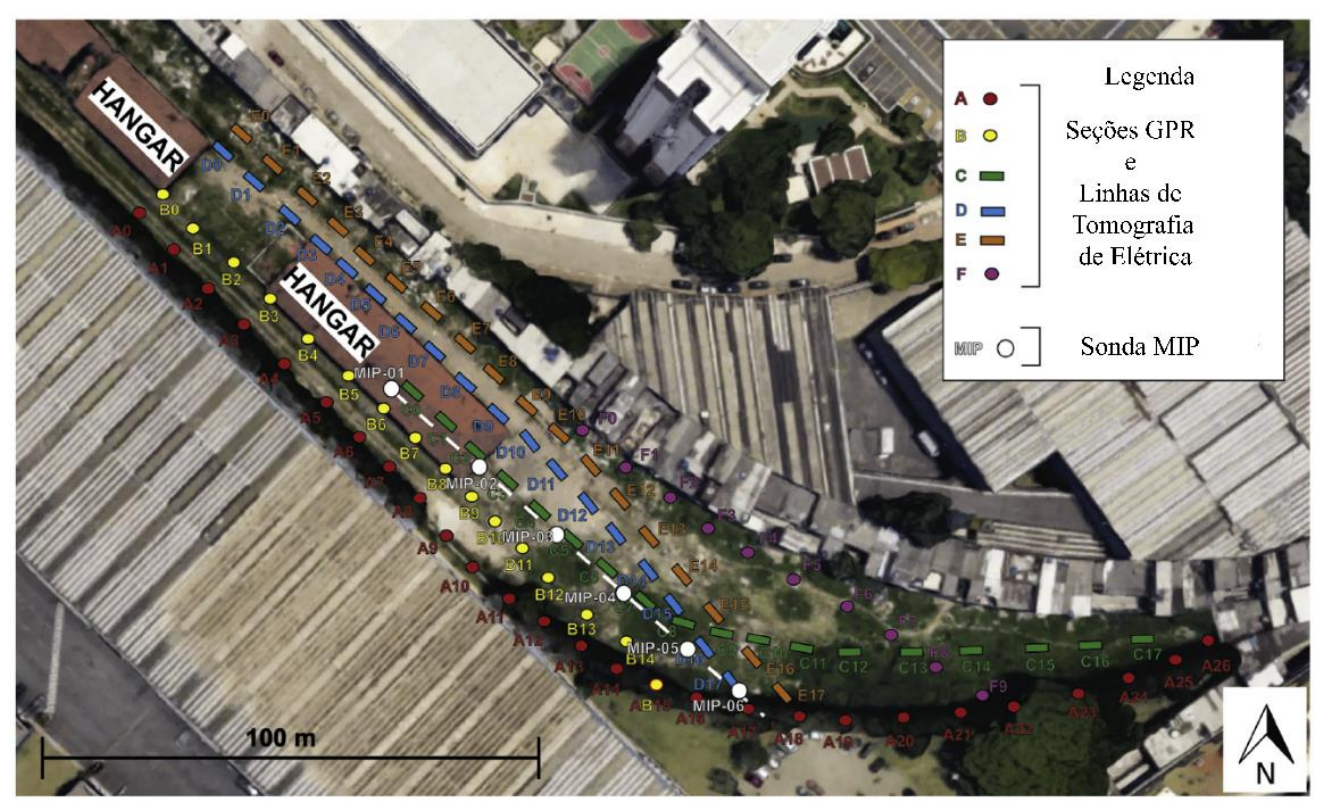

Figura 12. Croqui das linhas de aquisição com métodos geofísicos indiretos e com a sonda MIP. Modificado de (Netto, 2020).

A sonda MIP permite a caracterização da estratigrafia através da obtenção de um perfil de condutividade elétrica do ponto onde a sonda é inserida. Existe uma boa correlação entre a distribuição de resistividade obtida pelo método ER e pela sonda MIP. Com os perfis de resistividade de cada uma das sondagens com a sonda MIP foi possível se obter uma interpretação das diferentes camadas estratigráficas da área (Figura 13). A estratigrafia interpretada é constituída por uma camada argilosa mais superficial de aproximadamente 4 metros de espessura sobre uma camada arenosa de 5,5 metros de espessura que possui lentes de argila. A camada mais profunda é formada por sedimentos terciários constituída por camadas de areia e argila. 


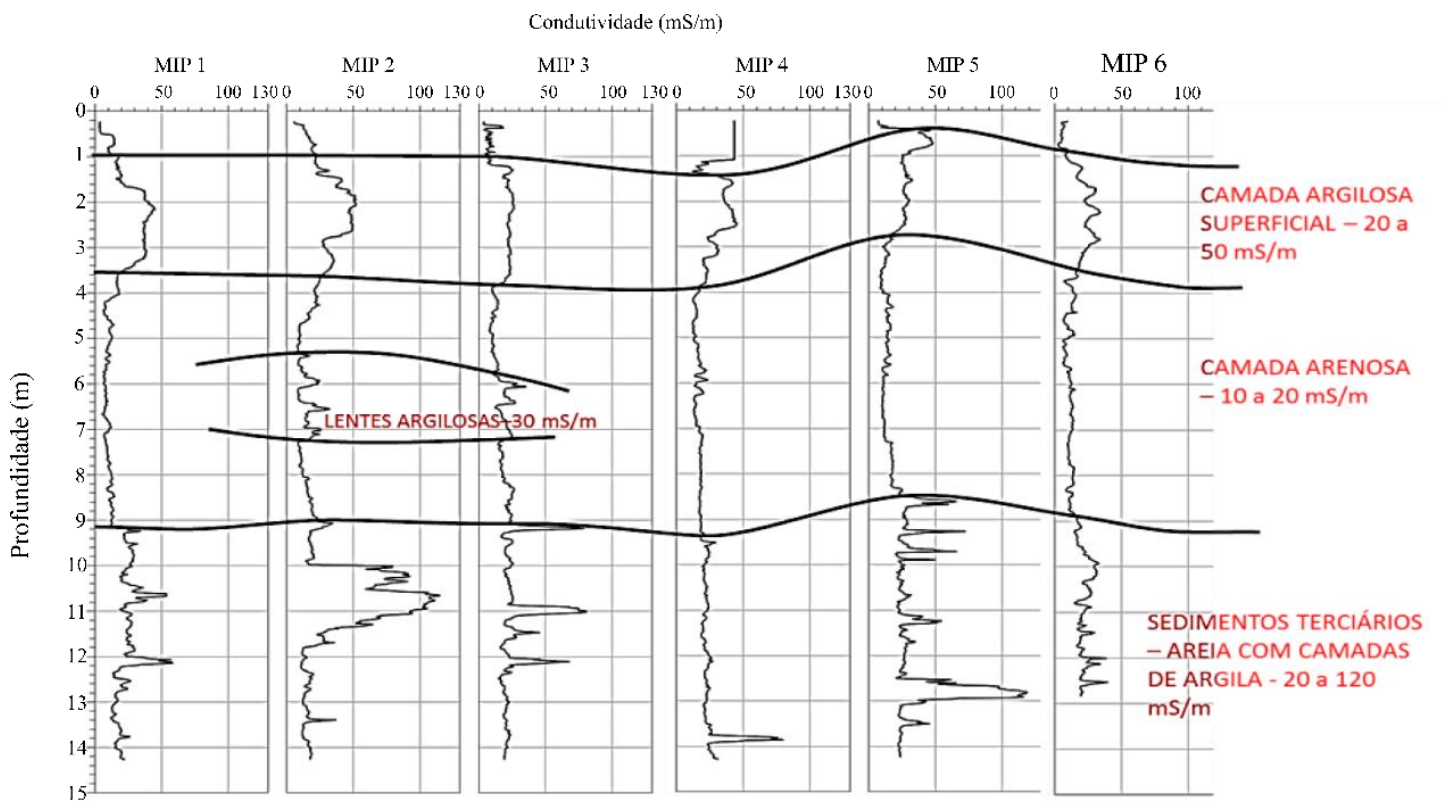

Figura 13. Perfis de resistividade elétrica obtidos com a sonda MIP e a interpretação estratigráfica. Perfis disponibilizados pelo IPT através de relatórios da área. 


\section{CAPÍTULO 3}

\section{FUNDAMENTOS TEÓRICOS}

\subsection{TEORIA DO ELETROMAGNETISMO}

A teoria do eletromagnetismo é sintetizada por quatro equações, conhecidas como equações de Maxwell, que descrevem as relações entre os campos elétricos e magnéticos e suas fontes. Essas equações são definidas em termos dos vetores intensidade do campo elétrico $\boldsymbol{E}(\mathrm{V} / \mathrm{m})$, intensidade do campo magnético $\boldsymbol{H}(\mathrm{A} / \mathrm{m})$, densidade de fluxo elétrico $\boldsymbol{D}\left(\mathrm{C} / \mathrm{m}^{2}\right)$, densidade do fluxo magnético $\boldsymbol{B}\left(\mathrm{Wb} / \mathrm{m}^{2}\right.$ ou $\left.\mathrm{T}\right)$ e densidade de corrente de condução elétrica $\boldsymbol{J}_{C}\left(\mathrm{~A} / \mathrm{m}^{2}\right)$. No caso em que não existem cargas livres no meio, as equações de Maxwell são dadas na sua forma diferencial no domínio do tempo pelas seguintes expressões:

Lei de Gauss da Elétrica

Lei de Gauss do Magnetismo

Lei de Faraday da Indução

Lei de Ampere e Maxwell

$$
\nabla \cdot \boldsymbol{D}=0
$$$$
\nabla \cdot \boldsymbol{B}=0
$$

$$
\nabla \times \boldsymbol{E}=-\frac{\partial \boldsymbol{B}}{\partial t}
$$

$$
\nabla \times \boldsymbol{H}=\boldsymbol{J}_{C}+\frac{\partial \boldsymbol{D}}{\partial t}
$$

A equação (3.4) nos mostra que um campo magnético pode ser gerado tanto por uma densidade de corrente de condução $\boldsymbol{J}_{C}$ quanto pela densidade de corrente de deslocamento $\boldsymbol{J}_{D}=$ $\frac{\partial \boldsymbol{D}}{\partial t}$.

É possível quantificar o comportamento de um meio (material arbitrário) quando este é submetido a um campo eletromagnético. Para isso deve-se definir as propriedades eletromagnéticas do meio utilizando as chamadas relações constitutivas do meio. Tais relações descrevem macroscopicamente como átomos e moléculas do meio se comportam na presença de um campo eletromagnético. Essas relações são dadas pelas seguintes expressões: 
Lei de Ohm

$$
\begin{aligned}
\boldsymbol{J}_{C} & =\sigma \boldsymbol{E} \\
\boldsymbol{B} & =\mu \boldsymbol{H} \\
\boldsymbol{D} & =\varepsilon \boldsymbol{E}
\end{aligned}
$$

Onde $\sigma$ é a condutividade elétrica $(\mathrm{S} / \mathrm{m}), \mu$ é a permeabilidade magnética $(\mathrm{H} / \mathrm{m})$ e $\varepsilon$ é a permissividade dielétrica $(\mathrm{F} / \mathrm{m})$.

A condutividade elétrica $\sigma$, definida pela equação (3.5) (Lei de Ohm), diz respeito a quantidade de cargas em movimento quando o meio é submetido a um campo elétrico. Em outras palavras, a condutividade elétrica mede a capacidade do meio de conduzir corrente elétrica.

Já a permeabilidade magnética $\mu$, definida pela equação (3.6), caracteriza a capacidade de magnetização do meio quando este é submetido a um campo magnético. A permeabilidade magnética do vácuo $\mu_{0}$, também chamada de constante magnética, é uma constante universal $\left(\mu_{0}=\right.$ $\left.4 \pi \times 10^{-7} \mathrm{H} / \mathrm{m}\right)$.

Por fim, a permissividade dielétrica $\varepsilon$, definida pela equação (3.7), caracteriza a capacidade do meio em ser polarizado na presença de um campo elétrico. A permissividade dielétrica do vácuo $\varepsilon_{0}$ foi estabelecida como uma constante universal $\left(\varepsilon_{0}=8,85 \times 10^{-12} \mathrm{~F} / \mathrm{m}\right)$ que também aparece na Lei de Coulomb definindo parte da constante da força de Coulomb entre cargas elétricas.

Através da manipulação algébrica das equações de Maxwell juntamente com as relações constitutivas do meio, além de algumas premissas feitas acerca do meio, é possível se obter expressões que descrevem a propagação dos campos elétricos e magnéticos (Telford, 1990). Essas expressões são chamadas de equações de Helmholtz.

Inicialmente é necessário implementar as relações constitutivas do meio nas equações de Maxwell. Substitui-se a equação (3.6) na equação (3.3), resultando na seguinte expressão:

$$
\nabla \times \boldsymbol{E}=-\mu \frac{\partial \boldsymbol{H}}{\partial t}
$$

De maneira análoga, substitui-se as equações (3.5) e (3.7) na equação (3.4), resultando na seguinte expressão:

$$
\nabla \times \boldsymbol{H}=\sigma \boldsymbol{E}+\varepsilon \frac{\partial \boldsymbol{E}}{\partial t}
$$


Supondo que os campos elétrico e magnético variam senoidalmente com o tempo, ou seja,

$$
\begin{aligned}
\boldsymbol{E}(t) & =E_{0} e^{i \omega t} \\
\boldsymbol{H}(t) & =H_{0} e^{i \omega t}
\end{aligned}
$$

onde $\omega=2 \pi f$ é a frequência angular de oscilação dos campos ( $\mathrm{rad} / \mathrm{s}), f$ é a frequência (Hz), $i=\sqrt{-1}$ é a unidade imaginária e $E_{0}$ e $H_{0}$ são as amplitudes dos campos elétrico e magnético, respectivamente. A variação senoidal dos campos permite definir o operador $\frac{\partial}{\partial t}=i \omega$ e empregalo nas equações (3.8) e (3.9), levando-as para o domínio da frequência:

$$
\begin{gathered}
\nabla \times \boldsymbol{E}=-\mu i \omega \boldsymbol{H} \\
\nabla \times \boldsymbol{H}=\sigma \boldsymbol{E}+\varepsilon i \omega \boldsymbol{E}
\end{gathered}
$$

Aplica-se então o operador rotacional nas equações (3.10) e (3.11), resultando em:

$$
\begin{gathered}
\nabla \times \nabla \times \boldsymbol{E}=-\mu i \omega \nabla \times \boldsymbol{H} \\
\nabla \times \nabla \times \boldsymbol{H}=\sigma \nabla \times \boldsymbol{E}+\varepsilon i \omega \nabla \times \boldsymbol{E}
\end{gathered}
$$

Substituindo-se a equação (3.10) em (3.13) e a equação (3.11) em (3.12), resulta:

$$
\begin{aligned}
& \nabla \times \nabla \times \boldsymbol{E}=-\mu i \omega(\sigma+\varepsilon i \omega) \boldsymbol{E} \\
& \nabla \times \nabla \times \boldsymbol{H}=-\mu i \omega(\sigma+\varepsilon i \omega) \boldsymbol{H}
\end{aligned}
$$

Aplicando a identidade vetorial $\nabla \times(\nabla \times \vec{A})=\nabla(\nabla \cdot \vec{A})-\nabla^{2} \vec{A}$ nas equações (3.14) e (3.15), obtem-se:

$$
\nabla(\nabla \cdot \boldsymbol{E})-\nabla^{2} \boldsymbol{E}=-\mu i \omega(\sigma+\varepsilon i \omega) \boldsymbol{E}
$$




$$
\nabla(\nabla \cdot \boldsymbol{H})-\nabla^{2} \boldsymbol{H}=-\mu i \omega(\sigma+\varepsilon i \omega) \boldsymbol{H}
$$

Sabendo que $i^{2}=-1$ e substituindo as equações (3.1) e (3.2) em (3.16) e (3.17) respectivamente, temos finalmente as equações de Helmholtz:

$$
\begin{aligned}
& \nabla^{2} \boldsymbol{E}=\left(\sigma \mu i \omega-\varepsilon \mu \omega^{2}\right) \boldsymbol{E} \\
& \nabla^{2} \boldsymbol{H}=\left(\sigma \mu i \omega-\varepsilon \mu \omega^{2}\right) \boldsymbol{H}
\end{aligned}
$$

onde o primeiro termo do lado direito das equações está relacionado com a corrente de condução, enquanto o segundo termo está relacionado com a corrente de deslocamento.

Os métodos geofísicos utilizam a propagação de campos eletromagnéticos em uma ampla gama de frequências que são escolhidas de acordo com a aplicação desejada. De acordo com a frequência, a propagação do campo eletromagnético pode ser descrita por três diferentes equações amplamente difundidas na área das ciências da Terra. Para frequências altas (acima de $1 \mathrm{MHz}$ ), onde a corrente de deslocamento é preponderante, a propagação do campo eletromagnético é regida pela Equação de Onda. Para frequências baixas (abaixo de $1 \mathrm{MHz}$ ) em meios condutivos, onde a corrente de condução é preponderante, a propagação do campo eletromagnético é regida pela Equação de Difusão. Para frequências baixas em meios com baixa condutividade ou para métodos de corrente contínua $(\omega=0)$ as equações (3.18) e (3.19) se reduzem à Equação de Laplace.

\subsection{MÉTODO GROUND PENETRATING RADAR (GPR)}

O GPR é um método geofísico eletromagnético bastante difundido em estudos da subsuperfície rasa. Este método opera em altas frequências (entre 10 e $2600 \mathrm{MHz}$ ) e permite um imageamento em alta resolução do subsolo e do interior de estruturas. A ampla gama de frequências de operação e a grande variedade de materiais dielétricos permitem com que o GPR seja utilizado em estudos de poucos centímetros até dezenas de metros de profundidade.

\subsubsection{Breve Histórico}

A primeira utilização de ondas eletromagnéticas para deteç̧ão de objetos é atribuída à Cristian Hulsmeyer em 1904. Hulsmeyer foi um inventor alemão e criador do primeiro aparelho 
de radar, chamado por ele de telemobilescope, criado com o objetivo inicial de ser utilizado na detecção de navios nos mares. Já a utilização de ondas eletromagnéticas para localização de objetos enterrados foi feita pela primeira vez em 1910 na Alemanha, por Gotthelf Leimbach e Heinrich Lowy (Daniels, 2004). Leimbach e Lowy utilizaram um sistema de antenas em furos verticais e compararam a magnitude dos sinais recebidos.

Nas décadas de 1960 e 1970 sinais eletromagnéticos foram amplamente utilizados em investigações sobre camadas de gelo (Evans, 1967; Annan e Davis, 1976). Ainda na década de 1970, ocorreu o desenvolvimento do Sistema de Radar de Sondagem Lunar que foi enviado à Lua pela missão Apollo 17 (Porcello et al, 1974). A partir daí, sinais eletromagnéticos passaram a ser utilizados em diversas áreas como mineração (Annan et al, 1988), arqueologia (Kenyon, 1977) e engenharia (Rubin and Fowler, 1978).

Atualmente o método é utilizado em planejamento urbano (Porsani e Sauck, 2007; Santos, 2014), estudos forenses (Borges et al, 2010; Almeida, 2016), estudos ambientais (Atekwana, 2010; Bertolla et al, 2014), engenharia (Giannakis, 2020), aplicações humanitárias (Porsani et al, 2019) e outras. Recentemente a Administração Nacional da Aeronáutica e Espaço (NASA - National Aeronautics and Space Administration) enviou um equipamento GPR para marte junto ao Rover Perseverance (Hamran, 2020).

\subsubsection{Teoria do Método}

Para as altas frequências de operação do método GPR, a permissividade dielétrica $\varepsilon$ é a propriedade mais importante e está ligada a propagação do sinal (Annan, 1996). Geralmente esta propriedade é descrita através do uso da equivalente adimensional permissividade dielétrica relativa ou constante dielétrica, sendo a razão entre a permissividade dielétrica do material e a permissividade dielétrica do vácuo:

$$
\varepsilon_{r}=\frac{\varepsilon}{\varepsilon_{0}}
$$

Nas aplicações geológicas, a permeabilidade magnética das rochas e minerais varia pouco com relação a permeabilidade magnética do vácuo (Keller, 1988), assim tomamos $\mu \approx \mu_{0}$.

As equações (3.18) e (3.19) podem ser reescritas da seguinte forma: 


$$
\begin{gathered}
\nabla^{2} \boldsymbol{E}+k^{2} \boldsymbol{E} \\
\nabla^{2} \boldsymbol{H}+k^{2} \boldsymbol{H}
\end{gathered}
$$

onde $k=\sqrt{\varepsilon \mu_{0} \omega^{2}-\sigma \mu_{0} i \omega}$ é o número de onda complexo. Um número complexo é composto por uma parte real e uma parte imaginária, portanto escreve-se o número de onda $k$ da seguinte maneira (Stratton, 1941):

$$
k=\sqrt{\varepsilon \mu_{0} \omega^{2}-\sigma \mu_{0} i \omega}=\alpha+i \beta
$$

onde $\alpha$ é o coeficiente de atenuação $(\mathrm{dB} / \mathrm{m})$ e $\beta$ é o coeficiente de propagação ( $\mathrm{rad} / \mathrm{m})$.

Manipulando os coeficientes $\alpha$ e $\beta$ utilizando séries de potência e considerando as altas frequências do método GPR, podemos reescreve-los como sendo:

$$
\begin{gathered}
\alpha=\frac{\sigma}{2} \sqrt{\frac{\mu_{0}}{\varepsilon}} \\
\beta=\omega \sqrt{\mu_{0} \varepsilon}
\end{gathered}
$$

Nota-se pela equação (3.24) que a atenuação do sinal eletromagnético é diretamente proporcional a condutividade elétrica.

Para meios com baixa perda $(\sigma \cong 0 \mathrm{~S} / \mathrm{m})$ o número de onda se reduz a $k_{-}=\omega \sqrt{\mu_{0} \varepsilon}$. Pela definição de velocidade de propagação de uma onda eletromagnética em termos do número de onda $k_{-}$e da frequência angular e usando a equação (3.20), temos:

$$
v=\frac{\omega}{\omega \sqrt{\mu_{0} \varepsilon_{0} \varepsilon_{r}}}=\frac{1}{\sqrt{\mu_{0} \varepsilon_{0}}} \frac{1}{\sqrt{\varepsilon_{r}}}=\frac{c}{\sqrt{\varepsilon_{r}}}
$$


onde $c \cong 3 \times 10^{8} \mathrm{~m} / \mathrm{s}$ é a velocidade da luz no vácuo. A equação (3.26) mostra que a velocidade de propagação da onda GPR, em meios com baixa perda, não depende da frequência do sinal.

A tabela 3 mostra os valores das propriedades elétricas de alguns materiais (Annan, 2003).

\begin{tabular}{|c|c|c|}
\hline Material & $\varepsilon_{r}$ & $\sigma(\mathbf{m S} / \mathbf{m})$ \\
\hline Ar & 1 & 0 \\
\hline Água Fresca & 81 & 0,5 \\
\hline Água Salgada & 81 & 3000 \\
\hline Solo Argiloso Seco & $4-6$ & 0,27 \\
\hline Solo Argiloso Saturado & $10-15$ & 50 \\
\hline Solo Arenoso Seco & $4-6$ & 0,14 \\
\hline Solo Arenoso Saturado & $15-30$ & 6,9 \\
\hline Petróleo & 2 & $10^{-8}$ \\
\hline Ferro/Aço & 1 & $10^{9}$ \\
\hline Concreto & $6-8$ & 0 \\
\hline Granito & 7 & 1 \\
\hline
\end{tabular}

Tabela 3. Propriedades elétricas de alguns materiais. (Annan, 1992; Craig, 1998).

Ao se deparar com uma interface que divide dois meios com diferentes propriedades elétricas, parte da energia do sinal eletromagnético é refletida. Para uma incidência normal à interface, pode-se definir o coeficiente de reflexão que quantifica a porcentagem do sinal que é refletida (Daniels, 2004):

$$
c r=\frac{\sqrt{\sigma_{1}+\varepsilon_{1} i \omega}-\sqrt{\sigma_{2}+\varepsilon_{2} i \omega}}{\sqrt{\sigma_{1}+\varepsilon_{1} i \omega}+\sqrt{\sigma_{2}+\varepsilon_{2} i \omega}}
$$

onde os subíndices 1 e 2 nas propriedades elétricas representam a correspondência à dois diferentes meios. Para meios com baixa perda $(\sigma \approx 0 \mathrm{~S} / \mathrm{m})$ e para uma frequência única de radiação, podemos reescrever o coeficiente de reflexão: 


$$
c r=\frac{\sqrt{\varepsilon_{r 1}}-\sqrt{\varepsilon_{r 2}}}{\sqrt{\varepsilon_{r 1}}+\sqrt{\varepsilon_{r 2}}}
$$

\subsubsection{Técnicas de Aquisição}

Existem diferentes técnicas para se executar uma aquisição com o método GPR. São elas: (1) Common Offset, (2) Common Mid Point (CMP) e (3) Wide Angle Reflection and Refration (WARR) (Porsani, 1999).

Entre as três técnicas mencionadas, a técnica "Common Offset" ou também chamada "Perfil de Reflexão com Afastamento Constante" é a mais utilizada. Esta técnica consiste em uma aquisição onde uma antena transmissora (Tx) e uma antena receptora $(\mathrm{Rx})$ são rebocadas sobre a superfície com um afastamento constante entre elas (Figura 14a). Um pulso é enviado por Tx e registrado por Rx em um intervalo pré-estabelecido de tempo ou distância. Cada pulso registrado por Rx é chamado de "Traço" ou "A-scan" e é composto por uma discretização no tempo da amplitude do campo eletromagnético. Cada A-scan obtido durante a aquisição é posicionado lado a lado formando um perfil chamado "radargrama" ou "B-scan" (Figura 14b). Nota-se na Figura $14 \mathrm{~b}$ que em cada A-scan existe a chegada de 3 pulsos em diferentes momentos. O primeiro pulso é referente a onda direta, o segundo pulso é referente a reflexão no alvo cilíndrico e o terceiro pulso é referente a reflexão na camada plana.

As técnicas de aquisição CMP e WARR são utilizadas para estimar a velocidade de propagação da onda eletromagnética em subsuperfície. Em uma aquisição com a técnica CMP, a antena transmissora blindada (Tx) e a antena receptora blindada (Rx) são afastadas uma da outra de uma forma simétrica com relação ao ponto médio (Figura 15a). A cada novo afastamento um A-scan é adquirido. Os A-scans são então posicionados lado a lado formando um perfil de aquisição CMP (Figura 15b) que tem informações referentes ao ponto médio comum entre as antenas, ou seja, uma sondagem de velocidades 1D. Em uma aquisição com a técnica WARR, a antena transmissora (Tx) é mantida fixa e a antena receptora $(\mathrm{Rx})$ se afasta adquirindo um A-scan a cada novo afastamento. Para uma aquisição WARR sobre as camadas planas do modelo da Figura 15b, o perfil resultante será idêntico ao perfil da Figura 15 b. 
a)
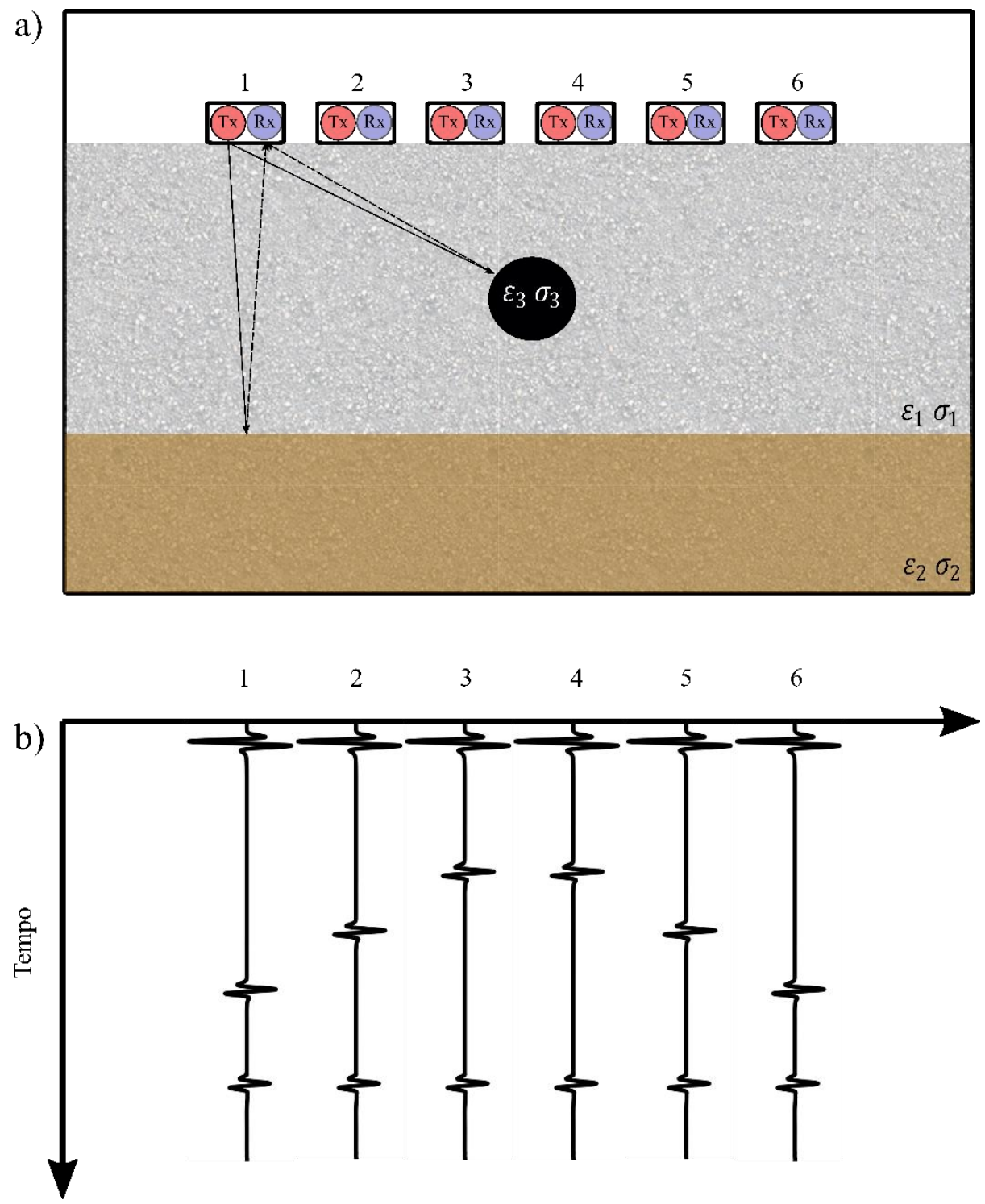

Figura 14. Croqui de uma aquisição GPR com a técnica Common Offset ou Perfil de Reflexão com Afastamento Constante. a) Aquisição de A-scans nos pontos de 1 a 6. b) B-scan da aquisição. 
a)
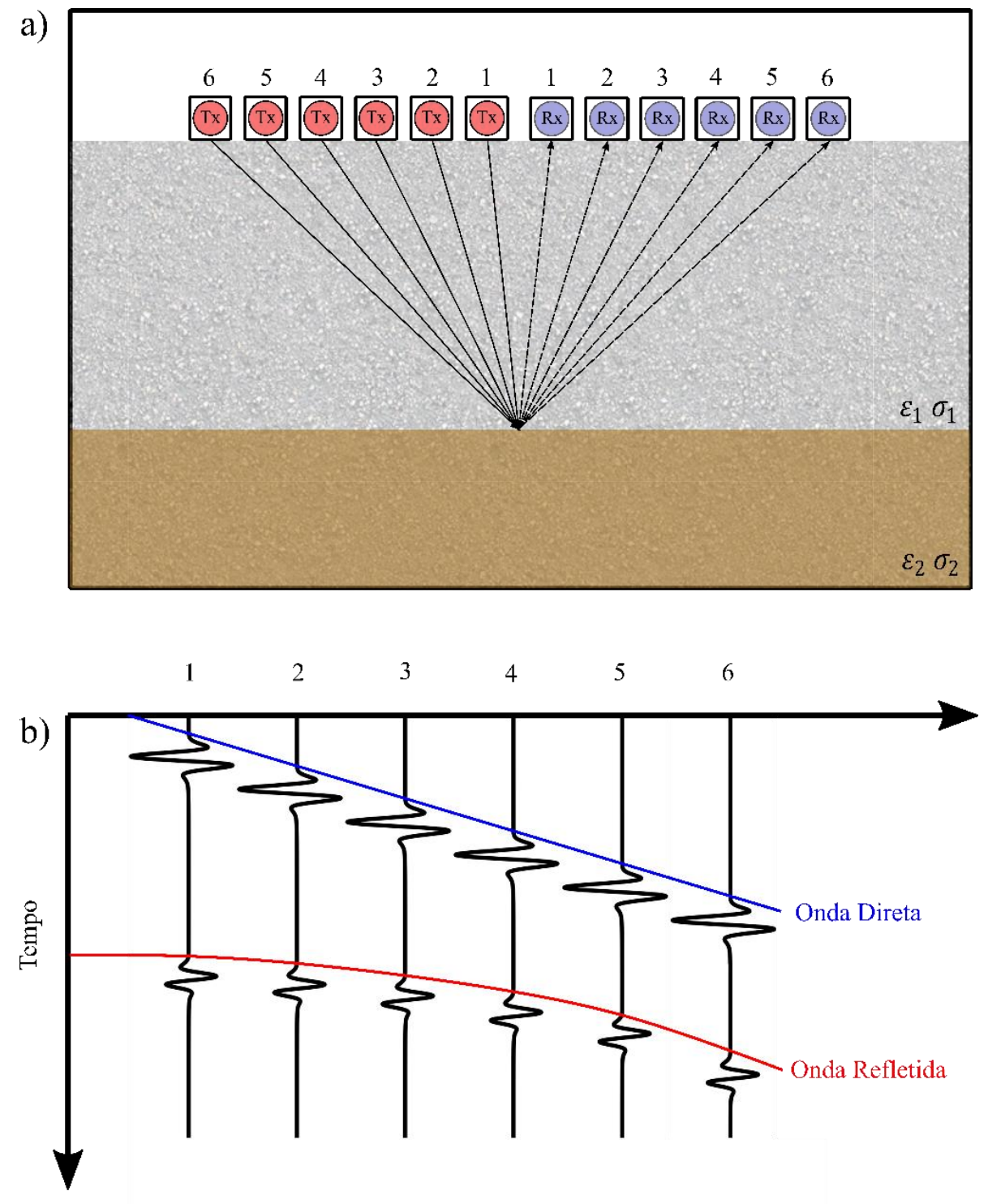

Figura 15. Croqui de uma aquisição GPR com a técnica Common Mid Point. a) Aquisição de A-scans nos pontos de 1 a 6. b) B-scan da aquisição mostrando as feições da onda direta no solo e onda refletida.

\subsubsection{Processamento de Dados}

Geralmente os radargramas são submetidos a um processamento que consiste em filtros e correções que são necessários para se fazer a interpretação dos dados. Nesta pesquisa o processamento foi feito usando o software ReflexWin Versão 7.2.3 (Sandmeier, 2012). Além das ferramentas implementadas no software ReflexW, foi utilizado um algoritmo de análise espectral escrito na linguagem de computador Python (Santos, 2014). 


\subsubsection{Processamento de Dados no ReflexWin}

Remoção do Ganho de Cabeçalho (Remove Gain Header): É possível que o operador do equipamento aplique ganhos aos radargramas para facilitar a visualização dos dados durante a aquisição. Para se fazer a interpretação correta dos dados deve-se retirar o ganho aplicado pelo operador. Somente depois da aplicação desta ferramenta as amplitudes correspondem as amplitudes reais das anomalias.

Filtro Dewow: Os dados de campo podem estar influenciados com uma frequência extremamente baixa causada pela presença de campos externos. Para eliminar esta componente dos dados é preciso utilizar o filtro dewow. Segundo Almeida (2016), um efeito secundário desta ferramenta é que, minimizando essas componentes de baixa frequência, pode-se compensar o efeito da filtragem passa-baixa causado pela geologia da área.

Correção do Tempo Zero (Move Start Time): É necessário ajustar o início do registro das amplitudes do sinal para que ele corresponda ao tempo zero do inicio da aquisição. O registro pela antena receptora é iniciado antes da emissão do sinal, isso garante que todas as amostras sejam registradas. Esse atraso da transmissão com relação ao registro deve ser removido para que não se cometa erros nas distribuições de profundidade no perfil.

Ganho: A aplicação de um ganho nos traços GPR tem como objetivo o aumento da amplitude do sinal para compensar a atenuação sofrida durante a propagação em um meio com condutividade maior que zero.

Filtro de Frequência: Esta ferramenta é aplicada com o objetivo de se remover as componentes de frequências indesejadas que podem estar contaminando o sinal GPR. Para se eliminar frequências altas, deve ser utilizado o filtro de frequência passa-baixa que permite que só as frequências abaixo de uma frequência de corte pré-estabelecida permaneçam nos dados. Para se eliminar frequências baixas, deve ser utilizado o filtro de frequência passa-alta que permite que só as frequências acima de uma frequência de corte pré-estabelecida permaneçam nos dados. Para eliminar frequências altas e baixas deve ser utilizado o filtro de frequência passa-banda que permite que só frequências entre duas frequências de corte permaneçam nos dados.

Remoção de Background (Background Removal): Esta ferramenta tem como objetivo eliminar efeitos de reverberação causados pelo acoplamento da antena com o solo. 


\subsubsection{Análise Espectral}

Uma maneira de se avaliar os resultados GPR comparando o conteúdo de um perfil com outros é através da análise do espectro de frequências. Uma técnica amplamente utilizada para se fazer a transformação de sinais no domínio do tempo para o domínio da frequência é a Transformada de Fourier. Apesar da Transformada de Fourier permitir a transferência do sinal para o domínio da frequência, essa transformada é limitada para sinais estacionários (Santos, 2014). Na Transformada de Fourier o espectro mostra a amplitude total de cada frequência e não fornece informações sobre a resolução de tempo das componentes espectrais. Usando a transformada de Fourier, o efeito de uma mudança abrupta em um sinal não estacionário espalha os eixos de frequência gerais. Este efeito torna a Transformada de Fourier incapaz de capturar as transições ao longo do tempo, sendo necessário um método aplicável a sinais não estacionários.

Uma alternativa é a Transformada de Fourier no Tempo Curto (STFT - Short Time Fourier Transform). Essa transformada é definida pela expressão a seguir:

$$
\operatorname{STFT}(t, \omega)=\int_{-\infty}^{\infty} f(\tau) \gamma(\tau-t) e^{-i \omega t} d \tau
$$

onde $\gamma(\tau-t)$ é o comprimento fixo da janela de análise deslocada no tempo $\tau$ centrada em torno de $t$. O espectrograma gerado pela aplicação da STFT é a representação bidimensional tempo-frequência e permite a análise da distribuição de energia do sinal no plano da frequênciatempo. Nesta pesquisa foi aplicada a STFT através de um algoritmo desenvolvido e disponibilizado pelo pesquisador Dr. Vinícius Rafael Neris dos Santos (Santos, 2014).

\subsection{MÉTODO DA ELETRORRESISTIVIDADE (ER)}

\subsubsection{Breve Histórico}

O método da Eletrorresistividade é utilizado para se identificar descontinuidades horizontais e verticais na resistividade elétrica das rochas em subsuperfície através da aplicação de correntes elétricas controladas no subsolo. No século XVIII, Gray e Wheeler descobriram sobre a resistividade das rochas e Watson descobriu sobre a condutividade do solo (Orellana, 1972). Essas descobertas abriram caminho para o desenvolvimento dos métodos elétricos. 
As primeiras utilizações deste método para prospecção mineral foram feitas no século XX, onde se destacaram os pesquisadores Conrad Schlumberger e Frank Wenner que desenvolveram, independentemente, arranjos de quatro eletrodos acoplados a superfície para as medidas de resistividade elétrica. Esses arranjos foram denominados arranjo Wenner e arranjo Schlumberger.

A partir da década de 1990 surgiram sistemas automáticos de coletas de dados que aceleram o processo de medidas. Este fato, combinado ao desenvolvimento da capacidade de cálculo dos computadores, fez com que o método da Eletrorresistividade tivesse um grande salto tanto na instrumentação quanto nos métodos computacionais de interpretação.

Atualmente o método da Eletrorresistividade tem sido aplicado em diversas áreas, como por exemplo, geologia (Braga, 1997; Borges, 2003), planejamento urbano (Borges, 2007; Cavenaghi, 2017), meio ambiente (Elis, 1999; Ustra, 2008), hidrogeologia (Cutrim et al, 2001) entre outros.

\subsubsection{Teoria do Método}

A resistividade elétrica, i.e., o inverso da condutividade elétrica, nada mais é do que a quantificação da dificuldade do material em conduzir corrente elétrica. A resistividade elétrica de um material pode ser definida como a resistência em Ohms entre as faces opostas de um cilindro do material (Kearey, 2002). Para o cilindro da Figura 16, onde R é a resistência do material (Ohm), $\mathrm{S}$ é a área da secção transversal $\left(\mathrm{m}^{2}\right)$ e $\mathrm{L}$ o comprimento $(\mathrm{m})$, a resistividade $\rho$ é dada por:

$$
\rho=R \frac{S}{L}
$$

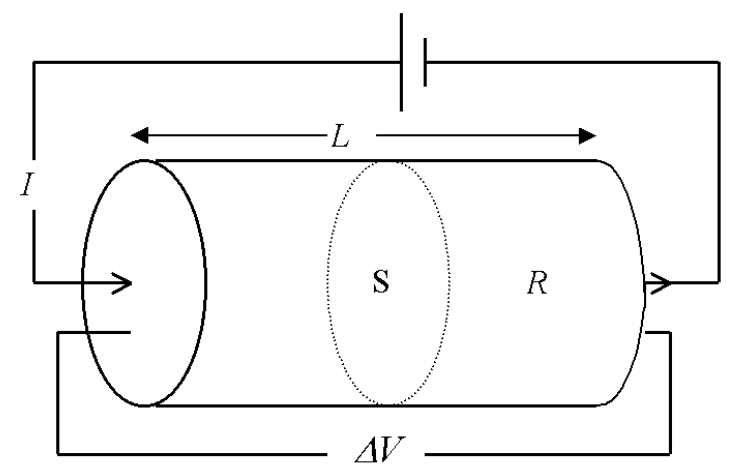

Figura 16. Cilindro com resistência R, área de secção transversal S e comprimento L. 
Aplicando-se uma diferença de potencial $\Delta V$ nas extremidades, gera-se uma corrente elétrica $I$ através do material. Uma forma da Lei de Ohm é dada por:

$$
R=\frac{\Delta V}{I}
$$

Substituindo a equação (3.30) em (3.31) temos a seguinte expressão para a resistividade do cilindro:

$$
\rho=\frac{\Delta V}{I} \frac{S}{L}
$$

Supondo um eletrodo que injeta corrente elétrica na superfície da Terra e considerando um meio de resistividade uniforme, temos que a corrente $I$ injetada pelo eletrodo se propaga para a subsuperfície radialmente na forma de uma semiesfera (Figura 17). Para fechar o circuito, existe um segundo eletrodo a uma distância muito grande.
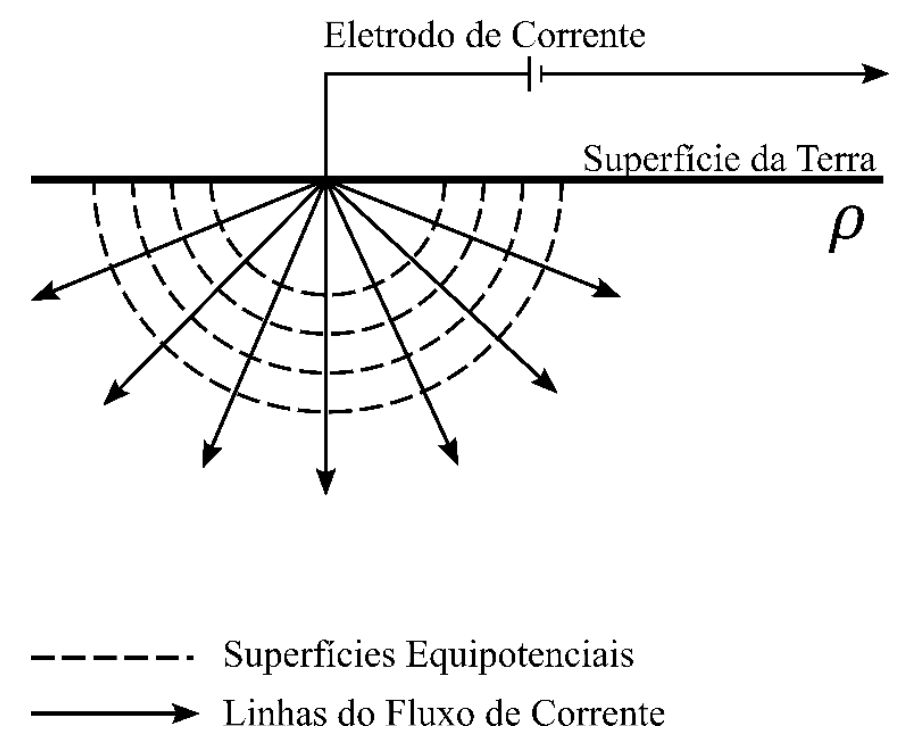

Figura 17. Fluxo de corrente elétrica e linhas equipotenciais devido a um eletrodo acoplado. O circuito é fechado por um segundo eletrodo de corrente a uma distância muito grande.

Para a configuração de injeção de corrente da Figura 17, temos que a resistividade definida pela equação (3.32) se torna: 


$$
\rho=\frac{\Delta V}{I} \frac{2 \pi r^{2}}{r}=\frac{\Delta V 2 \pi r}{I}
$$

onde r é a distância na direção radial em torno do eletrodo de corrente. Portanto, o potencial medido em um eletrodo a uma distância r do eletrodo de corrente (Figura 18) é dado por:

$$
\Delta V=\frac{\rho I}{2 \pi r}
$$

Considerando o caso onde o segundo eletrodo de corrente B está a uma distância curta do primeiro eletrodo de corrente A (Figura 19). O potencial $V_{M}$ medido por um eletrodo interno M é dado pela soma do potencial $V_{M A}$ devido ao eletrodo A e o potencial $V_{M B}$ devido ao eletrodo B, sendo expresso por:

$$
V_{M}=V_{M A}+V_{M B}=\frac{\rho I}{2 \pi r_{a}}-\frac{\rho I}{2 \pi r_{b}}
$$

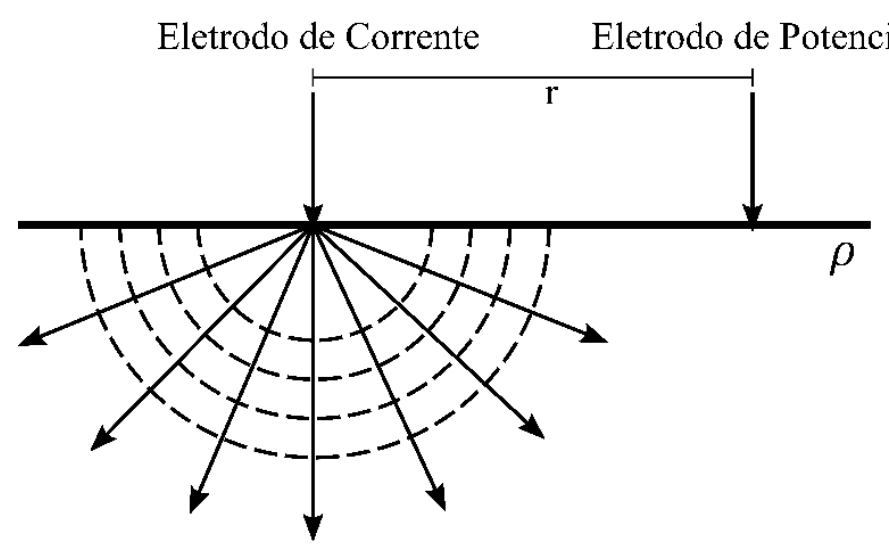

-ーーーー- Superfícies Equipotenciais

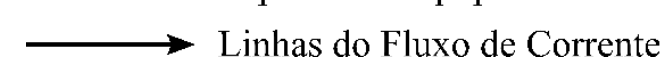

Figura 18. Dois eletrodos acoplados na superfície. 


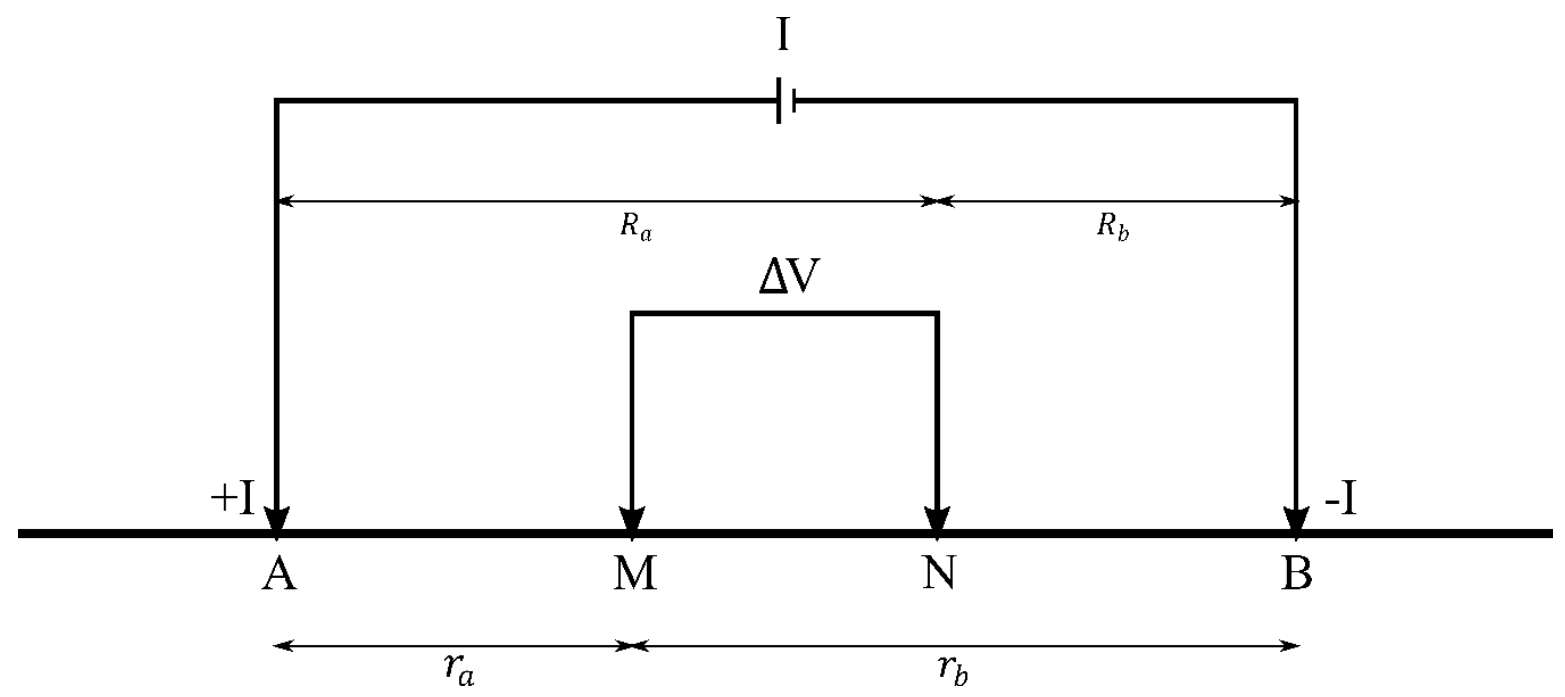

Figura 19. Arranjo de quatro eletrodos acoplados na superfície. A e B são eletrodos de corrente e $\mathrm{M}$ e $\mathrm{N}$ são eletrodos de potencial.

Da mesma maneira, o potencial $V_{N}$ medido no eletrodo de potencial $\mathrm{N}$ é dado pela soma do potencial $V_{N A}$ devido ao eletrodo A e o potencial $V_{N B}$ devido ao eletrodo B, sendo expresso por:

$$
V_{N}=V_{N A}+V_{N B}=\frac{\rho I}{2 \pi R_{a}}-\frac{\rho I}{2 \pi R_{b}}
$$

A diferença de potencial $\Delta V$ é dado por:

$$
\begin{gathered}
\Delta V=V_{M}-V_{N}=\left(V_{M A}+V_{M B}\right)-\left(V_{N A}+V_{N B}\right) \\
\Delta V=\frac{\rho I}{2 \pi r_{a}}-\frac{\rho I}{2 \pi r_{b}}-\frac{\rho I}{2 \pi R_{a}}+\frac{\rho I}{2 \pi R_{b}}=\rho I\left(\frac{1}{2 \pi r_{a}}-\frac{1}{2 \pi r_{b}}-\frac{1}{2 \pi R_{a}}+\frac{1}{2 \pi R_{b}}\right)
\end{gathered}
$$

A expressão entre parênteses da equação (3.38) é chamada de fator geométrico $K$. Por fim, isolando a resistividade na equação (3.38), pode-se utilizar arranjos de eletrodos sobre distribuições arbitrárias de resistividade onde a resistividade aparente pode ser calculada pela seguinte expressão:

$$
\rho_{a}=K \frac{\Delta V}{I}
$$


onde $\rho_{a}$ é a resistividade aparente, $\Delta V$ é a diferença de potencial medida entre os eletrodos de potencial, $I$ é a corrente injetada pelos eletrodos de corrente e $K$ é o fator geométrico do arranjo. A resistividade aparente na equação (3.39) é chamada de aparente pois não reflete a verdadeira distribuição de resistividade em subsuperfície, sendo uma estimativa da resistividade total do volume de rochas compreendido em subsuperfície entre os eletrodos.

\subsubsection{Técnicas e Arranjos de Aquisição}

Existem muitas configurações de eletrodos para uma aquisição com o método de Eletrorresistividade. Como já mencionado, existem os arranjos Wenner e Schlumberger nomeados pelos seus desenvolvedores. Para esses arranjos, o ponto de medida da resistividade aparente é atribuído ao ponto médio entre os eletrodos de potencial. Já a profundidade desta medida depende da distância entre os eletrodos de corrente. A principais técnicas de aquisição são (1) a Sondagem Elétrica Vertical (SEV) que é capaz de realizar uma sondagem na vertical da resistividade aparente e (2) o Caminhamento Elétrico (CE) que é capaz de realizar medidas de resistividade aparente na horizontal. Na Figura 20 é apresentado como os eletrodos são movimentados para se realizar as medidas com cada uma das técnicas. Além dos arranjos Wenner e Schlumberger, também são amplamente utilizados os arranjos Dipolo-Dipolo e Polo-Dipolo (Figura 21). 


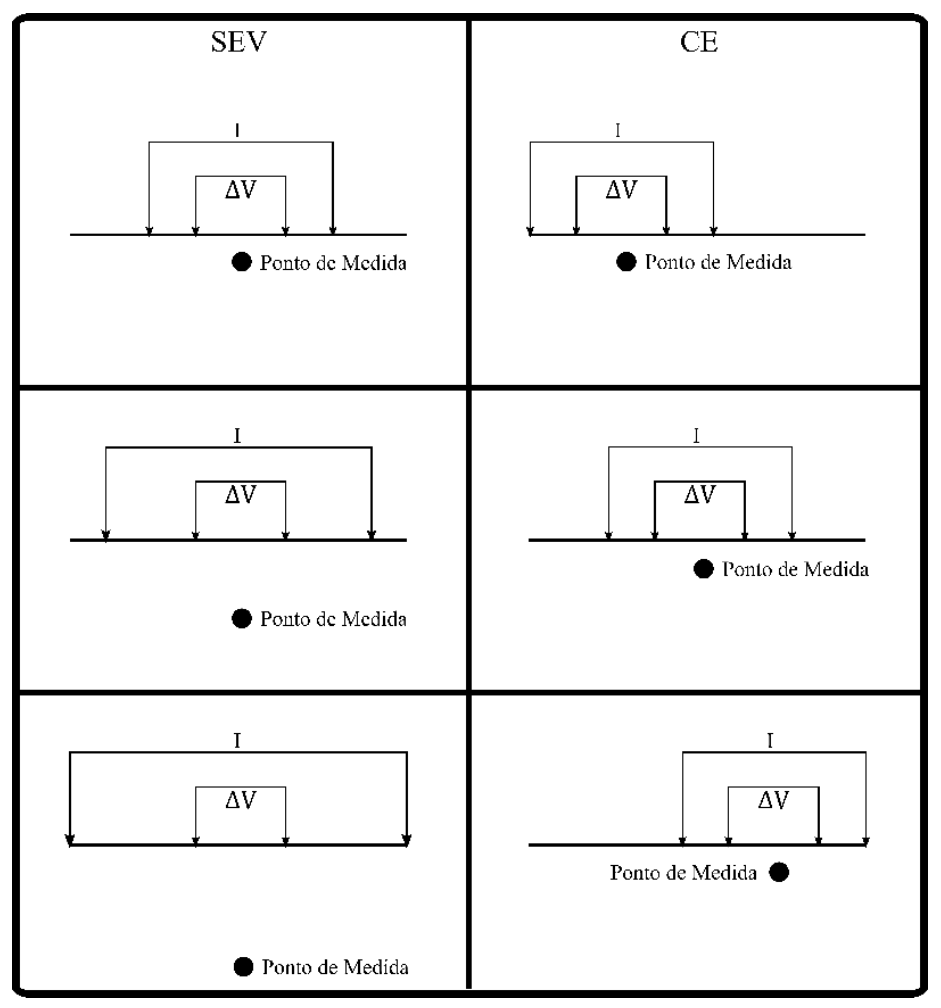

Figura 20. Movimentação dos eletrodos para as técnicas de Sondagem Elétrica Vertical (SEV) e Caminhamento Elétrico (CE). 


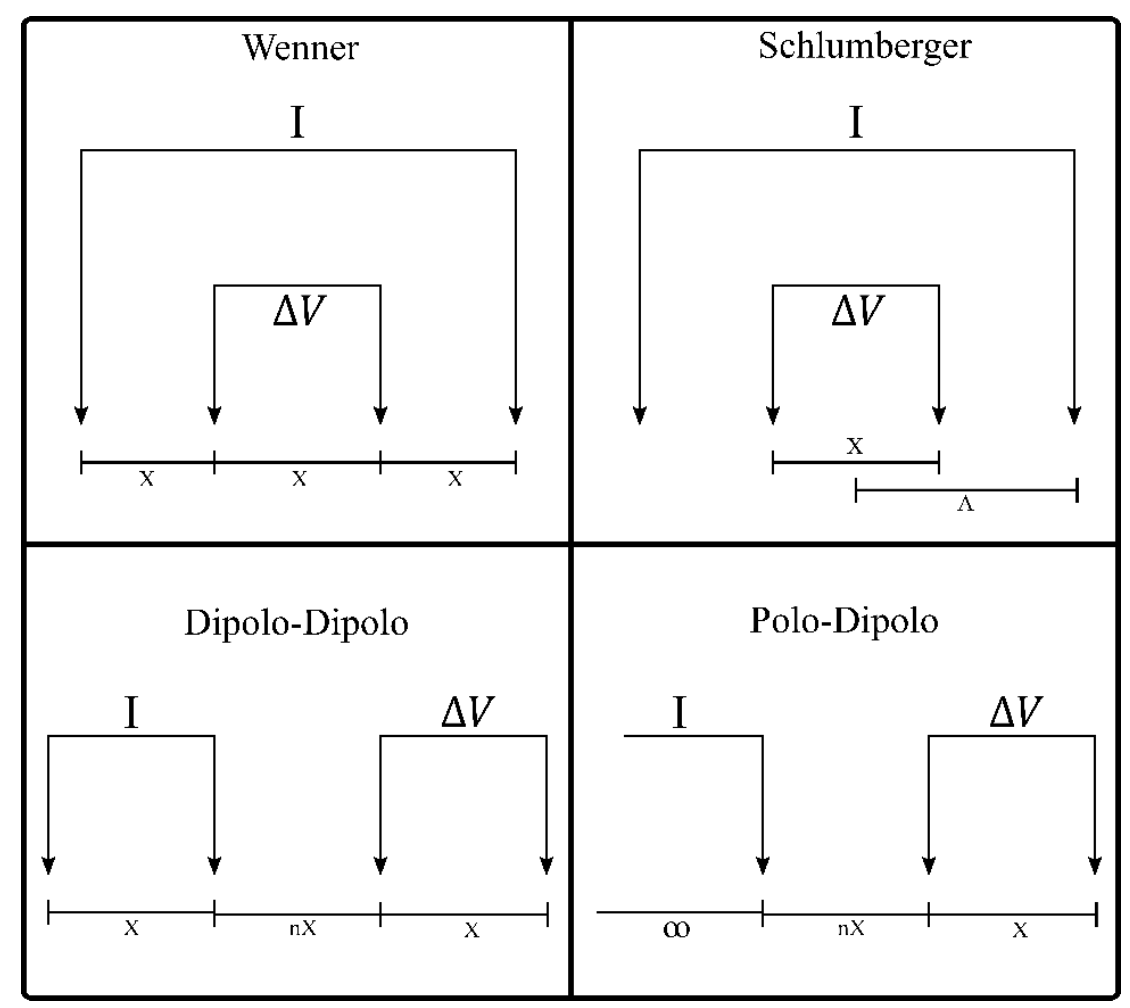

Figura 21. Principais arranjos de eletrodos usados em aquisições de Eletrorresistividade.

A profundidade do ponto de medida, chamada de profundidade de investigação, depende do arranjo de eletrodos. Segundo ROY and APPARAO (1971), para o arranjo Wenner com espaçamento $\mathrm{X}$ entre eletrodos de potencial, a profundidade de investigação é $0,11 \cdot \mathrm{X}$. Para $\mathrm{o}$ arranjo Schlumberger a profundidade de investigação é 0,125·X. Para o arranjo Dipolo-Dipolo com a distância $\mathrm{X}$ entre os pontos médios entre os eletrodos de corrente e de potencial, a profundidade de investigação é $0,195 \cdot X$.

No arranjo Dipolo-Dipolo, os níveis de investigação são dados por diferentes valores de $\mathrm{nX}$. Usando um conjunto com diversos eletrodos de potencial, pode-se realizar a tomografia elétrica de subsuperfície, como mostra a Figura 22. Nesta pesquisa foi utilizada a técnica de tomografia elétrica com arranjo Dipolo-Dipolo. 


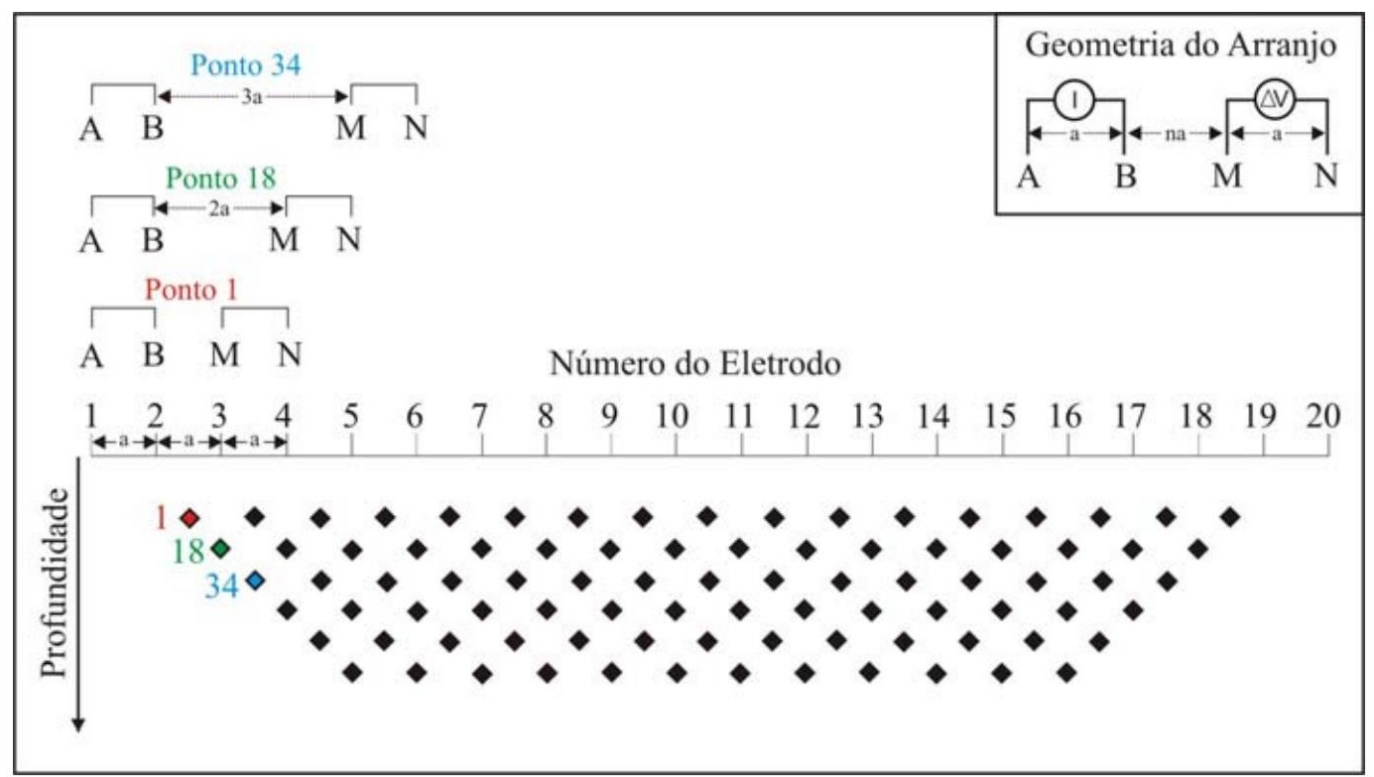

Figura 22. Arranjo Dipolo-Dipolo e as sequências de medidas para se obter a tomografia elétrica (Borges, 2007).

\subsubsection{Eletrorresistividade com Acoplamento Capacitivo $(R C)$}

O método de Eletrorresistividade tradicional requer a cravação de eletrodos no solo para que se possa injetar a corrente elétrica e medir o potencial gerado. Isso torna a aplicação do método tradicional limitado à terrenos que não tenham pavimentação ou superfícies rochosas aflorantes. Além disso, quando se deseja fazer uma investigação de detalhe, o método tradicional requer uma grande quantidade de eletrodos cravados a pequenas distâncias, o que pode inviabilizar sua aplicação devido a grande demanda de tempo.

Para contornar essas limitações, foi desenvolvido um equipamento capaz de injetar corrente alternada no solo através de um acoplamento capacitivo. Este tipo de acoplamento pode ser utilizado em meios altamente resistivos e com superfícies rígidas como asfalto e concreto (Osella et al, 2012). Além disso, este equipamento pode realizar uma aquisição contínua de dados, possibilitando a investigação de grandes áreas rapidamente (Kuras et al, 2006). Este método é empregado através do arranjo Dipolo-Dipolo e em regime quase-estático, onde a corrente de condução é predominante sobre a corrente de deslocamento, as medidas com acoplamento capacitivo são essencialmente equivalentes as do método tradicional.

Segundo Kuras (2002), as características do modo de operação do método de Eletrorresistividade com Acoplamento Capacitivo (RC) são: (1) as frequências de operação são moderadas, em torno de 16,5 kHz; (2) As aquisições são feitas com medidas que operam no regime 
quase-estático; (3) O acoplamento com o solo é feito por capacitância; (4) Quando não há materiais condutivos próximos a linha de aquisição, os efeitos indutivos são negligenciáveis.

Os equipamentos utilizados para uma aquisição com o método RC são basicamente um transmissor, um conjunto de receptores, cabos dipolares para a conexão, uma corda que pode ter diferentes comprimentos e um computador portátil responsável pelo controle da aquisição e o armazenamento de dados. Os cabos dipolares são acoplados ao solo por capacitância (Figura 23).

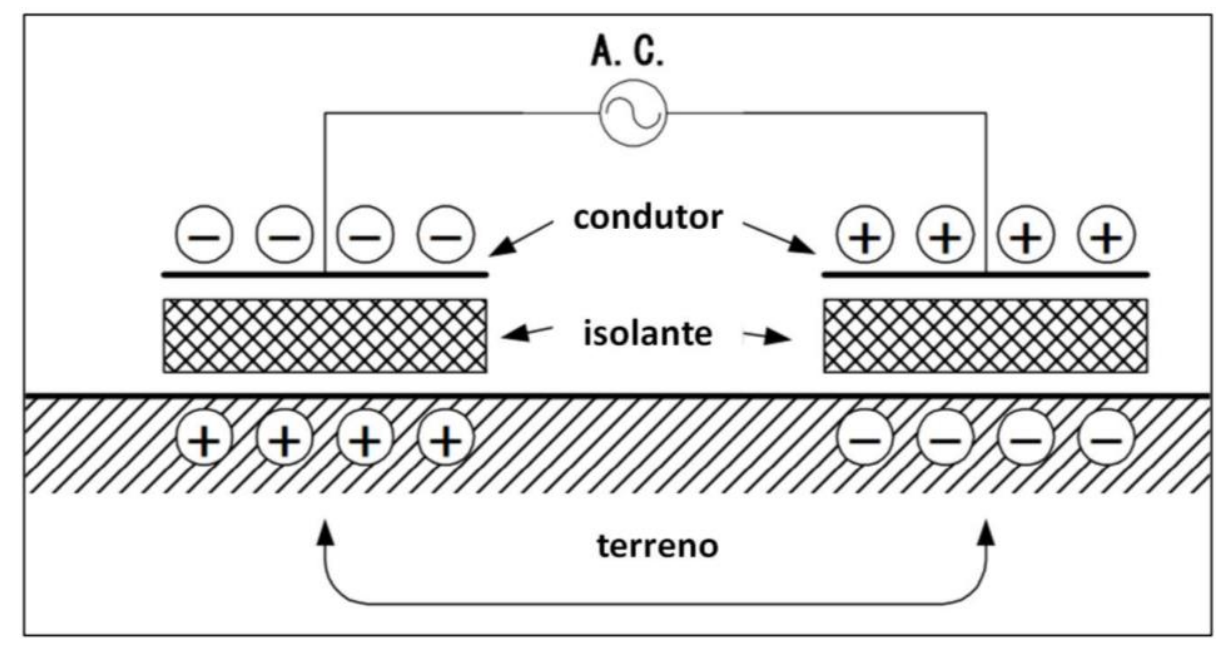

Figura 23. Modelo do acoplamento capacitivo no método da Eletrorresistividade com acoplamento capacitivo (Yamashita et al, 2004).

O equipamento utilizado nesta pesquisa é o OhmMapper, da fabricante Geometrics. Este equipamento é capaz de adquirir duas medições por segundo com distâncias entre dipolos podendo variar entre os valores de 1,25m, 2,5m, 5m, 7,5m e 10m (Cavenaghi, 2017). O arranjo dos elementos do equipamento é montado com cabos dipolares ligando os receptores entre si e uma corda não condutora ligando o transmissor ao resto do sistema. Um peso é utilizado para garantir o bom acoplamento ao solo.

Os cabos dipolares do OhmMapper são equivalentes aos eletrodos do método convencional. Internamente os cabos são compostos de um par trançado de dois fios, um preenchimento não condutor e uma malha de cobre enrolado ao redor do preenchimento. Sobre a malha de cobre existe um isolante resistente. Neste sistema, o isolante resistente faz o papel do dielétrico do capacitor e a malha de cobre faz o papel de uma das placas do capacitor (Figura 24). Uma vez que o cabo é colocado sobre o solo, este faz o papel da outra placa do capacitor (Geometrics, 2001). 


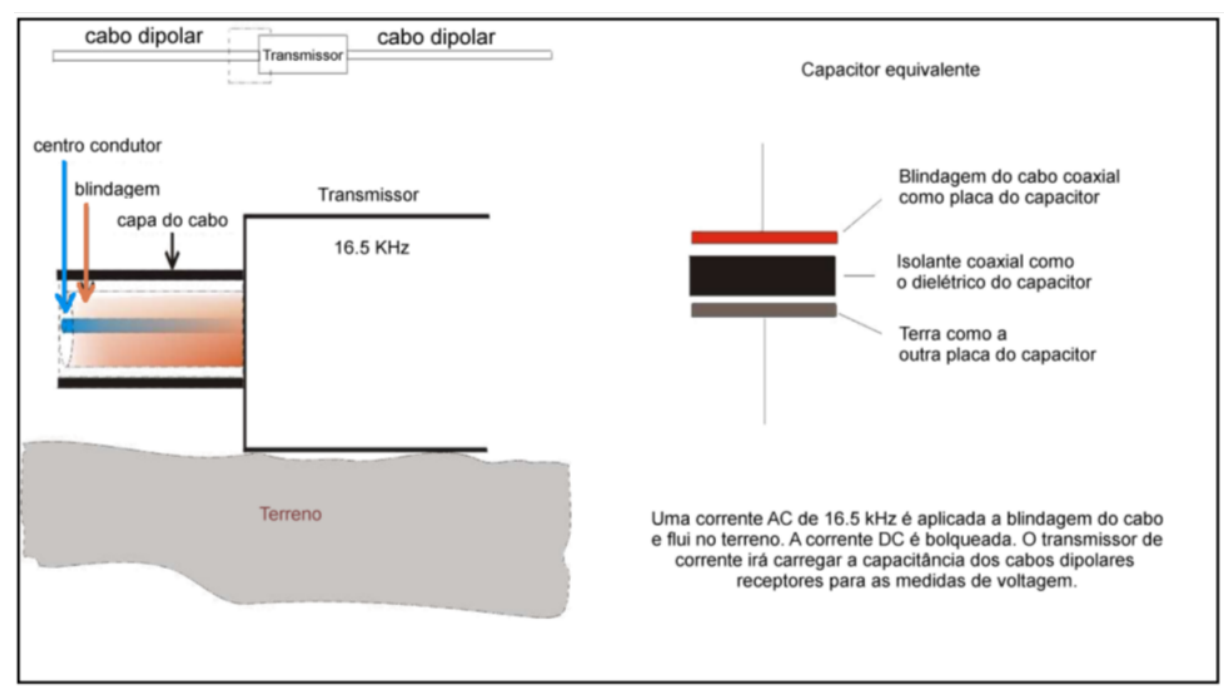

Figura 24. Croqui do funcionamento do acoplamento capacitivo através da utilização de cabos dipolares

(Cavenaghi, 2017).

\subsubsection{Inversão dos Dados}

Os valores de resistividade calculados com base nas medições de potencial e corrente são chamados de resistividade aparente. Para se obter a distribuição real de resistividade em subsuperfície, os valores de resistividades aparentes devem ser submetidos a um processo de inversão. Para os dados desta pesquisa foi utilizado um software já implementado e usado comercialmente chamado RES2DINV versão 3.01 (Geotomo, 2003). Este software usa o método de otimização por mínimos quadrados com restrição de suavização (Loke and Barker, 1996).

Para ilustrar o processo de inversão foi utilizado um modelo sintético de blocos retangulares caracterizado pelos valores de resistividade de cada bloco (Figura 25). Este modelo simula uma pluma de contaminação por hidrocarboneto com décadas de existência, onde a ação de microrganismos é significante. Neste modelo conceitual, o contaminante é um DNAPL caracterizado por uma alta resistividade de $5.000 \Omega$.m e está presente em um solo caracterizado por uma resistividade com uma ordem de grandeza menor de $200 \Omega$.m. O nível d'água está a 2,8 $\mathrm{m}$ de profundidade fazendo com que a resistividade do solo aumente para 400 S.m. A ação de microrganismo é implementada através de uma camada mais condutiva $(0.1 \Omega . m)$ ao redor das fases residual e adsorvida do contaminante acima do lençol freático. $\mathrm{O}$ contaminante presente abaixo do nível d'água representa a fase dissolvida do hidrocarboneto e sua forma no modelo corresponde ao movimento do contaminante no sentido do fluxo subterrâneo. 
O modelo da Figura 25 contém uma distribuição de resistividade elétrica sobre a qual serão calculados os valores de resistividade aparente simulando uma aquisição de ER (Sauck, 2000). Simulações deste tipo são chamadas de modelagem direta e neste caso a modelagem direta foi feita utilizando o software RES2DMOD versão 3.03 (Geotomo, 2002). Para esta modelagem foram utilizados os seguintes parâmetros: arranjo Wenner, espaçamento de $1 \mathrm{~m}$ entre eletrodos, 36 eletrodos e 11 níveis de investigação. Foi adicionado um ruído aleatório simbólico de $1 \%$ nos valores de resistividade aparente calculados.

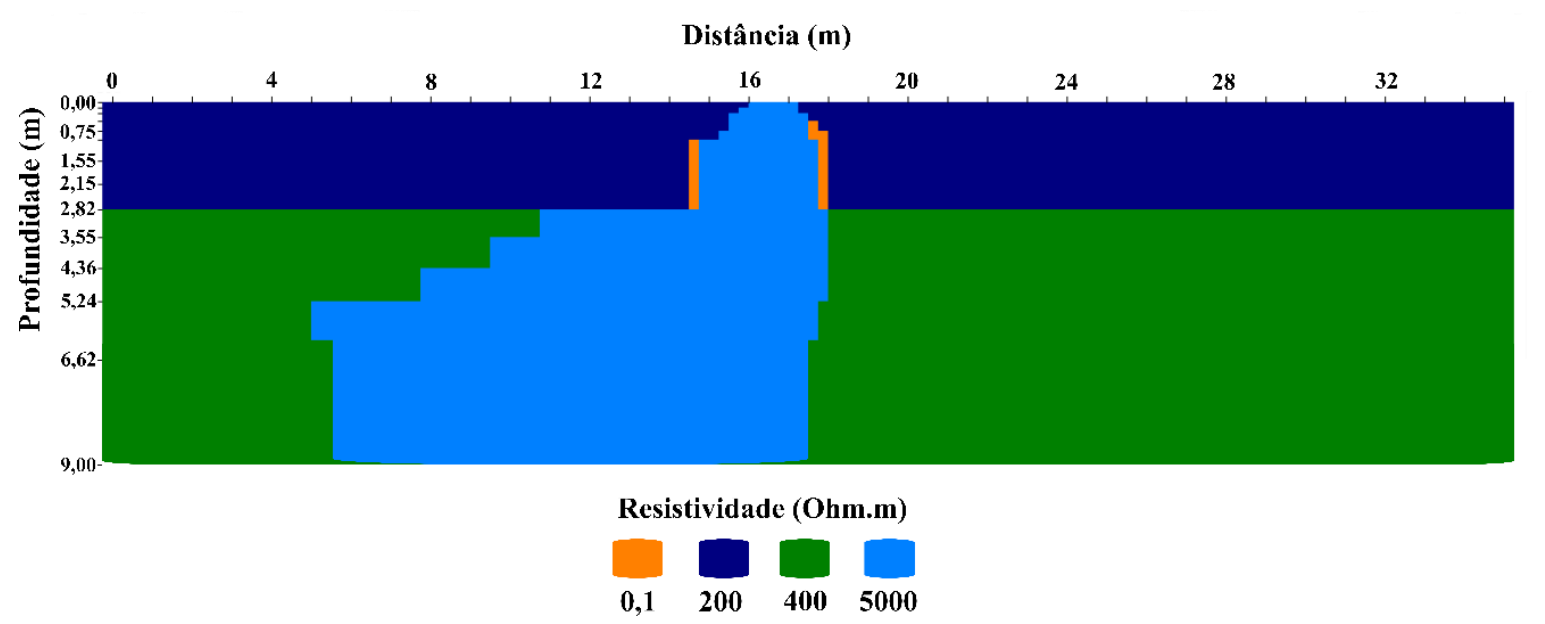

Figura 25. Modelo sintético de distribuição de resistividade (Ohm.m) simulando uma pluma de contaminação por DNAPL com décadas de existência.

A Figura 26 mostra a distribuição de resistividade aparente resultado da modelagem sobre o modelo da Figura 25. O processo de inversão (ou modelagem inversa) tenta recuperar o modelo de resistividade original com base na distribuição de resistividade aparente. Isso é feito através de um processo onde se busca reduzir a diferença entre o modelo de resistividade aparente calculado e as medidas de resistividade aparente ajustando os modelos de resistividade. A diferença é dada pelo erro da raiz média ao quadrado (RMS). 


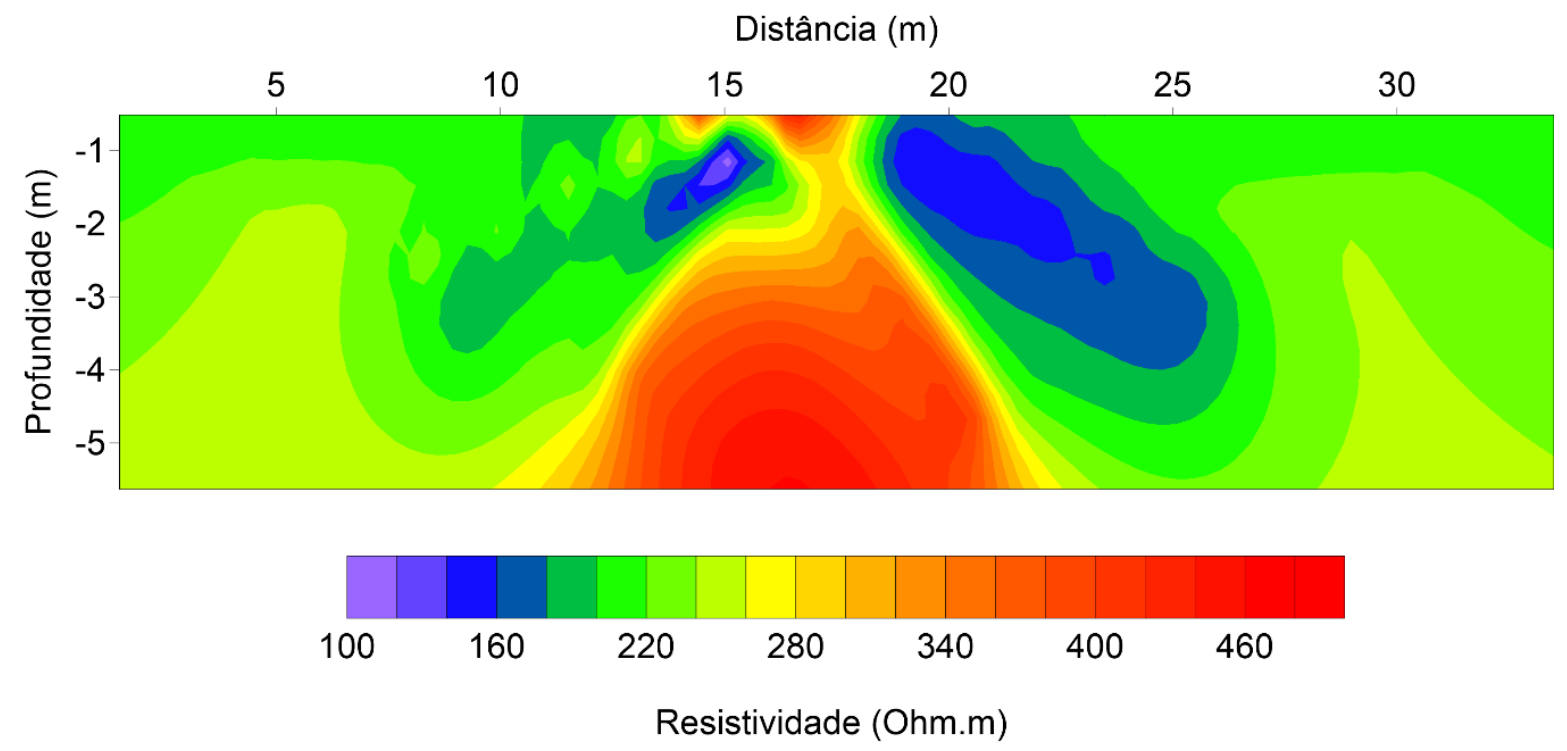

Figura 26. Distribuição de resistividade aparente, com 1\% de ruído, calculado sobre o modelo da Figura 25.

O resultado da inversão para esta modelagem sintética é apresentado na Figura 27. Nota-se que o processo conseguiu recuperar os elementos do modelo sintético conceitual de pluma que foi definido para a modelagem. As anomalias em azul de mais baixas resistividades são provenientes das camadas condutivas que correspondem ao processo de ação microbiana. A anomalia resistiva acima do nível d'água corresponde as fases residual e adsorvida do contaminante enquanto a anomalia resistiva abaixo do nível d'água corresponde a fase dissolvida. Nota-se ainda uma anomalia condutiva mais à esquerda que não corresponde ao local exato dos blocos condutivos do modelo. Essa anomalia mostra que o processo de inversão não é exato pois busca pelo melhor ajuste através do método de quadrados mínimos. Este resultado será muito útil para auxiliar nas interpretações dos resultados dos dados reais desta pesquisa. 


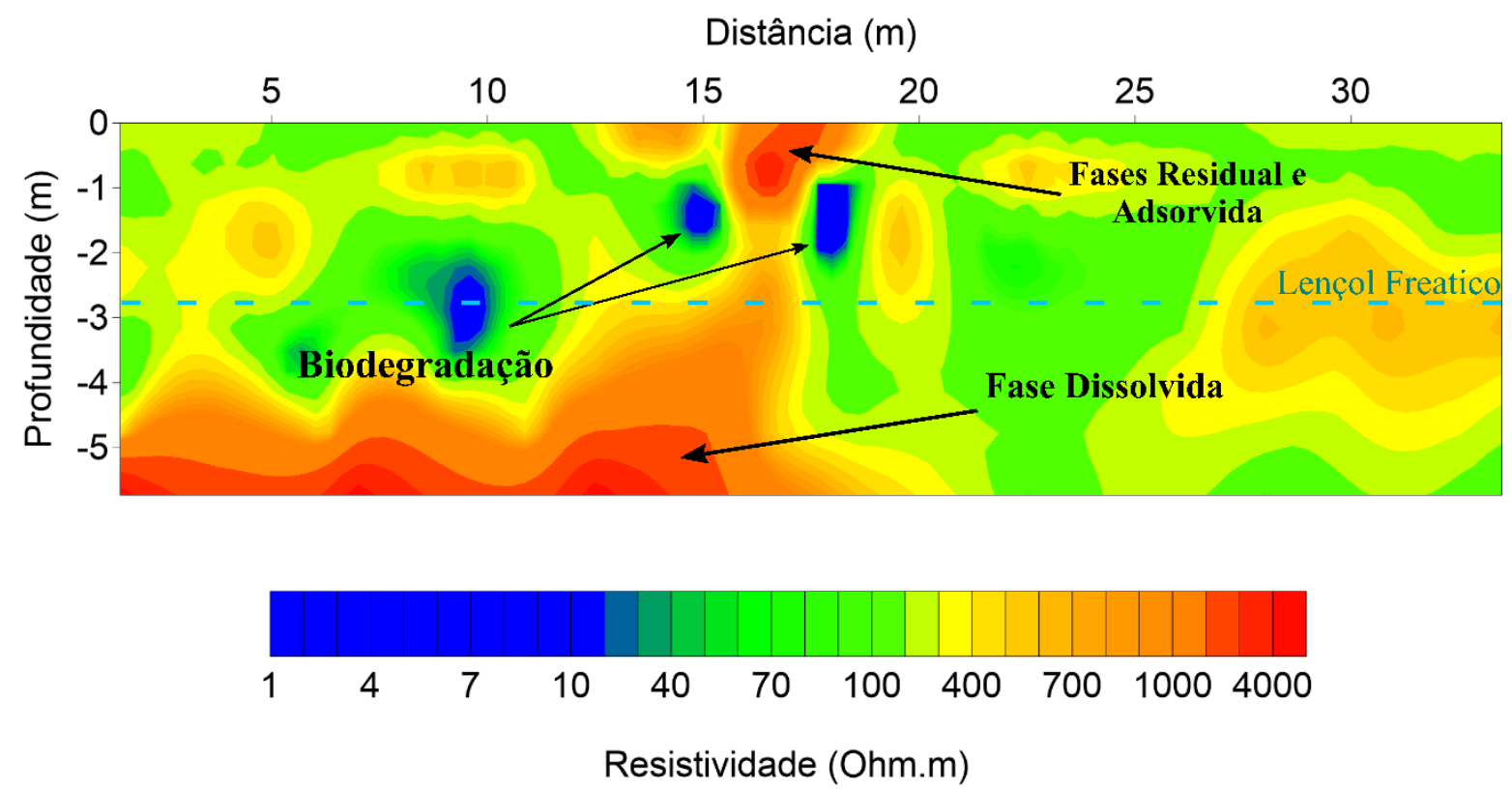

Figura 27. Resultado do processo de inversão dos dados sintéticos gerados a partir do modelo da Figura 25. 


\section{CAPÍTULO 4}

\section{AQUISIÇÃO DOS DADOS}

\subsection{COLETA DE AMOSTRAS DE SOLOS}

Com o objetivo de caracterizar a estratigrafia rasa da área de estudo e para a coleta de amostras de solos foram feitas 4 perfurações (Figura 4). Os furos e a extração de amostras foram feitos com o auxílio dos pesquisadores do IPT. A estratigrafia observada foi apresentada na Figura 5.

Os furos Trado 1 e Trado 3 (Figura 4) estão localizados nas posições onde não existe contaminação. Estas posições não apresentaram sinais de contaminações de acordo com as análises químicas e não estavam próximas a nenhuma fonte potencial de contaminação. As amostras de solo retiradas nesses furos foram, portanto, consideradas livres de contaminação.

O furo Trado 2 foi feio na posição da antiga autoclave onde era feito o processo de impregnação da madeira pelo óleo creosoto. Nesta posição as análises químicas mostraram alta concentração de contaminantes (Figuras 8 e 10). Durante a perfuração, o cheiro do contaminante era forte, ficando evidente que as amostras coletadas nesse furo estavam contaminadas. Já o furo Trado 4 foi feito próximo as posições dos antigos tanques de armazenamentos de creosoto (Figura 4).

\subsection{EXPERIMENTOS EM LABORATÓRIO}

Com o objetivo de guiar e validar as interpretações feitas para os resultados da aplicação dos métodos geofísicos indiretos, foram feitos dois experimentos em laboratório. O primeiro tratase de medidas de resistividade diretamente das amostras de solo retiradas da área de estudos. $\mathrm{O}$ segundo trata-se de um levantamento GPR com uma antena de alta frequência sobre tanques de prova utilizando o óleo creosoto retirado da área de estudos pelos pesquisadores do IPT.

\subsubsection{Medidas de Resistividade das Amostras de Solos}


Com as amostras de solos coletadas na área de estudos, foram feitas medidas de resistividade através de um sistema construído com um tubo de PVC e eletrodos de aço inox (Figura 28). As amostras foram colocadas no tubo de PVC com geometria conhecida e então uma corrente elétrica foi injetada através dos eletrodos de corrente nas extremidades do tubo. O contato entre os eletrodos de corrente e a amostra foi mantido bem ajustado. Como eletrodos de potencial foram utilizados parafusos de aço inox dispostos de maneira a garantir um bom contato com a amostra dentro do tubo. Para a injeção de corrente elétrica e medida do potencial gerado foi utilizado o resistivímetro Syscal R2, da fabricante IRIS instruments. Com os valores de corrente elétrica injetada e a diferença de potencial medido, é calculado o valor de resistividade através da equação (3.30), onde S é a área da secção transversal do cilindro de PVC e L é a distância entre os parafusos que medem o potencial.

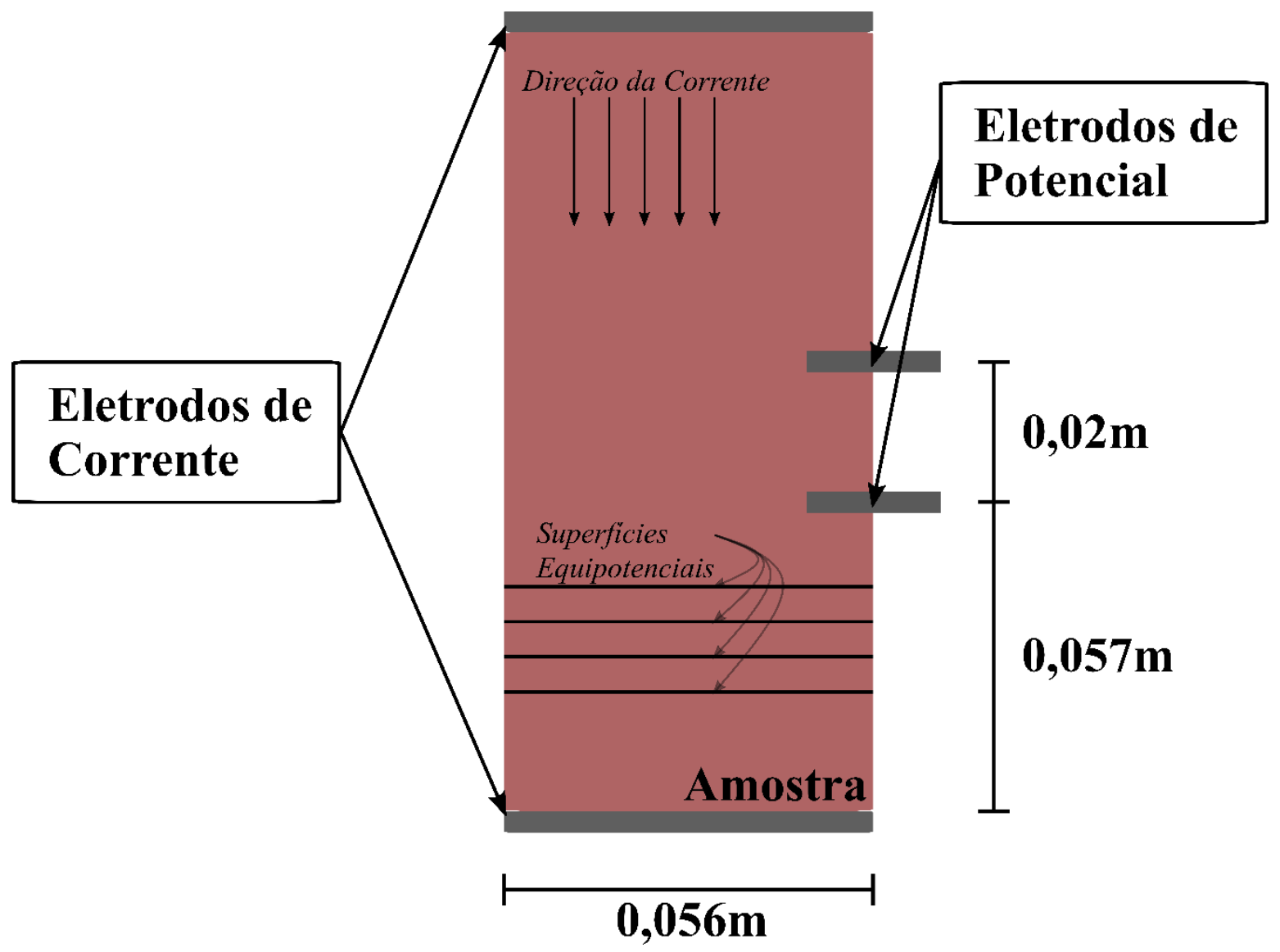

Figura 28. Croqui do arranjo dos eletrodos e das amostras de solos durante o experimento.

As amostras coletadas nos furos Trado 1 e Trado 2 foram utilizadas no mesmo estado que foram retiradas da área. Para isso, as amostras foram mantidas seladas para que não perdessem a 
umidade natural. Portanto, os valores de resistividade obtidos com essas amostras podem ser considerados os valores de resistividade reais de cada tipo de solo nas posições desses furos.

As amostras coletadas no furo Trado 1 foram ainda utilizadas para um estudo que tinha como objetivo medir a resistividade de cada nível de concentração de creosoto no solo. Para isso, as amostras foram preparadas com diversas concentrações de creosoto e então as resistividades de cada uma das amostras foram medidas. Esse estudo gerou uma curva de valores de resistividade depende da concentração de creosoto no solo. A Figura 29a mostra o sistema de medição para esse experimento durante a aquisição. A Figura 29b mostra o processo de adição de creosoto nas amostras de solo. Este experimento em particular foi feito em conjunto com o pesquisador do IPT Alexandre Muselli. 
a)
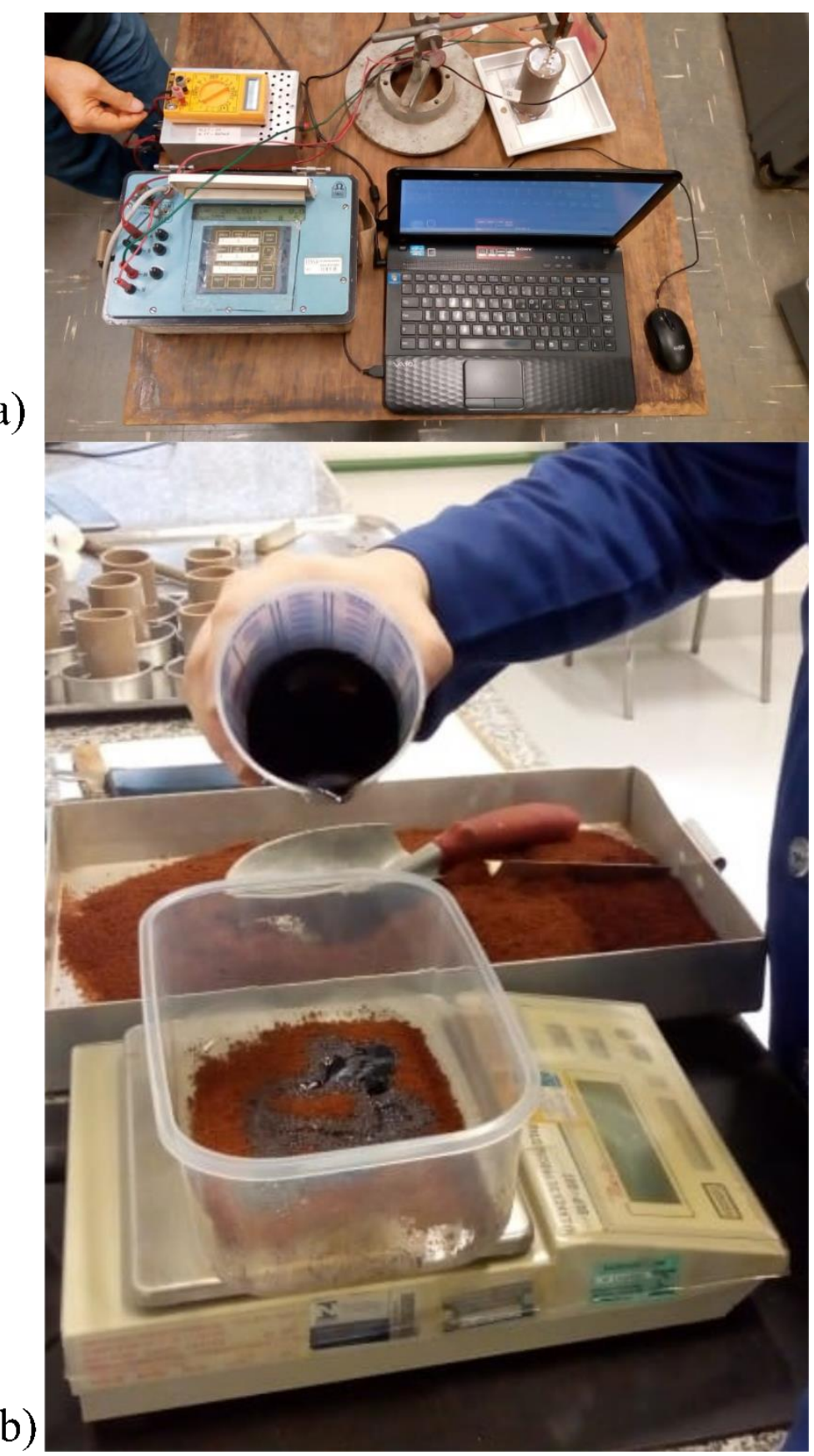

Figura 29. Experimento de medida de resistividade das amostras. a) Sistema desenvolvido para medição. b) Processo de adição de creosoto nas amostras. 


\subsubsection{Aquisições GPR}

Com o objetivo de prever as anomalias nos sinais GPR devido a contaminação por creosoto, foi conduzido um experimento que consistiu em aquisições GPR sobre caixas com areia e com solo argiloso vermelho representativo da área de estudo. As aquisições GPR foram feitas com uma antena de alta frequência $(2600 \mathrm{MHz})$ da fabricante GSSI.

Além da análise dos perfis GPR no domínio do tempo, foi feita a aplicação da Short Time Fourier Transform (STFT) tanto no perfil sem contaminação quanto no perfil contaminado para a análise dos dados no domínio da frequência. Assim, deve-se obter uma referência sobre a influência da presença do contaminante sobre o espectro de amplitude dos dados GPR.

Inicialmente, dados GPR foram adquiridos sobre as caixas preenchidas apenas pelos dois tipos de solos, caracterizando os dados sobre áreas não contaminadas. Depois foi instalado um recipiente preenchido por creosoto nas caixas. Sobre esse recipiente enterrado foram feitas novas aquisições, caracterizando os dados sobre áreas contaminadas. $\mathrm{O}$ recipiente foi escolhido de maneira que seu material fosse fino o suficiente e com propriedades eletromagnéticas ideais para ser negligenciado nos dados. Assim, apenas o contraste do creosoto com a areia e com o solo argiloso vermelho seria visível nos dados. As Figuras 30 e 31 mostram os croquis da caixa de solo argiloso e de areia, respectivamente, com os recipientes enterrados. 

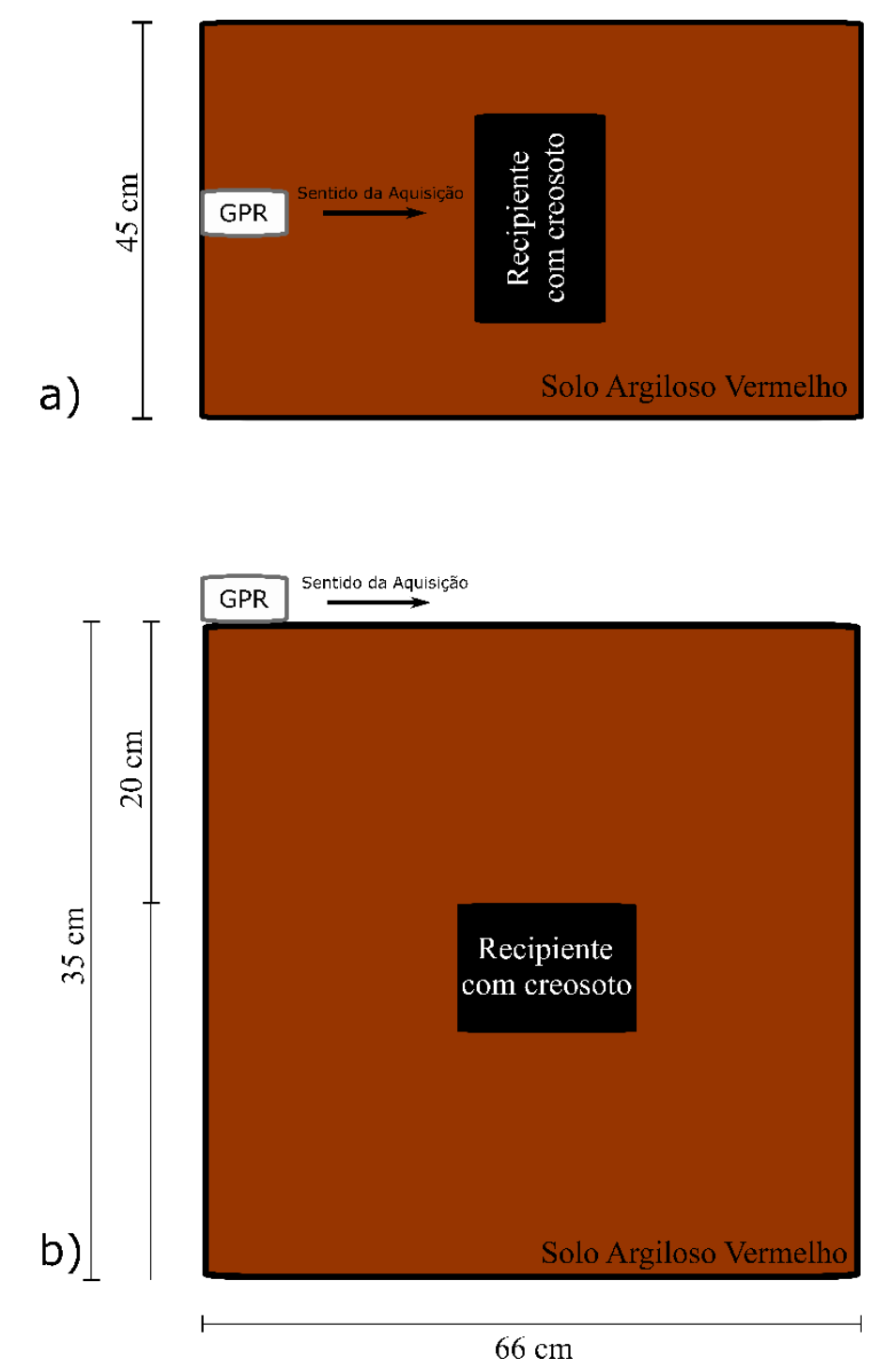

Figura 30. Croqui da caixa de solo argiloso vermelho utilizada para a aquisição com antena GPR de alta frequência. a) Visão em planta do experimento. b) Visão lateral do experimento. 
a)

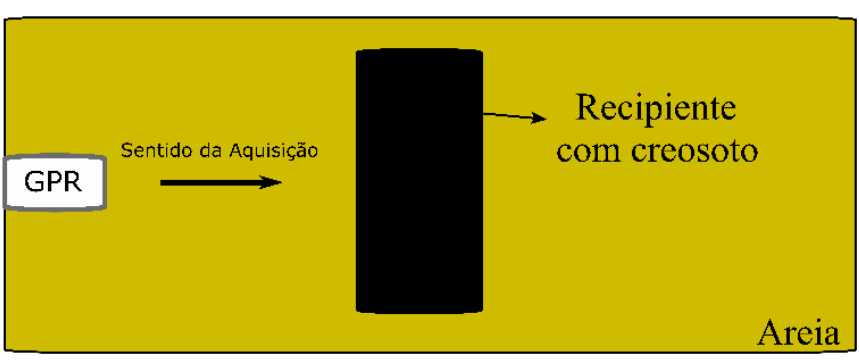

b)

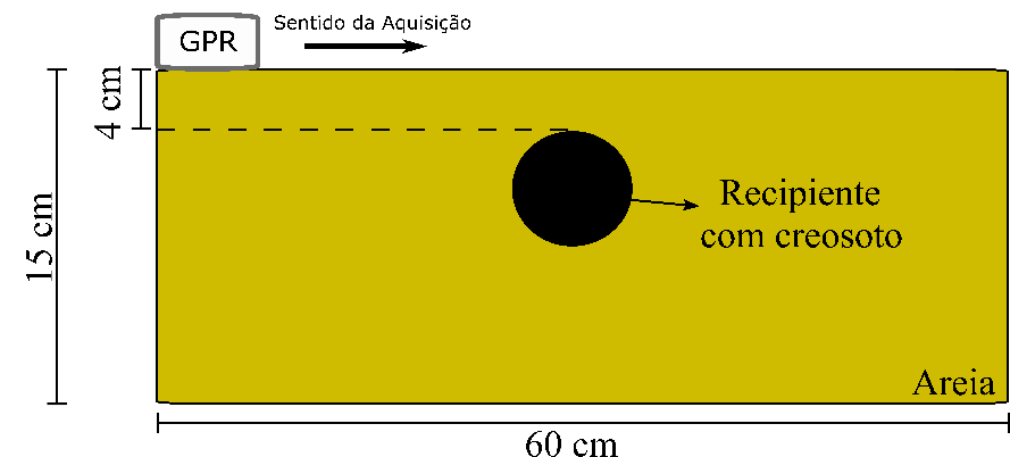

Figura 31. Croqui da caixa de areia utilizada para a aquisição com antena GPR de alta frequência. a) Visão em planta do experimento. b) Visão lateral do experimento.

A Figura 32 a seguir mostra a antena GPR de $2600 \mathrm{MHz}$ durante a aquisição de dados desse experimento. Nota-se que uma chapa de PVC foi utilizada para evitar que partículas de solo entrassem nas fissuras das rodas (odômetro) da antena. 


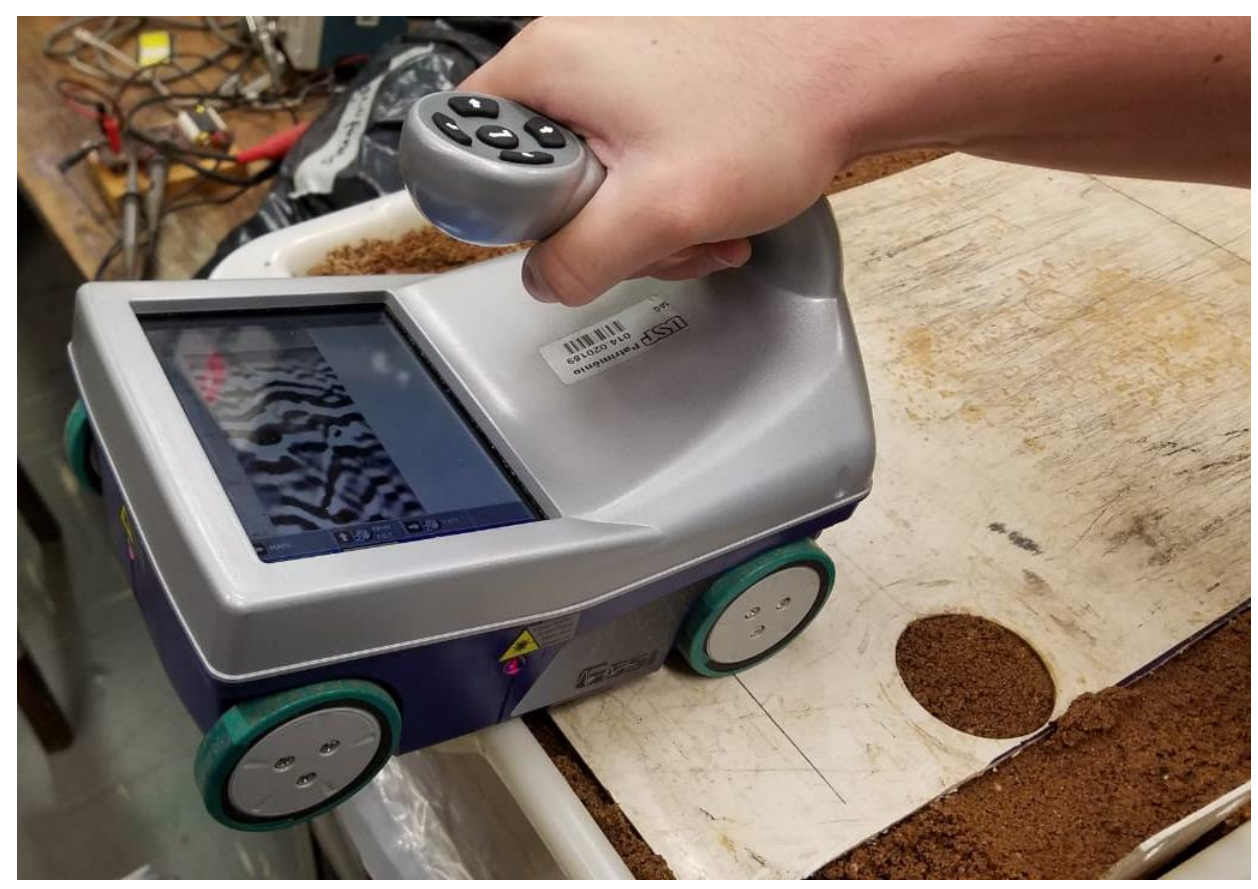

Figura 32. Aquisição sobre a caixa de areia utilizando a antena GPR GSSI de $2600 \mathrm{MHz}$.

\subsection{GROUND PENETRATING RADAR (GPR)}

Para as aquisições de perfis de reflexão com afastamento constante, foram designadas três linhas principais e um grid para a aquisição de linhas que irão compor o modelo pseudo-3D (Figura $33)$.

As linhas principais foram escolhidas com base nas análises químicas das amostras solos e de água e nas antigas fontes potenciais de contaminação. A Linha Background está localizada onde não há contaminação. A Linha Central está localizada onde foi constada a contaminação do solo e da água e próximo onde se localizavam as antigas autoclaves e tanques de creosoto. A Linha Lateral está localizada onde se dispunham os antigos tanques de creosoto. Já o grid para a geração do modelo pseudo-3D busca englobar a posição de uma das antigas autoclaves. Para a composição do modelo 3D foram adquiridas linhas equiespaçadas com $20 \mathrm{~cm}$ uma da outra. 


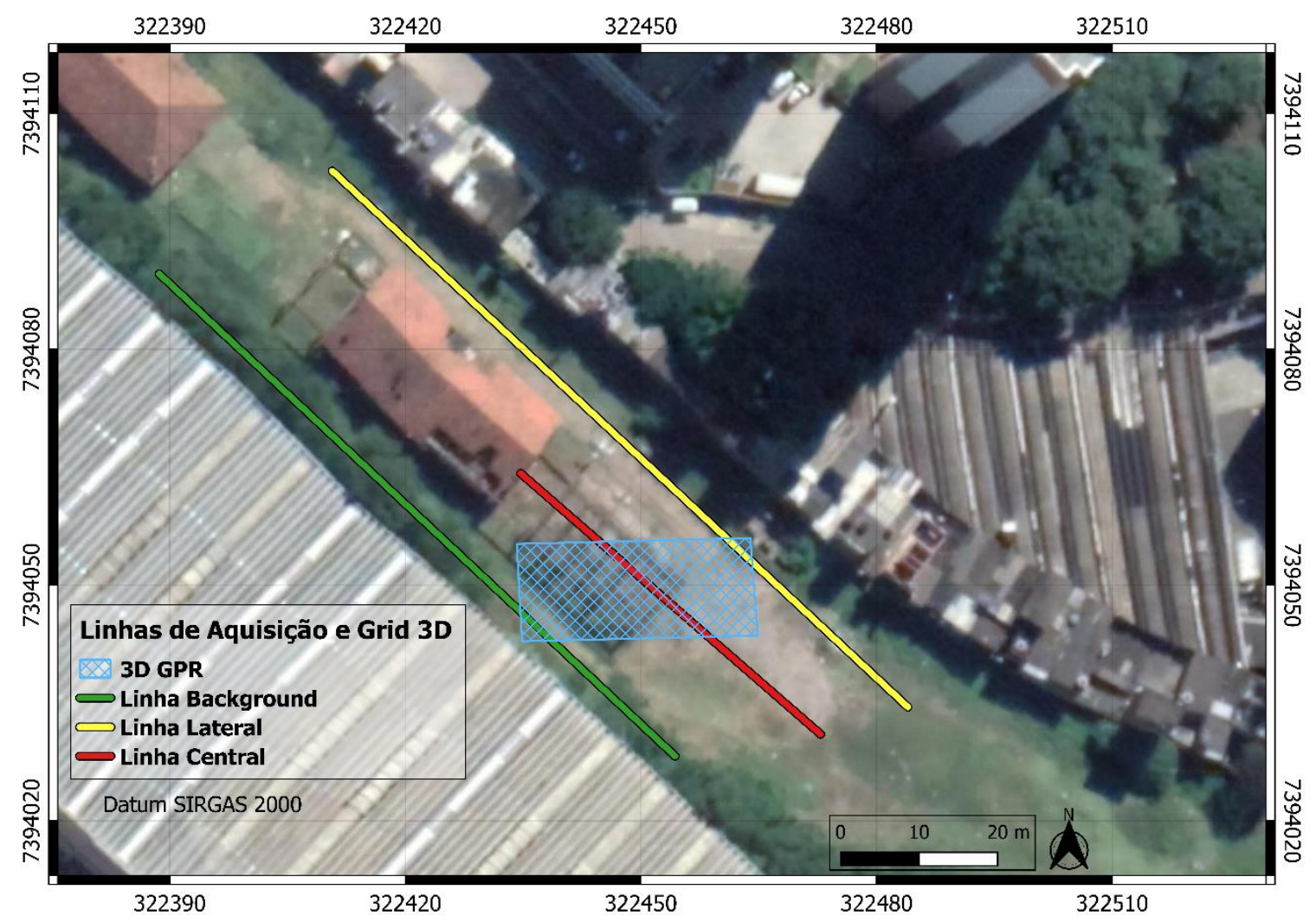

Figura 33. Mapa das localizações das linhas de aquisição de perfis de reflexão com afastamento constante (common offset) e da malha GPR pseudo-3D.

Para as três linhas principais foram adquiridos perfis tanto com antenas de baixas frequências quanto de altas frequências (200, 270, 400 e $900 \mathrm{MHz})$. Para as linhas que compõem o grid foram utilizadas as antenas de 270 e $900 \mathrm{MHz}$. As antenas e as unidades de controle (SIR 3000 e SIR 4000) utilizadas são da fabricante GSSI. Os parâmetros de aquisição foram colocados de acordo com as especificações contidas no manual (Tabela 5). As Figuras 34a e 34b mostram os equipamentos, de 200 e $900 \mathrm{MHz}$ respectivamente, em funcionamento durante as aquisições.

\begin{tabular}{|l|l|l|l|l|}
\hline Frequência (MHz) & Range de Tempo & \multicolumn{1}{|c|}{$\begin{array}{c}\text { Amostras por } \\
\text { Traço }\end{array}$} & Traços por Metro & $\begin{array}{c}\text { Taxa de } \\
\text { Transmissão (kHz) }\end{array}$ \\
\hline 200 & 100 & 512 & 50 & 100 \\
\hline 270 & 75 & 512 & 50 & 100 \\
\hline 400 & 75 & 512 & 50 & 100 \\
\hline 900 & 30 & 512 & 50 & 100 \\
\hline
\end{tabular}

Tabela 5. Parâmetros de aquisição dos dados GPR para cada uma das antenas utilizadas. 


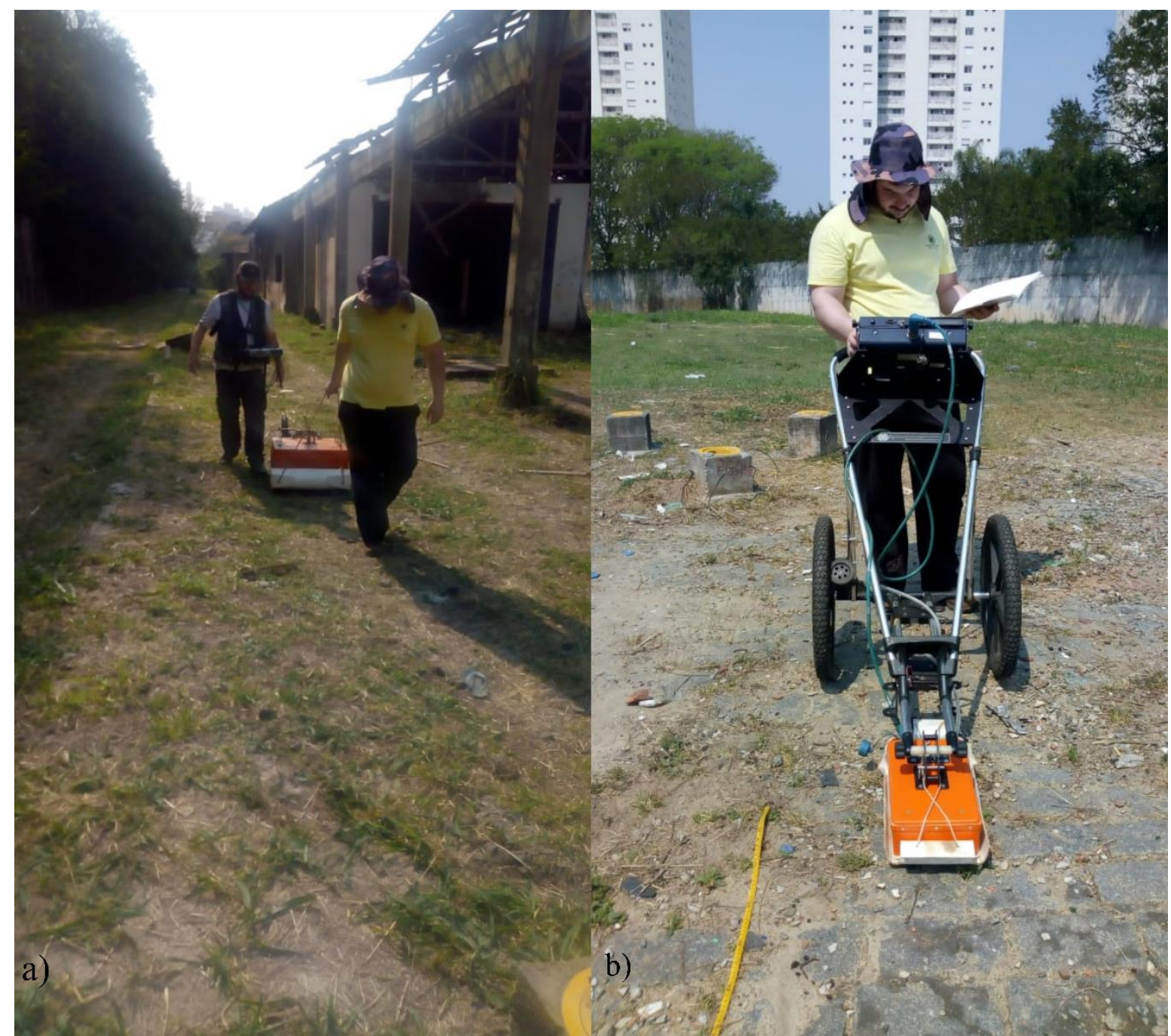

Figura 34. Fotos das aquisições GPR na área de estudo. a) Antena de $200 \mathrm{MHz}$. b) Antena de $900 \mathrm{MHz}$.

Além dos perfis de reflexão com afastamento constante, foram feitas diversas sondagens com a técnica CMP para a geração de um modelo 3D de velocidades de ondas EM (Figura 35). O grid formado busca englobar a posição de uma das antigas autoclaves. Duas antenas GSSI de 200 $\mathrm{MHz}$ foram utilizadas. As aquisições das CMP's foram feitas com passo de $5 \mathrm{~cm}$ e com offset máximo de 6 metros. 


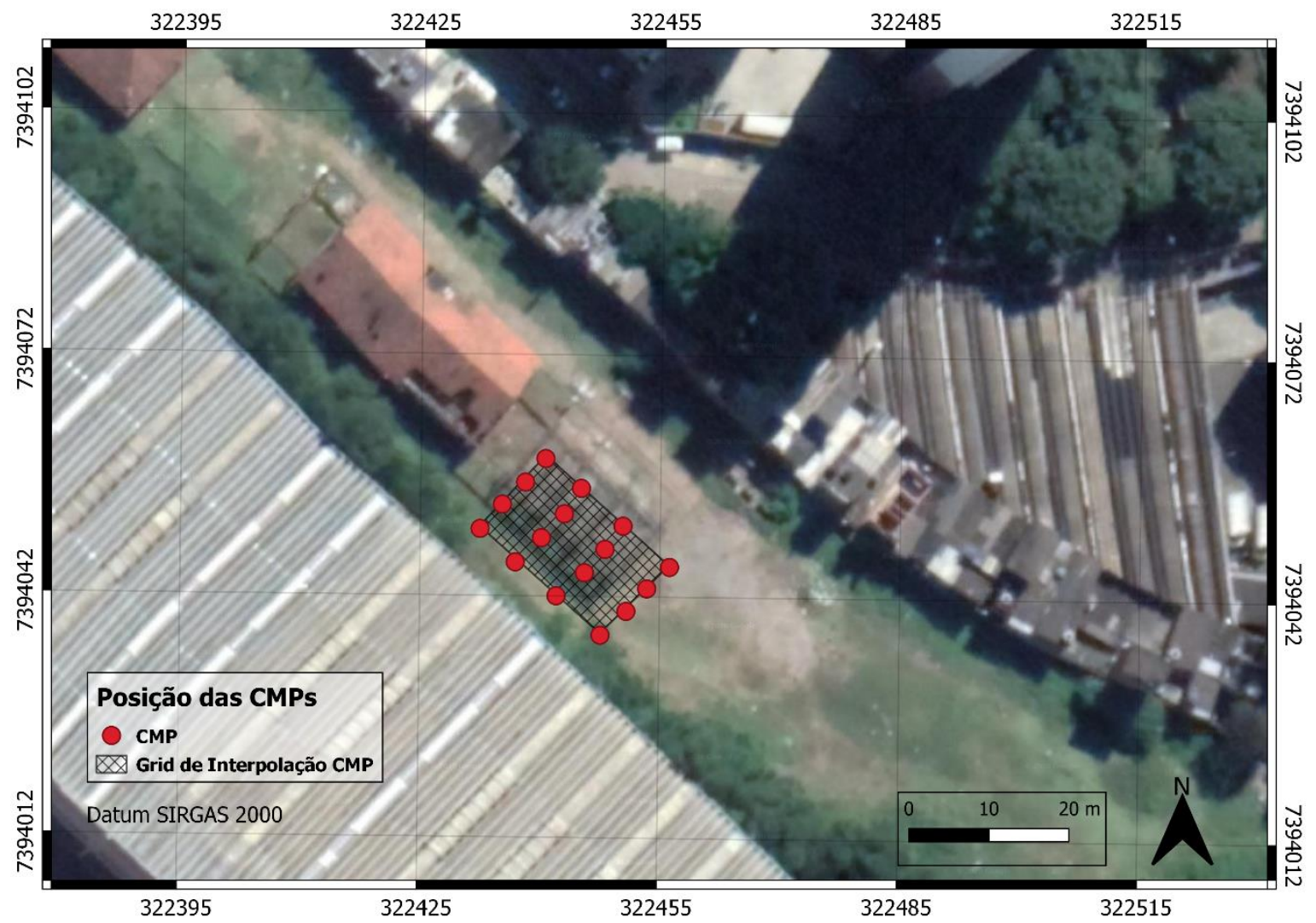

Figura 35. Mapa das localizações das aquisições CMP (common mid point) e da malha de interpolação das CMPs.

\subsection{ELETRORRESISTIVIDADE (ER)}

Buscando a correlação entre os dados GPR e de Eletrorresistividade, foram adquiridos dados de caminhamento elétrico sobre as três linhas indicadas na Figura 36 que correspondem às mesmas três linhas sobre as quais foram adquiridos os perfis GPR. Uma vez que a área tem sua maior parte coberta por paralelepípedo e piso concretado, as aquisições com este método foram restritas. A cravação de eletrodos foi possível devido a retirada de paralelepípedos de algumas posições.

Para a aquisição com este método foi utilizado o arranjo dipolo-dipolo com eletrodos de aço inox e espaçamento entre eletrodos de 2,5 metros. Para um acoplamento adequado com o solo foi ainda utilizado bentonita. O equipamento de medição utilizado foi o Syscal R2 acoplado ao sistema Elrec para controlar a distribuição dos diferentes canais em operação de medição. 


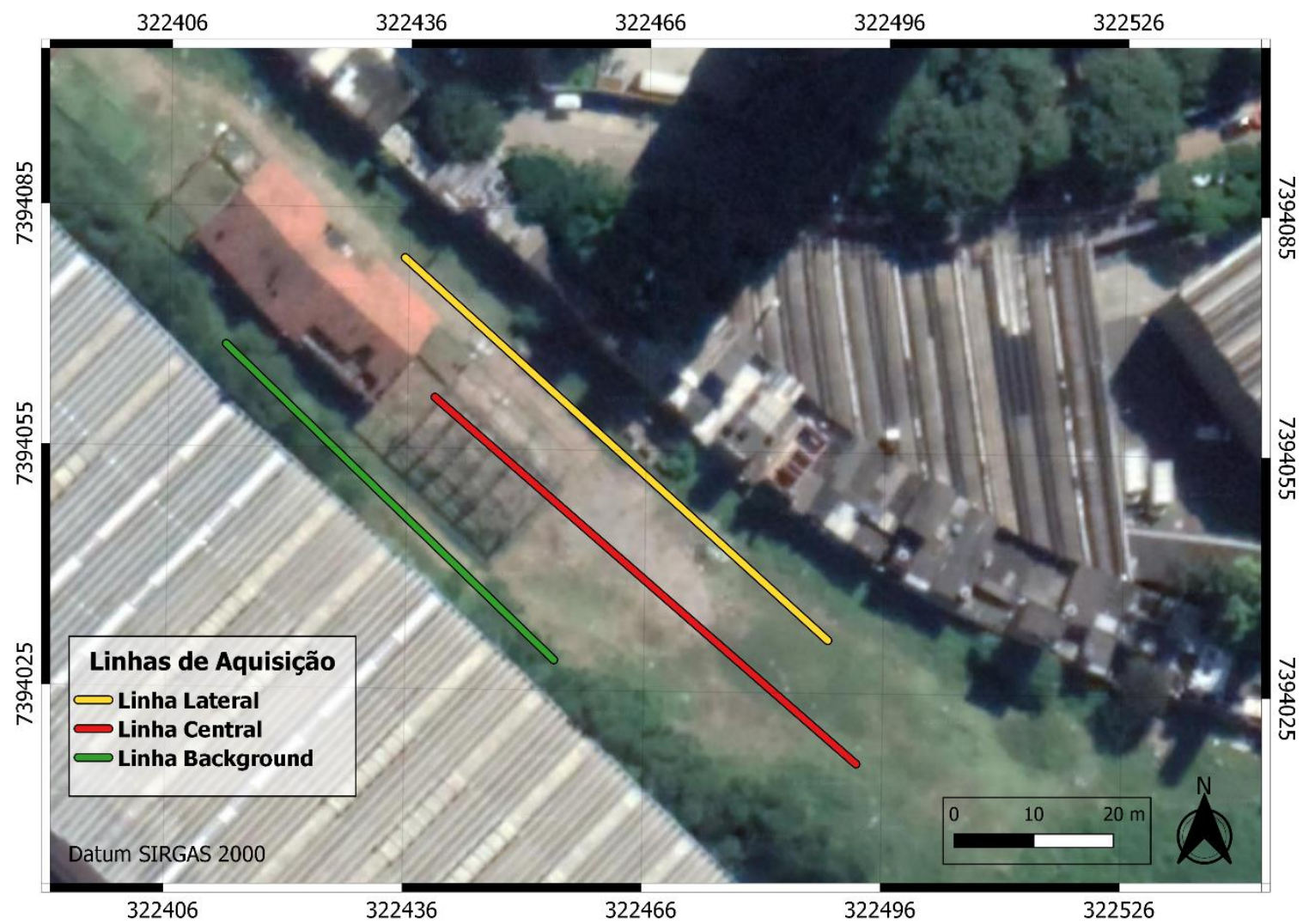

Figura 36. Mapa das localizações das linhas de aquisição de Eletrorresistividade (ER) Dipolo-Dipolo.

\subsection{ELETRORRESISTIVIDADE COM ACOPLAMENTO CAPACITIVO (RC)}

Foram feitas aquisições sobre as mesmas três linhas principais e sobre um grid com objetivo de gerar um modelo psedo-3D (Figura 37). Tanto o grid quanto as linhas correspondem às mesmas adquiridas com o método GPR. As linhas que compõem o grid foram adquiridas a cada 2,5 metros de distância uma da outra. 


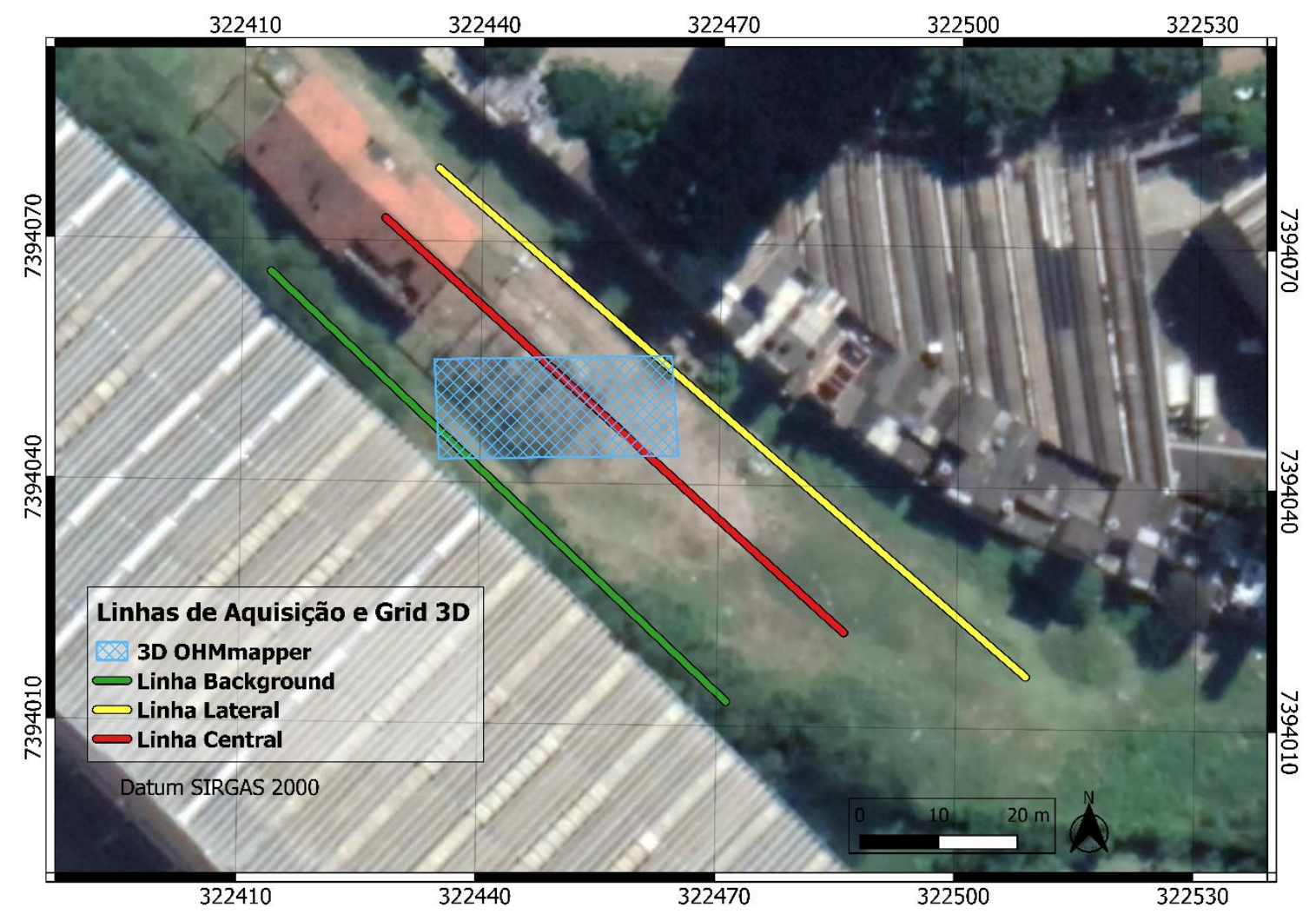

Figura 37. Mapa das localizações das linhas de aquisição e da malha 3D de Eletrorresistividade Capacitiva (RC).

Para as aquisições com o método RC, foi utilizado o equipamento OhmMapper da fabricante Geometrics (Figura 38). Tanto para as três linhas principais quanto para as linhas que irão compor o modelo 3D, foram utilizados um transmissor e dois receptores e cordas de comprimento de $1,25 \mathrm{~m}, 2,5 \mathrm{~m}$ e $5 \mathrm{~m}$. As linhas com as três cordas foram empilhadas utilizando-se um software específico chamado MagMap2000 da empresa Geometrics. Esse empilhamento é feito para se explorar tanto a profundidade máxima que a corda de 5 metros permite atingir quanto a resolução máxima que a corda de 1,25 metros proporciona. 


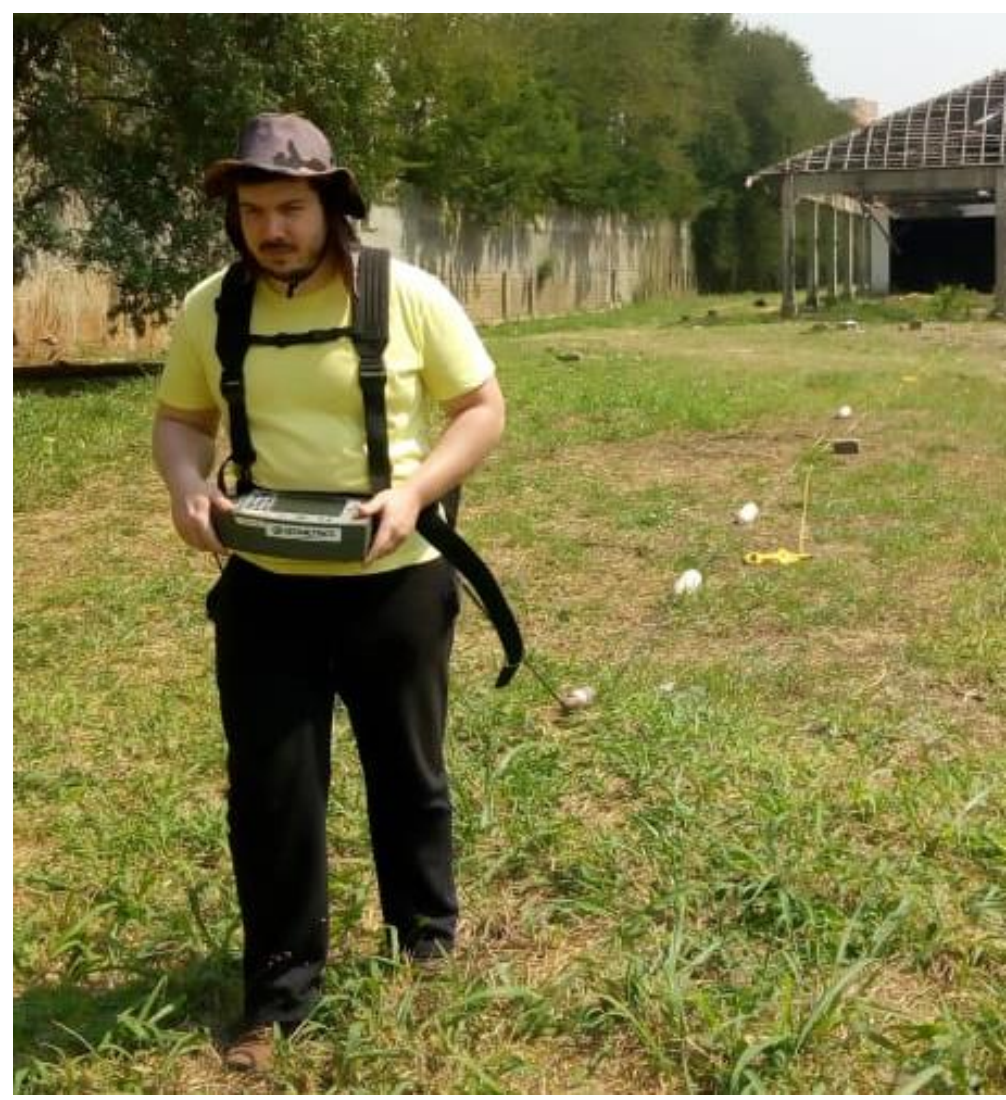

Figura 38. Foto da aquisição com o equipamento OhmMapper sobre a área de estudo. 


\section{CAPÍTULO 5}

\section{RESULTADOS}

Neste capítulo são apresentados os resultados dos experimentos em laboratório e das aquisições dos dados realizadas com os métodos geofísicos (GPR, ER e RC) sobre a área de estudo. A estratigrafia definida a partir das perfurações e dos dados pré-disponíveis é utilizada para guiar as interpretações acerca das profundidades das anomalias observadas nos resultados geofísicos. Já os resultados dos experimentos em laboratório fornecem uma referência para a interpretação das amplitudes das anomalias obtidas nos resultados de GPR, ER e RC.

\subsection{EXPERIMENTOS EM LABORATÓRIO}

\subsubsection{Medidas de Resistividade das Amostras de Solos}

Com os resultados das medidas de resistividade das amostras diretos dos furos Trado $1 \mathrm{e}$ Trado 2, foi gerada a Tabela 4. Nota-se que, de forma geral, os solos contaminados do furo Trado 2 tem as resistividades mais baixas que os solos do furo Trado 1 sem contaminação. A diferença de resistividade mais considerável entre o solo contaminado e sem contaminação é observada no solo argiloso vermelho, apresentando uma resistividade de 917 Ohm.m quando sem contaminação e 122 Ohm.m quando contaminado.

Com os solos argiloso vermelho, cinza intermediário e com a areia foi conduzido o experimento de aumento da concentração de creosoto. As Figuras 42 a 44 mostram os resultados desse experimento, onde são plotados os dados obtidos e um ajuste de um polinômio de grau 2 feito sobre os dados. De forma geral, nota-se que com o aumento da concentração de creosoto, há também um aumento nos valores de resistividade das amostras. Na Figura 39 observa-se que para concentrações menores, entre $0 \%$ e $12 \%$, a resistividade do solo aumenta lentamente. A partir de concentrações em torno de $16 \%$, a resistividade aumenta rapidamente, chegando em torno de 8.000 Ohm.m para a concentração de $35 \%$. 


\begin{tabular}{|c|c|c|}
\hline AMOSTRA & $\begin{array}{c}\text { RESISTIVIDADE } \\
(\Omega \cdot \mathrm{m}) \\
\text { Trado } 1\end{array}$ & $\begin{array}{c}\text { RESISTIVIDADE } \\
(\Omega \cdot \mathrm{m}) \\
\text { Trado } 2\end{array}$ \\
\hline 8. Paralelepípedo & 100.000 & 100.000 \\
\hline Aterro & - & - \\
\hline Solo Argiloso Vermelho & 917 & 122 \\
\hline Solo Argiloso Cinza Escuro & 674 & 100 \\
\hline Solo Argiloso Cinza Claro & 598 & - \\
\hline Solo Argiloso Preto & 142 & 78 \\
\hline Solo Argiloso Cinza Intermediário & 129 & 49 \\
\hline Solo Argiloso Cinza Saturado & 186 & 93 \\
\hline
\end{tabular}

Tabela 4. Resultados dos valores de resistividade (Ohm.m) das amostras calculados a partir das medidas de diferença de potencial e de corrente elétrica durante o experimento. 


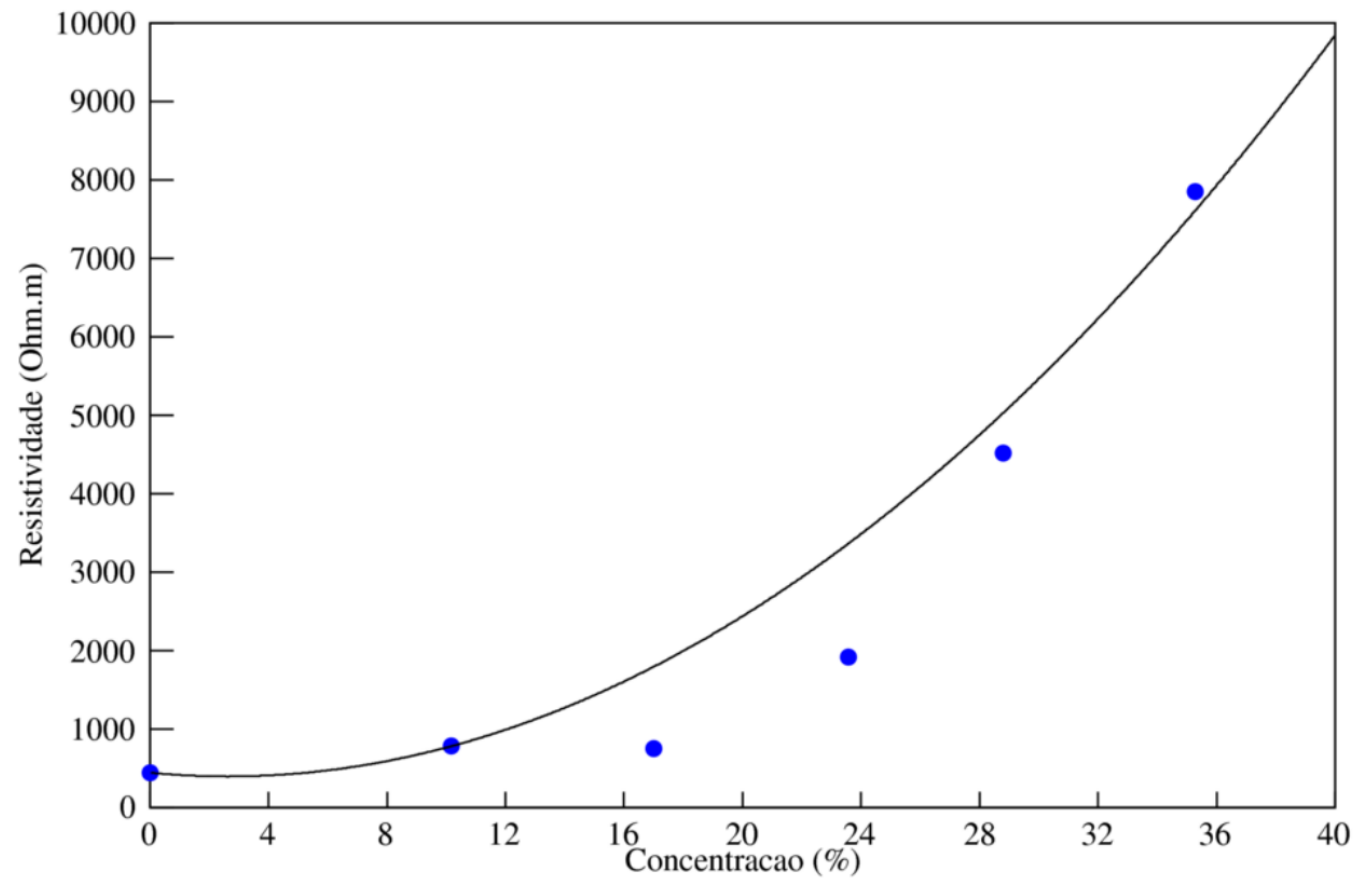

Figura 39. Curva de resistividade pela concentração de creosoto obtida a partir do ajuste aos dados da medição sobre as amostras do solo argiloso vermelho.

Na Figura 40 observa-se um comportamento parecido ao anterior, porém, neste caso, é possível notar que os valores de resistividades medidos aumentam rapidamente desde concentrações mais baixas até atingir valores altos em torno de $2500 \mathrm{Ohm}$.m para concentrações em torno de $18 \%$. As duas argilas apresentaram um comportamento coerente entre elas de aumento dos valores de resistividade com a concentração de contaminante.

Por fim, a Figura 41 mostra que o comportamento da areia é ligeiramente diferente. Notase um aumento mais lento dos valores de resistividade com a concentração do contaminante. Apesar disso, no geral o comportamento é coerente sendo observado um aumento da resistividade com o aumento da concentração de creosoto. 


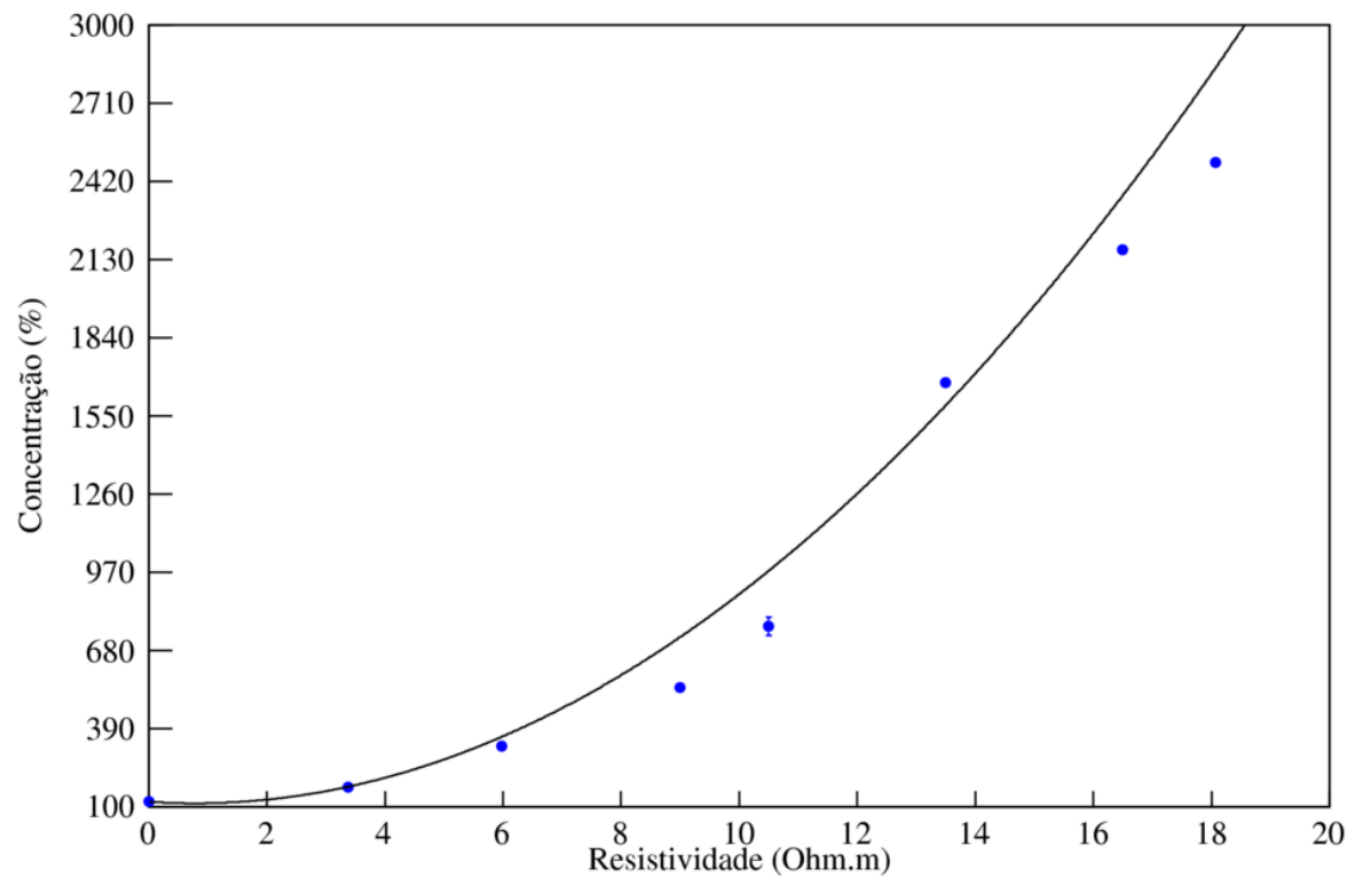

Figura 40. Curva de resistividade pela concentração de creosoto obtida a partir do ajuste aos dados da medição sobre as amostras do solo argiloso cinza intermediário.

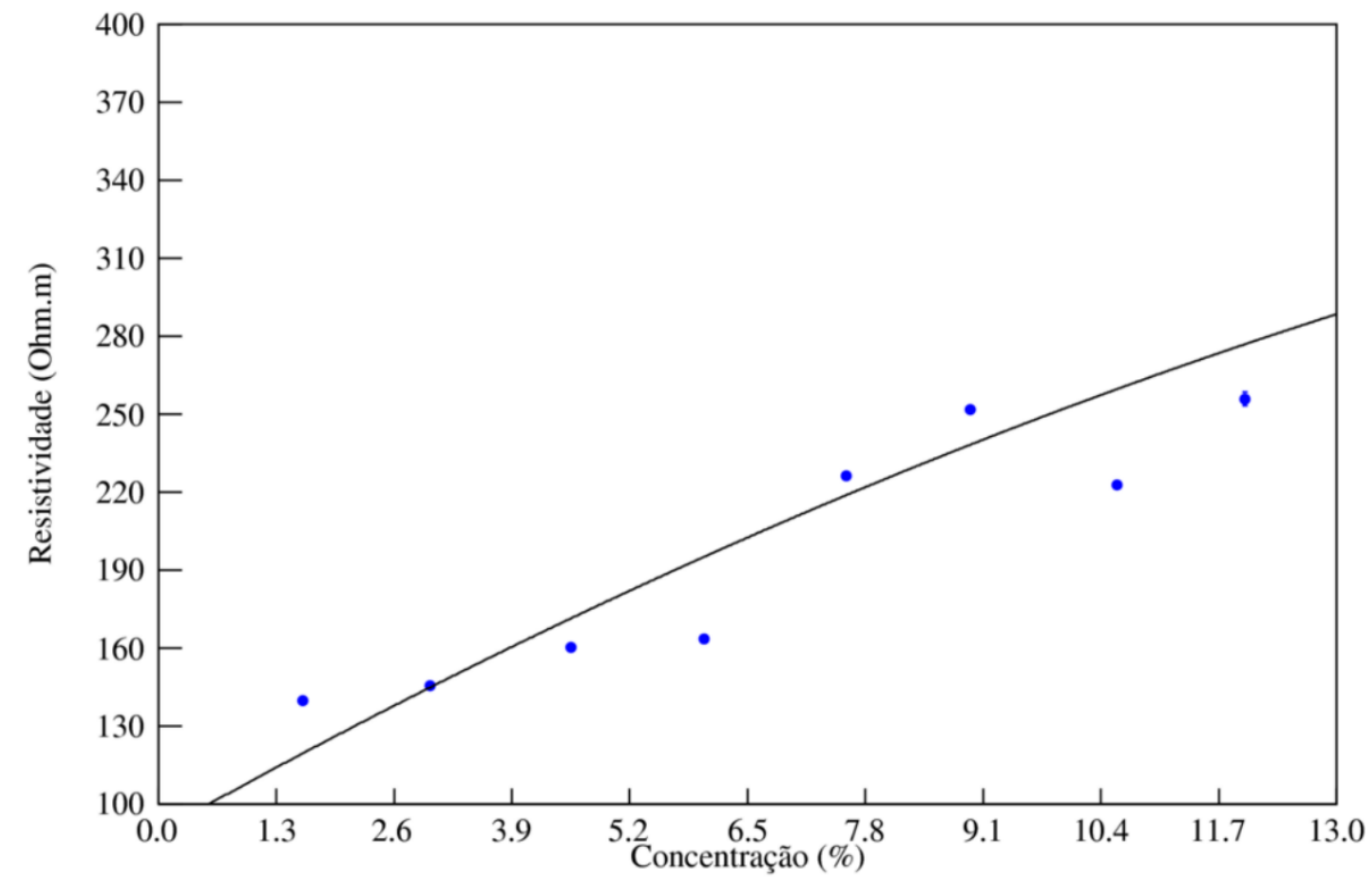

Figura 41. Curva de resistividade pela concentração de creosoto obtida a partir do ajuste aos dados da medição sobre as amostras da areia. 
Os resultados desses experimentos mostraram que a contaminação por creosoto pode afetar a resistividade do solo de diferentes maneiras. As diminuições das resistividades observadas nas medidas das amostras da área indicam que podemos esperar zonas mais condutivas associadas as plumas de creosoto. Este fato pode estar relacionado à biodegradação do contaminante em subsuperfície, uma vez que esse processo pode alterar drasticamente as propriedades elétricas do meio contaminado. Já o aumento da resistividade observado no estudo com diferentes concentrações de creosoto nos mostra que o contaminante no estado natural, i.e., sem ação de biodegradação é altamente resistivo, ou seja, zonas muito resistivas podem estar associadas a plumas de creosoto no estado original. Além disso, este experimento sugere que a concentração de creosoto pode ser inferida com base no valor de resistividade da pluma.

\subsubsection{Aquisições e Análise Espectral GPR}

O experimento utilizando as caixas de areia e solo argiloso vermelho geraram os perfis GPR apresentados a seguir. A Figura 42 mostra o resultado da aquisição sobre a caixa de solo argiloso vermelho representativo da área de estudo sem o recipiente preenchido por creosoto. O solo foi preparado de forma a retirar qualquer heterogeneidade que poderia resultar em uma reflexão no perfil GPR. Na Figura 42 uma reflexão é observada em torno de 7 nanosegundos (ns) proveniente da interface entre o fundo da caixa e o piso. Outra reflexão pode ser observada no centro do perfil, i.e., na posição em torno de 2 ns. Esta reflexão possivelmente é resultado de uma heterogeneidade residual no solo apesar do preparo antes da aquisição.

A Figura 43 apresenta o resultado da aquisição sobre a caixa de solo argiloso vermelho contendo o recipiente preenchido por creosoto. Nota-se uma reflexão de maior amplitude no centro do perfil, em torno de 4 nanosegundos, proveniente do recipiente preenchido com creosoto. Esta reflexão mostra que o contraste de permissividade dielétrica entre o solo argiloso vermelho e o óleo creosoto pode gerar reflexões nos dados GPR. A reflexão devido ao fundo da caixa ainda pode ser observada. 


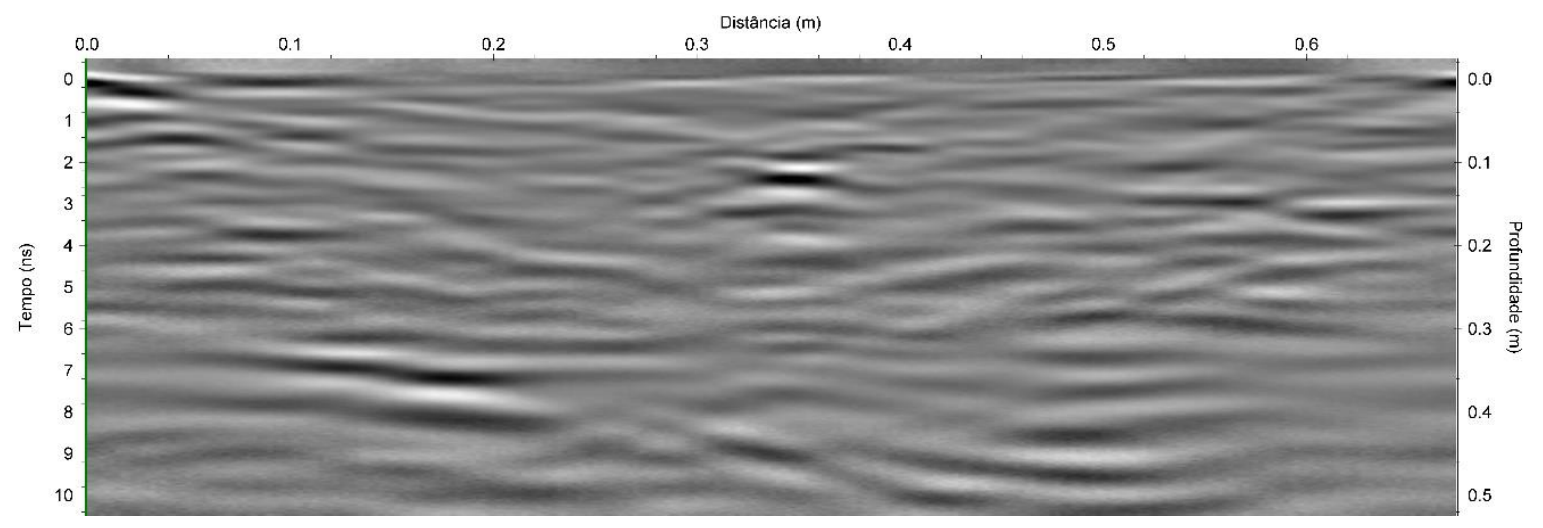

Figura 42. Perfil GPR de $2600 \mathrm{MHz}$ sobre a caixa de argila vermelha.

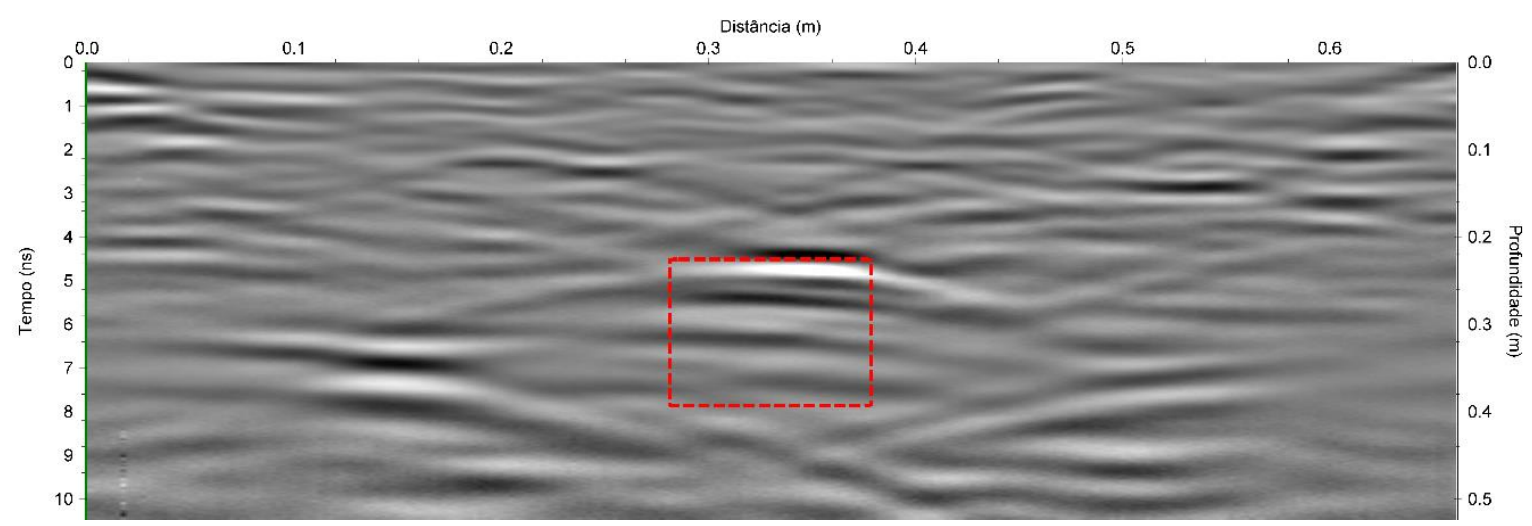

Figura 43. Perfil GPR de $2600 \mathrm{MHz}$ sobre a caixa de argila vermelha com o recipiente preenchido por creosoto enterrado.

A Figura 44 apresenta o resultado da aquisição sobre a caixa de areia. Nota-se claramente a reflexão proveniente do fundo da caixa, em torno de 2 a 3,5 nanosegundos, correspondendo a uma profundidade de $15 \mathrm{~cm}$. Observando o perfil da Figura 45, que corresponde a caixa de areia com o recipiente preenchido por creosoto, nota-se uma forte reflexão de forma hiperbólica no centro do perfil (posição de 0,3 m), em $1 \mathrm{~ns}$, proveniente do recipiente preenchido por creosoto. Novamente é observado que o contraste de permissividade dielétrica entre o creosoto e a areia é capaz de gerar reflexões nítidas nos perfis GPR. 


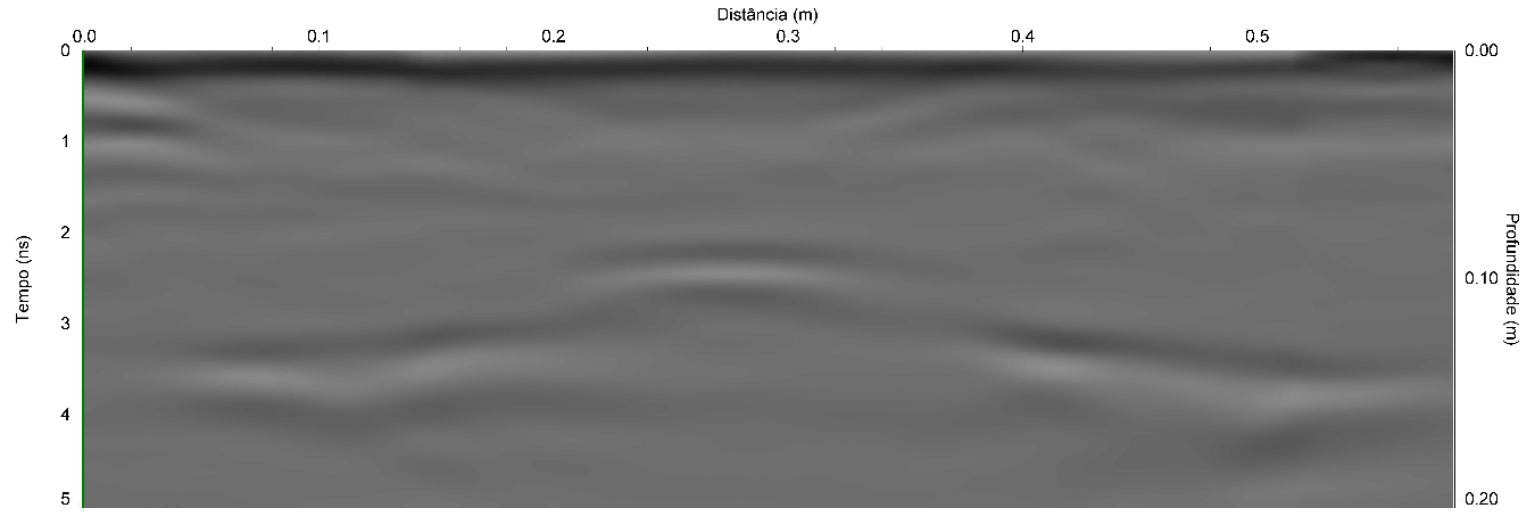

Figura 44. Perfil GPR de $2600 \mathrm{MHz}$ sobre a caixa de areia.

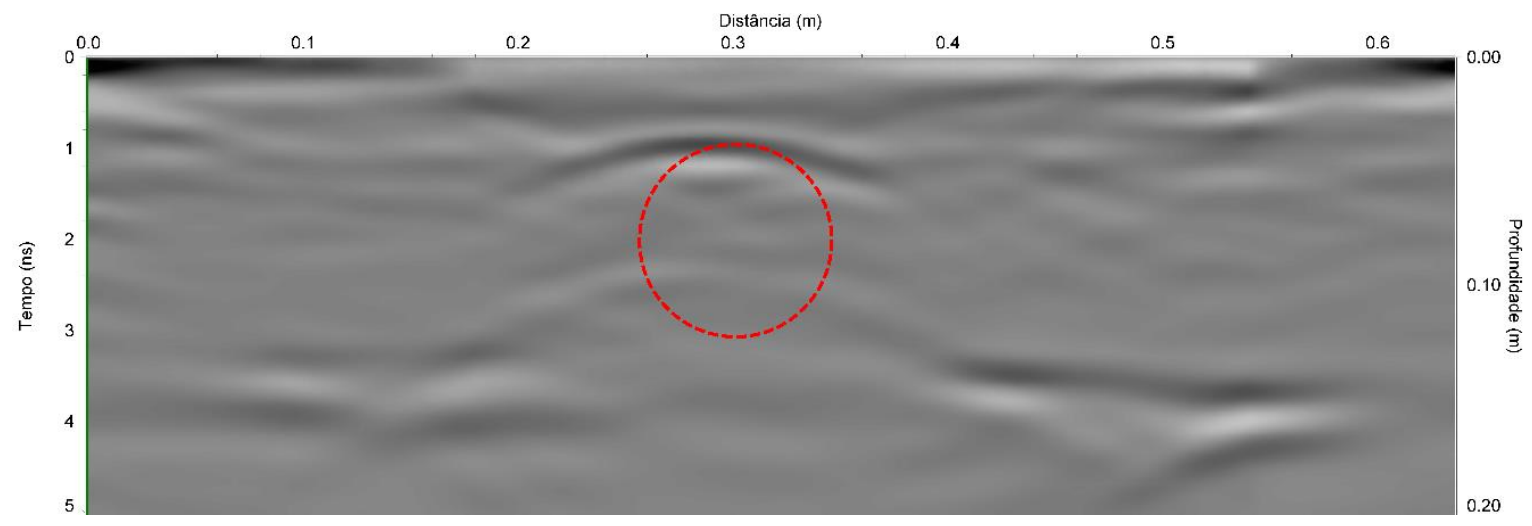

Figura 45. Perfil GPR de $2600 \mathrm{MHz}$ sobre a caixa de areia com o recipiente preenchido por creosoto enterrado.

Um algoritmo de análise espectral (Santos, 2014) foi aplicado aos 4 perfis mostrados acima, visando uma maneira de se detectar a contaminação. Os resultados são apresentados nas Figuras 46 e 47. A Figura 46 mostra o resultado da aplicação do algoritmo de análise espectral para os dois perfis adquiridos sobre a caixa de argila sem e com o recipiente com contaminante. A Figura 46a mostra que as maiores amplitudes não estão associadas à frequência central (FC) de operação da antena. Nota-se que no centro do perfil do espectograma, em frequências em torno de $2000 \mathrm{MHz}$ há uma amplitude em torno de 0,3 a 0,4 com relação a maior amplitude normalizada. Pela Figura $46 \mathrm{~b}$ nota-se que a presença do contaminante faz com que as maiores amplitudes sejam agora associadas a frequências ainda mais baixas. Isso pode ser observado nas anomalias no centro do perfil, na frequência em torno de $2000 \mathrm{MHz}$, onde agora está associada a uma amplitude de 0,1 com relação a maior amplitude normalizada.

A Figura 47 apresenta o resultado da aplicação do algoritmo de análise espectral para os dois perfis adquiridos sobre a caixa de areia sem e com o recipiente com contaminante. A Figura 
47a mostra que nas frequências próximas a FC de operação da antena, ou seja, $2600 \mathrm{MHz}$, a amplitude é baixa, em torno de 0,2 com relação a maior amplitude normalizada. Já a Figura 47b mostra que com a presença do creosoto, no centro do perfil, a amplitude associada à frequências próximas a FC de operação da antena seja menor, em torno de 0,1 com relação a maior amplitude normalizada. Nas Figuras 47a e 47b as maiores amplitudes estão associadas a frequências muito baixas, podendo indicar um ruído de baixa frequência no sinal.

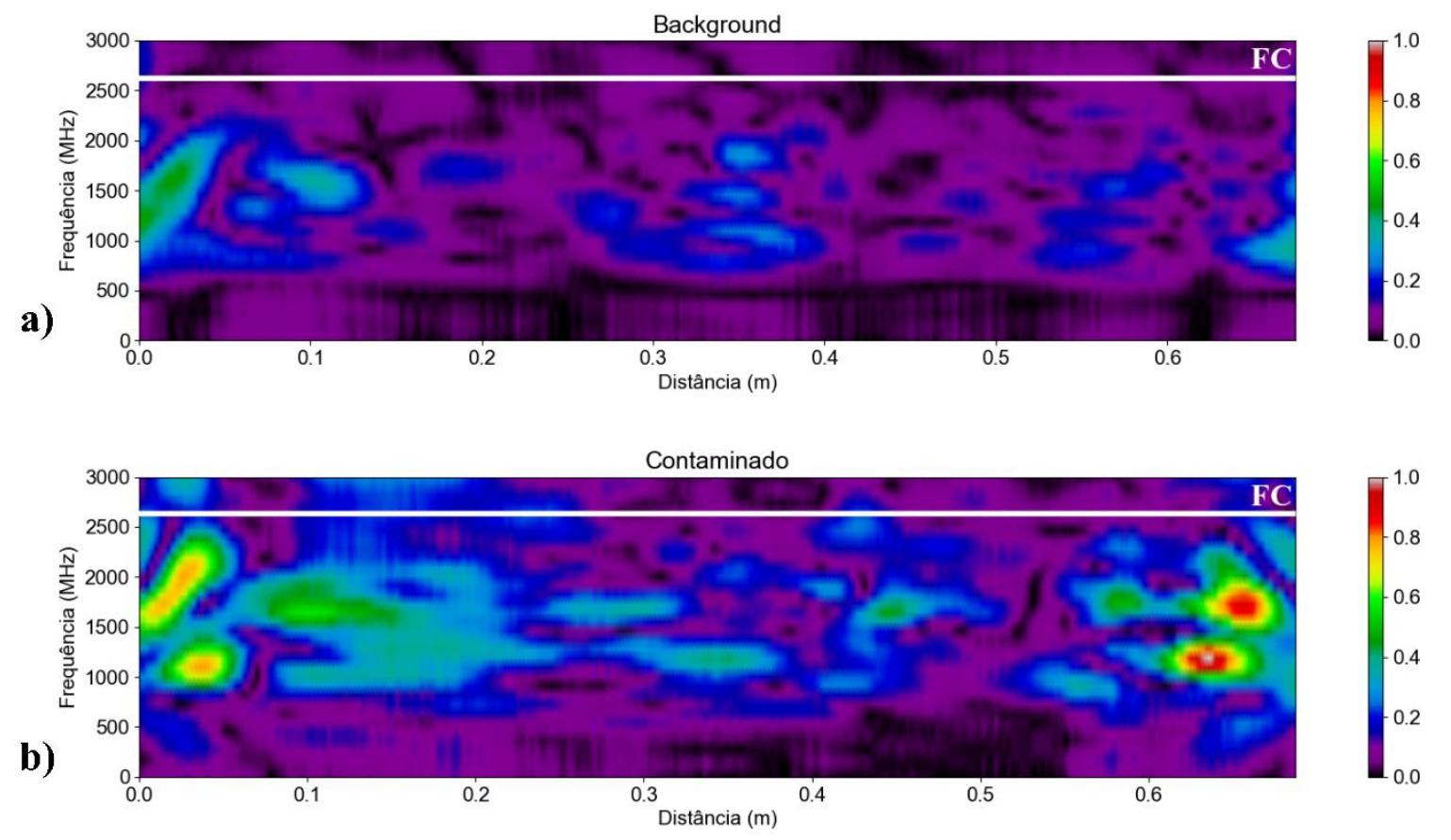

Figura 46. Espectrograma dos dados de $2600 \mathrm{MHz}$ sobre a caixa de argila vermelha. a) Sem contaminação. b) Com recipiente preenchido com creosoto. 

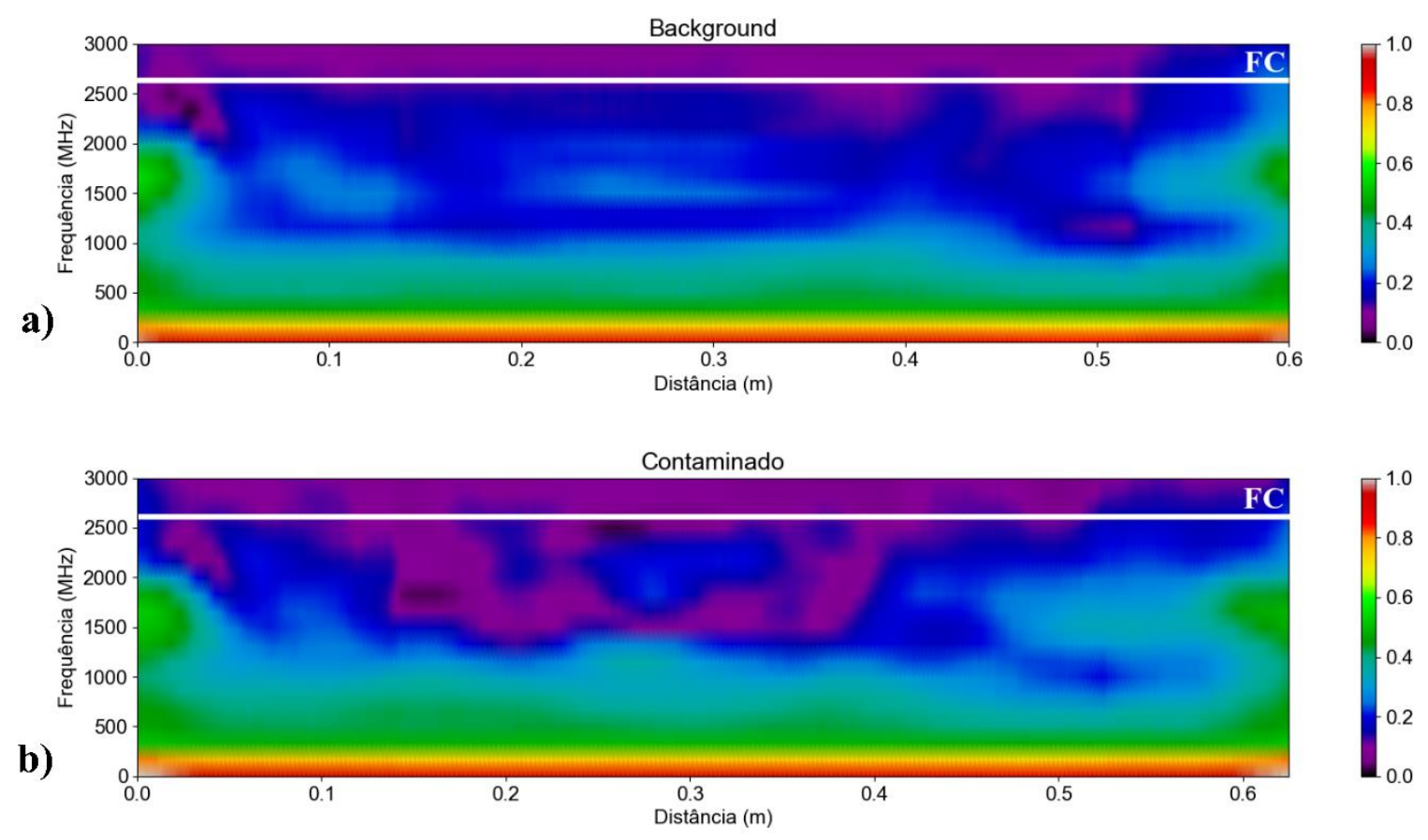

Figura 47. Espectrograma dos dados de 2600 MHz sobre a caixa de areia. a) Sem contaminação. b) Com recipiente de preenchido com creosoto.

Os resultados deste experimento, embora ainda preliminares, mostraram que a presença do creosoto pode ser detectada através da análise dos radargramas. Além disso, aparentemente, a presença do creosoto causa uma alteração no espectro de amplitude do sinal GPR. Neste caso, a presença do creosoto faz com que a amplitude das frequências próximas a FC de operação da antena seja menor. Estes resultados ainda precisam ser melhor analisados e mais pesquisas são requeridas.

\subsection{GROUND PENETRATING RADAR (GPR)}

A seguir são apresentados os resultados das aquisições com o método GPR sobre as linhas e sobre o grid na área de estudo, assim como os resultados dos levantamentos CMP. As Figuras 48 a 51 mostram os resultados GPR da linha de background para as frequências de 200, 270, 400 e $900 \mathrm{MHz}$, respectivamente. Na Figura 48 é possível notar três camadas bem definidas no perfil que correspondem a estratigrafia observada nas perfurações. A primeira camada observada é marcada com a linha tracejada vermelha, em torno de $30 \mathrm{~cm}$ de profundidade, corresponde a interface entre o aterro e o solo argiloso vermelho. A segunda camada é marcada com a linha tracejada azul, em torno de 1,0 metro de profundidade, corresponde a interface entre o solo argiloso vermelho e o solo argiloso cinza escuro. A terceira camada é marcada com a linha tracejada verde, em torno de 1,7 
metros de profundidade, corresponde a interface entre o solo argiloso cinza escuro e o solo argiloso preto.

No perfil GPR de $270 \mathrm{MHz}$ (Figura 49) também foram observadas e interpretadas as três camadas mencionadas acima. Neste caso, o limite de profundidade do perfil é menor, chegando a aproximadamente 2,2 metros de profundidade, o que era esperado uma vez que se trata de uma frequência de operação menor. Para ambos os perfis, nas Figura 48 e 55, após a camada de solo argiloso preto o sinal é atenuado rapidamente. Isso se deve ao fato desta camada apresentar uma baixa resistividade, em torno de 142 Ohm.m, de acordo com as medições em laboratório (Tabela 4).

Os perfis das Figuras 50 e 51 são ainda mais limitados em profundidade, pois se tratam de perfis adquiridos com antenas de mais altas frequências, i.e., 400 e 900 MHz. No caso da Figura 50, foi possível delimitar a primeira interface e parte da segunda interface no lado direito do perfil. No caso da Figura 51, as duas primeiras interfaces foram observadas.

Os resultados das aquisições GPR sobre a linha de background mostraram que a utilização do GPR pode ajudar na definição da estratigrafia rasa da área de estudo com grande precisão. Esta definição fica limitada em áreas onde se tem camadas argilosas muito condutivas, pois o sinal é atenuado rapidamente.

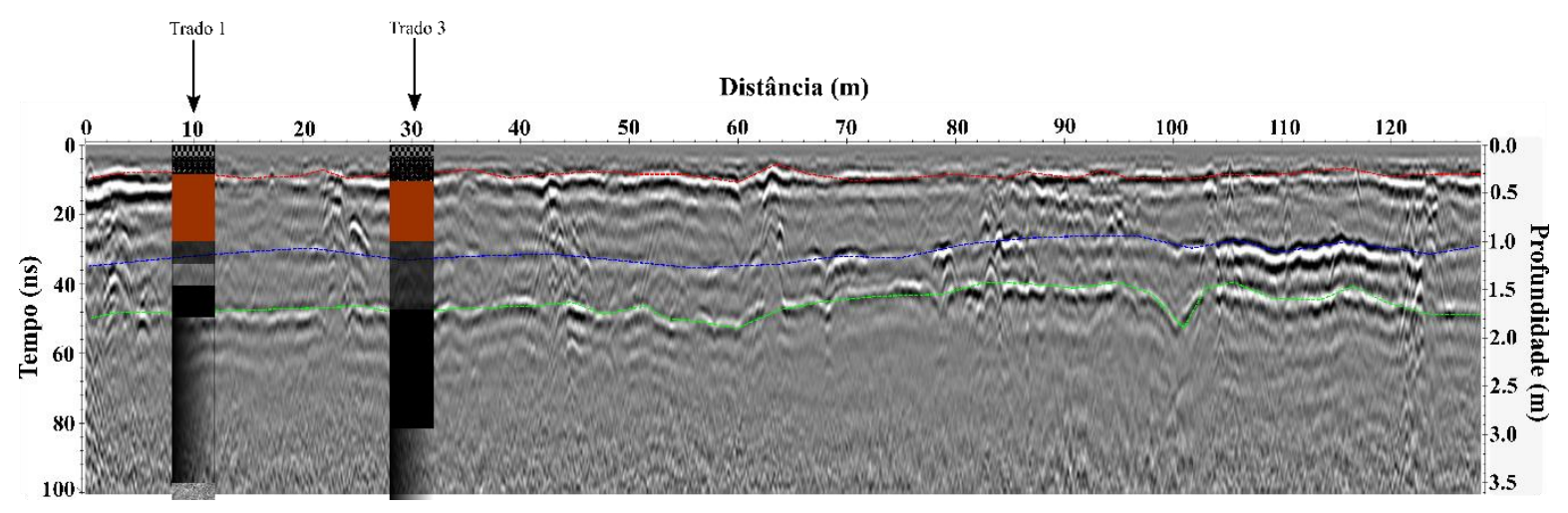

Figura 48. Perfil GPR de $200 \mathrm{MHz}$ sobre a linha de background. 


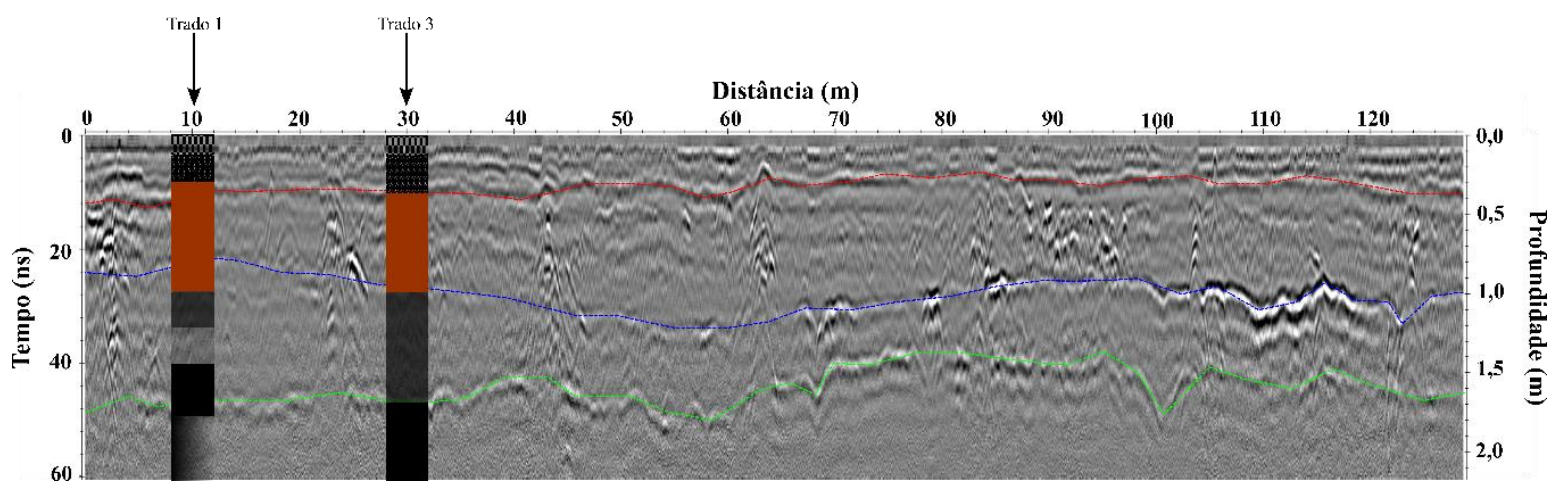

Figura 49. Perfil GPR de $270 \mathrm{MHz}$ sobre a linha de background.

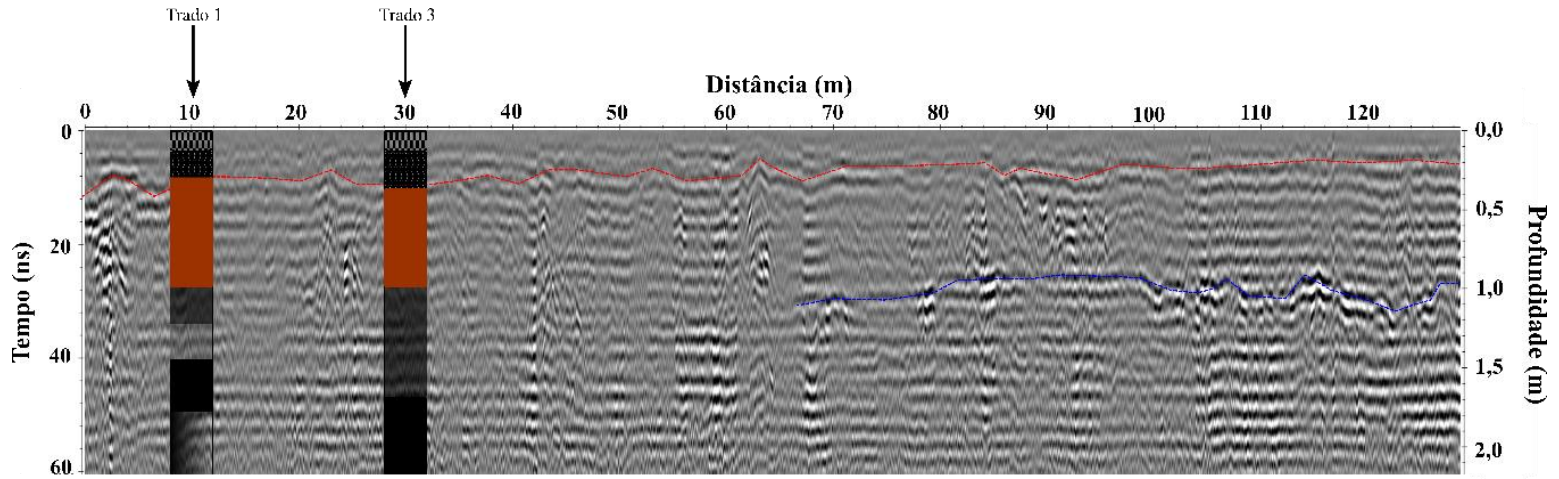

Figura 50. Perfil GPR de $400 \mathrm{MHz}$ sobre a linha de background.

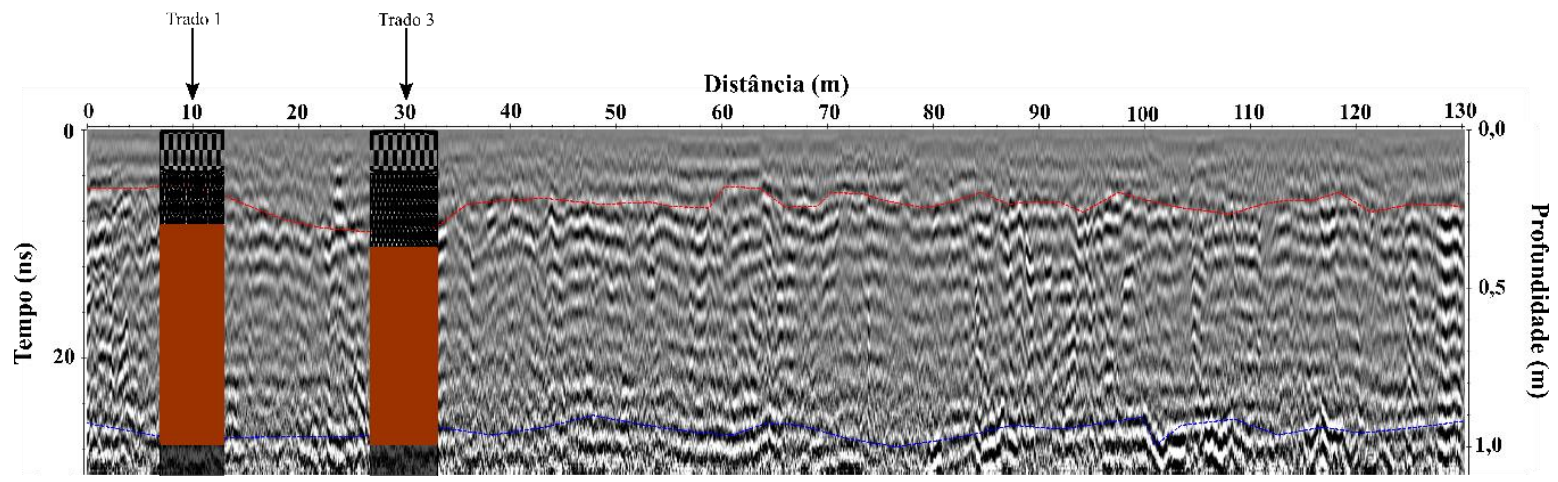

Figura 51. Perfil GPR de $900 \mathrm{MHz}$ sobre a linha de background.

As Figuras 52 a 55 mostram os resultados GPR da linha central para as frequências de 200, 270, 400 e 900 MHz, respectivamente. Na Figura 52 é possível notar que nos primeiros 10 metros do perfil o sinal sofre com um ruído de reverberação. Isto geralmente acontece quando não há o acoplamento ideal da antena com o solo. Neste caso o desacoplamento da antena ocorreu devido à grande quantidade de entulho presente neste trecho, onde a antena mais larga de $200 \mathrm{MHz}$ não foi 
capaz de contornar. No restante do perfil é possível observar a primeira interface interpretada com a linha tracejada vermelha. Entre as posições de 15 e 30 metros ao longo do perfil, a superfície tem um patamar de concreto. Esse patamar causou um descolamento para baixo da primeira interface, uma vez que não foram adquiridos dados de topografia, este efeito era esperado. A interface entre o concreto do patamar e o solo gerou uma reflexão de alta amplitude, o que não permitiu que o sinal penetrasse para as camadas mais profundas. A partir de 30 metros ao longo do perfil, os efeitos do patamar desaparecem e novamente é possível observar interfaces mais profundas. Em torno da posição de 10 metros ao longo do perfil, a uma profundidade de aproximadamente 1,0 metro, é possível observar uma interface anômala de alta amplitude de reflexão que não é observada em outras partes do perfil. Esta interface sugere o acúmulo de contaminante nesta região. Resultados semelhantes podem ser encontrados na literatura (Sauck, 2000; Atekwana et al, 2010)

No perfil da Figura 53 nota-se que o efeito do patamar de concreto também é observado. Observamos também, em torno da posição de 10 metros ao longo do perfil, uma região anômala com possível acúmulo de contaminante.

O perfil da Figura 54 teve seu início deslocado em 17 metros para trás. As anomalias em torno de 12 metros ao longo do perfil não são cobertas pelos perfis anteriores. Essas anomalias com fortes reflexões podem indicar a presença de elevada concentração de contaminante. Neste perfil também é observado o efeito do patamar de concreto. O perfil da Figura 55 apresenta novamente uma reflexão na posição de 10 metros ao longo do perfil que pode estar relacionada com a presença do contaminante acumulado sobre a interface.

O acumulo de contaminante sobre uma interface com condutividade hidráulica baixa faz com que o contraste de permissividade dielétrica entre as camadas seja maior, proporcionando assim uma reflexão com maior amplitude. Além disso, o óleo creosoto em seu estado intacto é altamente resistivo, permitindo uma maior penetração do sinal onde a concentração de creosoto é maior. Esses fatores podem ser as causas das reflexões observadas nos perfis das Figuras 52, $53 \mathrm{e}$ 55, assim como uma penetração maior nas anomalias no perfil da Figura 54. 


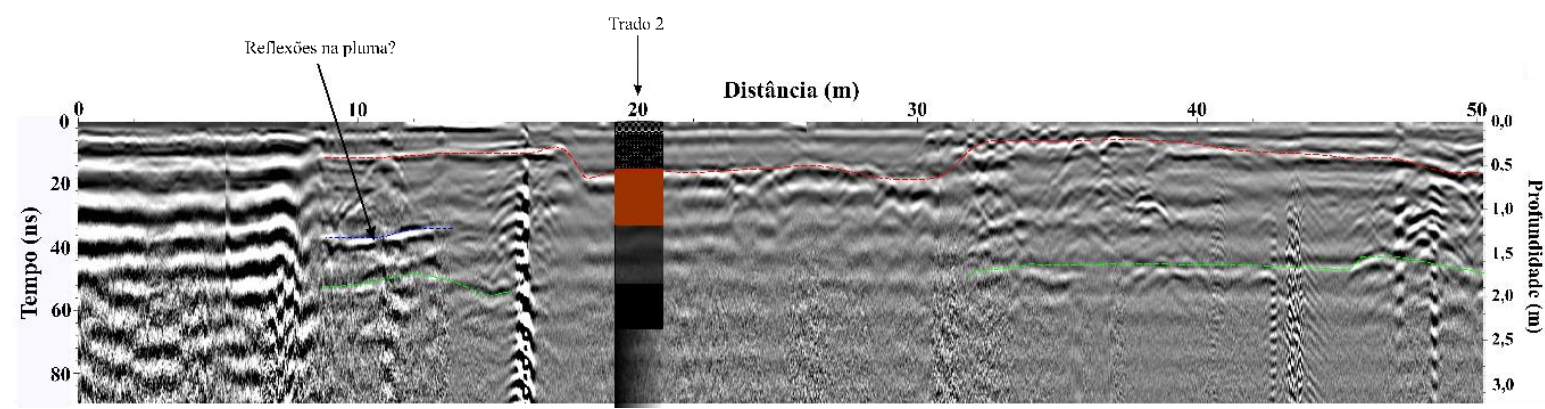

Figura 52. Perfil GPR de $200 \mathrm{MHz}$ sobre a linha central.

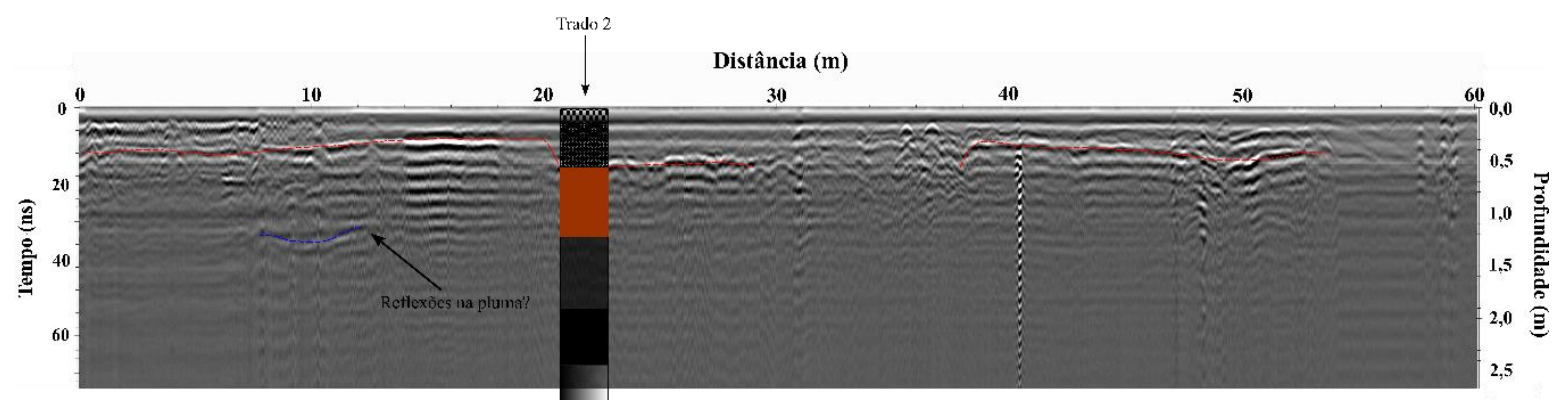

Figura 53. Perfil GPR de $270 \mathrm{MHz}$ sobre a linha central.

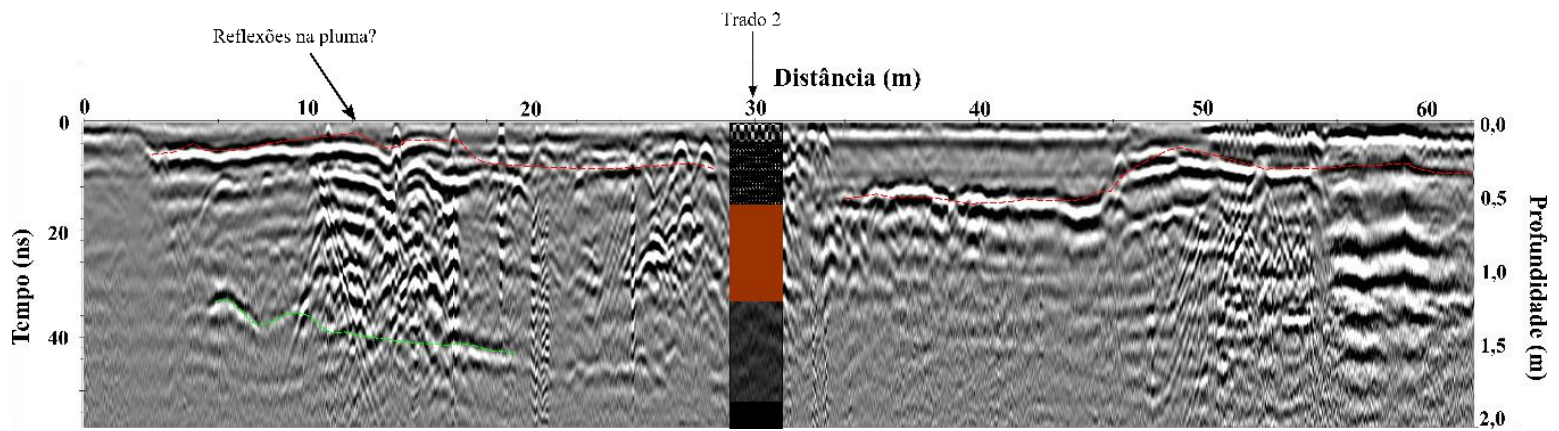

Figura 54. Perfil GPR de $400 \mathrm{MHz}$ sobre a linha central.

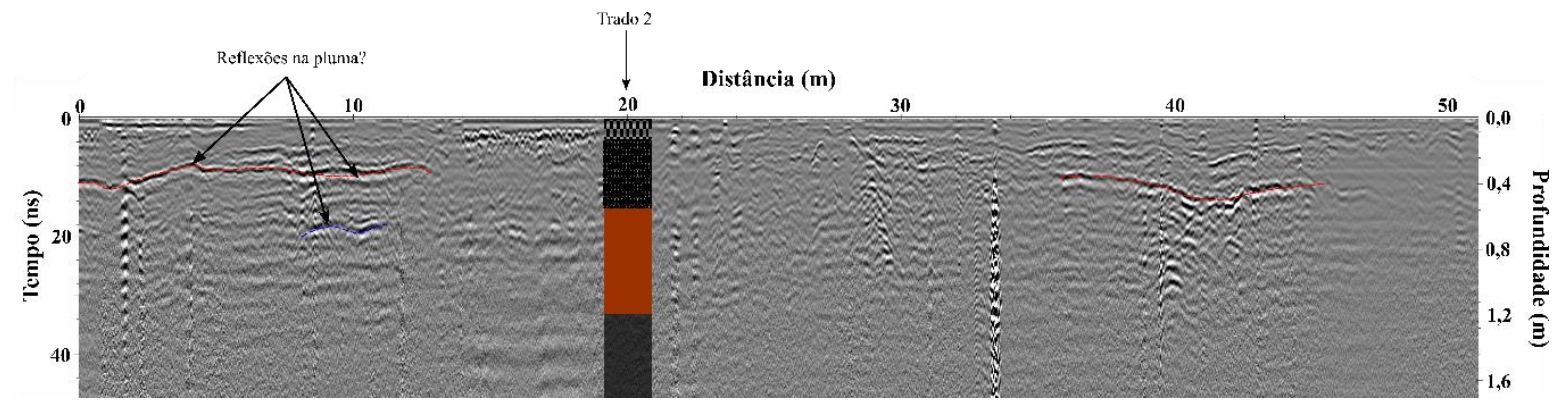

Figura 55. Perfil GPR de $900 \mathrm{MHz}$ sobre a linha central. 
As Figuras 56 a 59 mostram os resultados GPR da linha lateral para as frequências de 200, 270, 400 e $900 \mathrm{MHz}$, respectivamente. Em todos os perfis estão apontadas as posições dos antigos tanques de creosoto. No perfil da Figura 56 é possível identificar as camadas da estratigrafia. Entre as posições de 20 e 40 metros ao longo do perfil, exatamente nas posições dos antigos tanques de creosoto, as reflexões na segunda interface desaparecem. Este fato pode estar relacionado com a presença do contaminante no solo. O perfil da Figura 57 é semelhante ao anterior, sendo possível notar o desaparecimento da segunda interface na posição dos antigos tanques de creosoto.

Os perfis das Figura 55 e 59 estão 8 metros deslocados para trás com relação a posição inicial dos perfis anteriores. Tanto para o perfil da Figura 58 quanto para o perfil da Figura 59 notase o desaparecimento das reflexões na primeira e na segunda camada.

Ao comparar os perfis das Figuras 57 e 58, observa-se que as reflexões na terceira camada (linha tracejada verde) estão deslocadas de quase $60 \mathrm{~cm}$. O motivo para este deslocamento ainda não foi descoberto., mas parece estar relacionado com o fato da frequência mais elevada de 400 MHz ser mais sensível a presença do solo argiloso cinza escuro condutor, fazendo com que o sinal penetre no solo de forma mais lenta. Entretanto, mais estudos são necessários para o completo entendimento deste deslocamento.

O desaparecimento das reflexões nas interfaces nas regiões dos tanques pode indicar que a concentração de creosoto se distribuí entre as camadas de tal forma que as permissividades dielétricas das camadas estejam próximas do mesmo valor, criando assim uma "zona sem reflexões" para as interfaces.

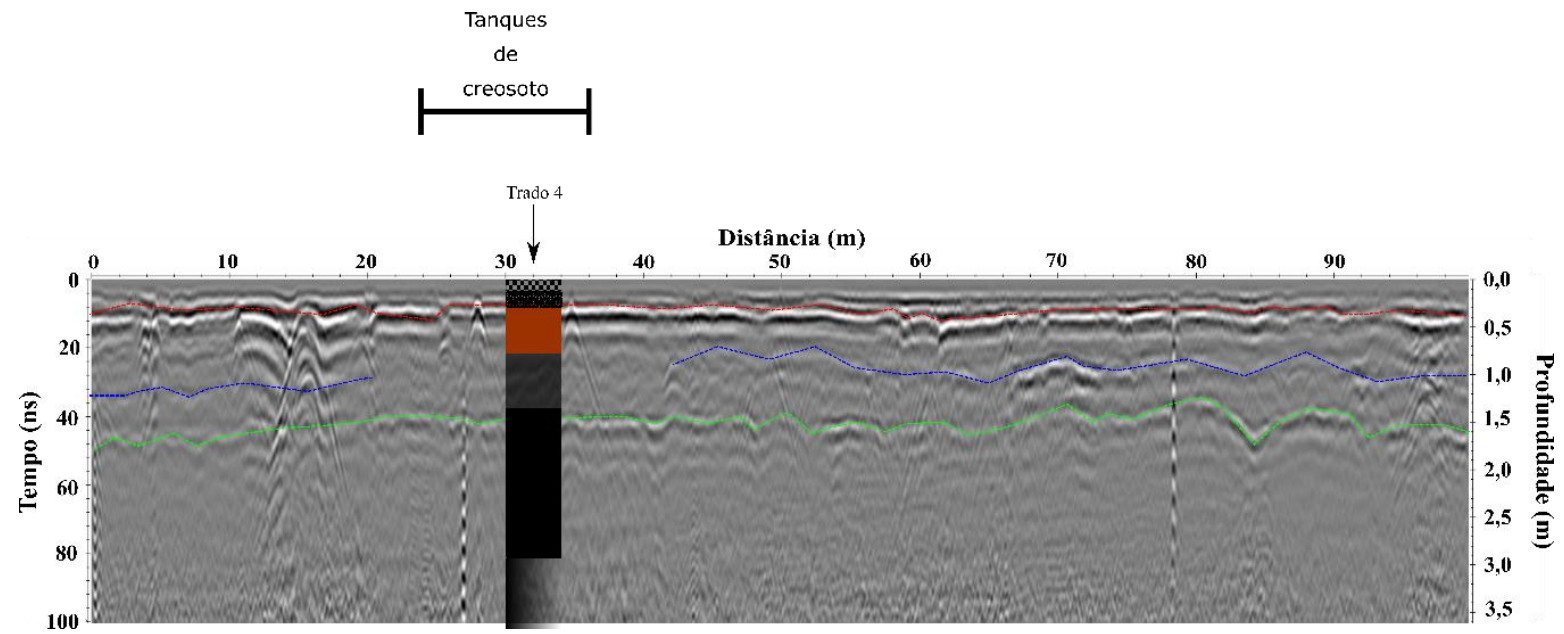

Figura 56. Perfil GPR de $200 \mathrm{MHz}$ sobre a linha lateral. 


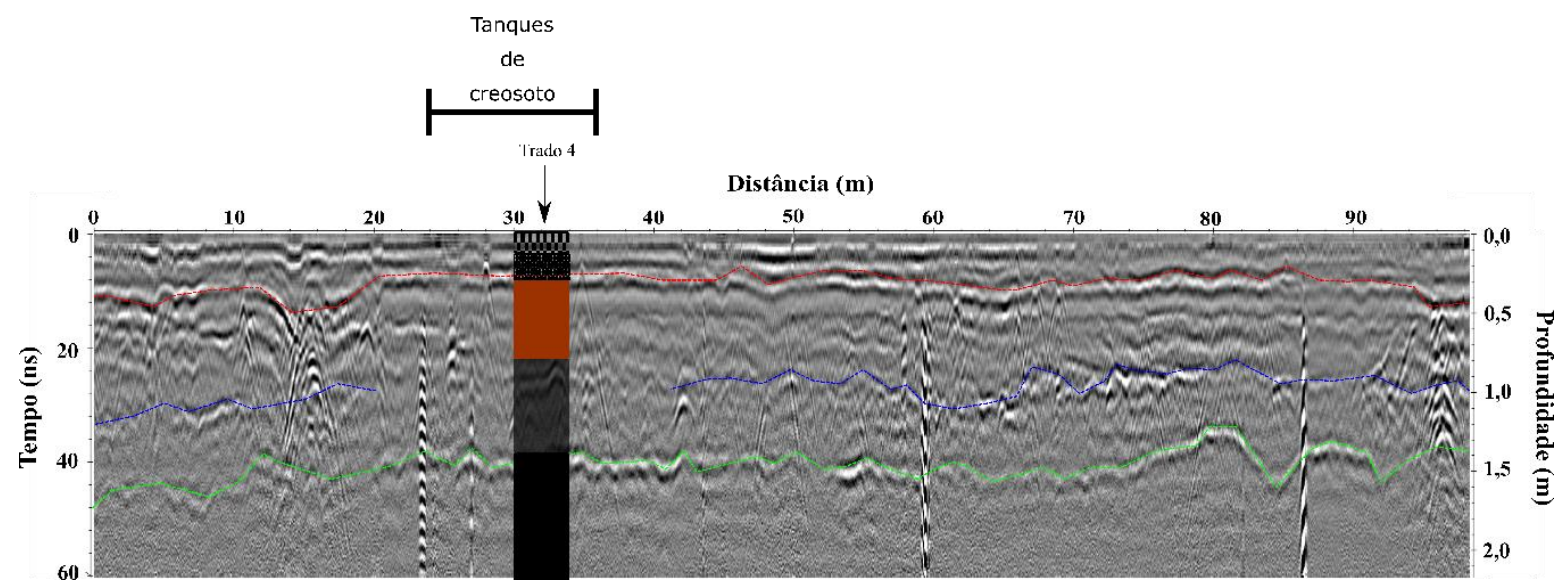

Figura 57. Perfil GPR de $270 \mathrm{MHz}$ sobre a linha lateral.

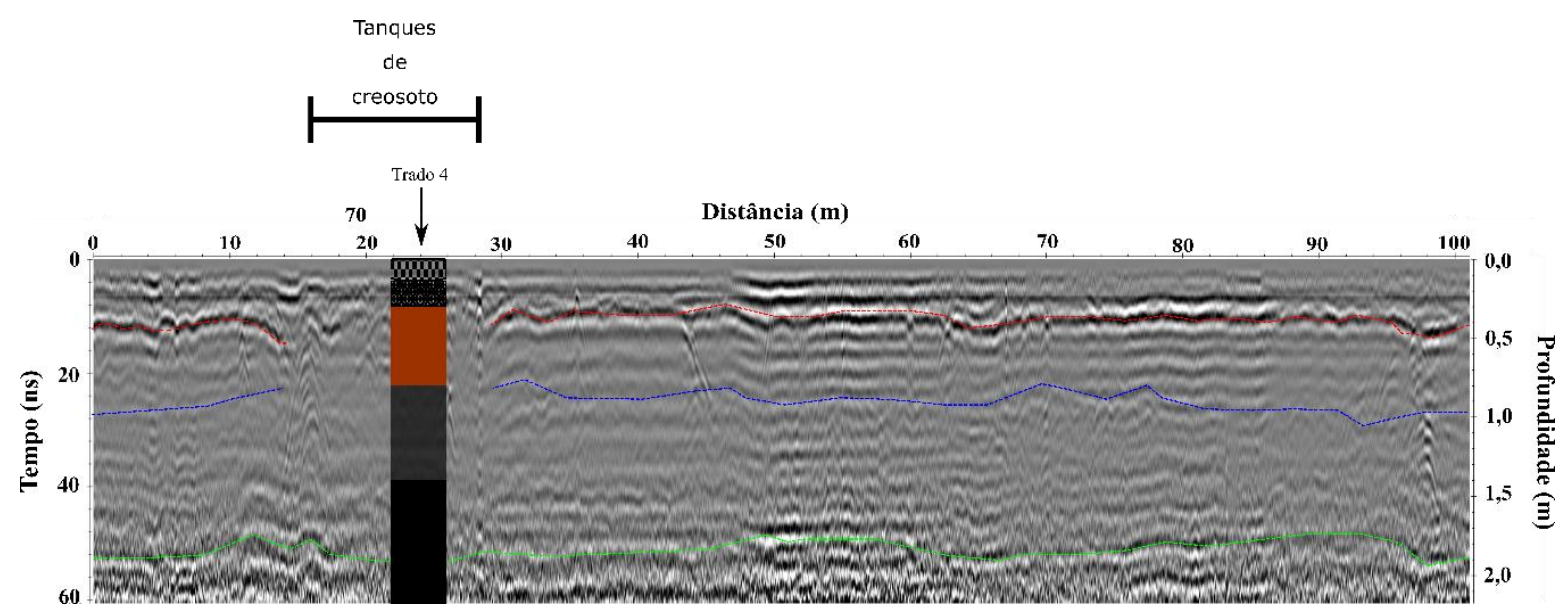

Figura 58. Perfil GPR de $400 \mathrm{MHz}$ sobre a linha lateral.

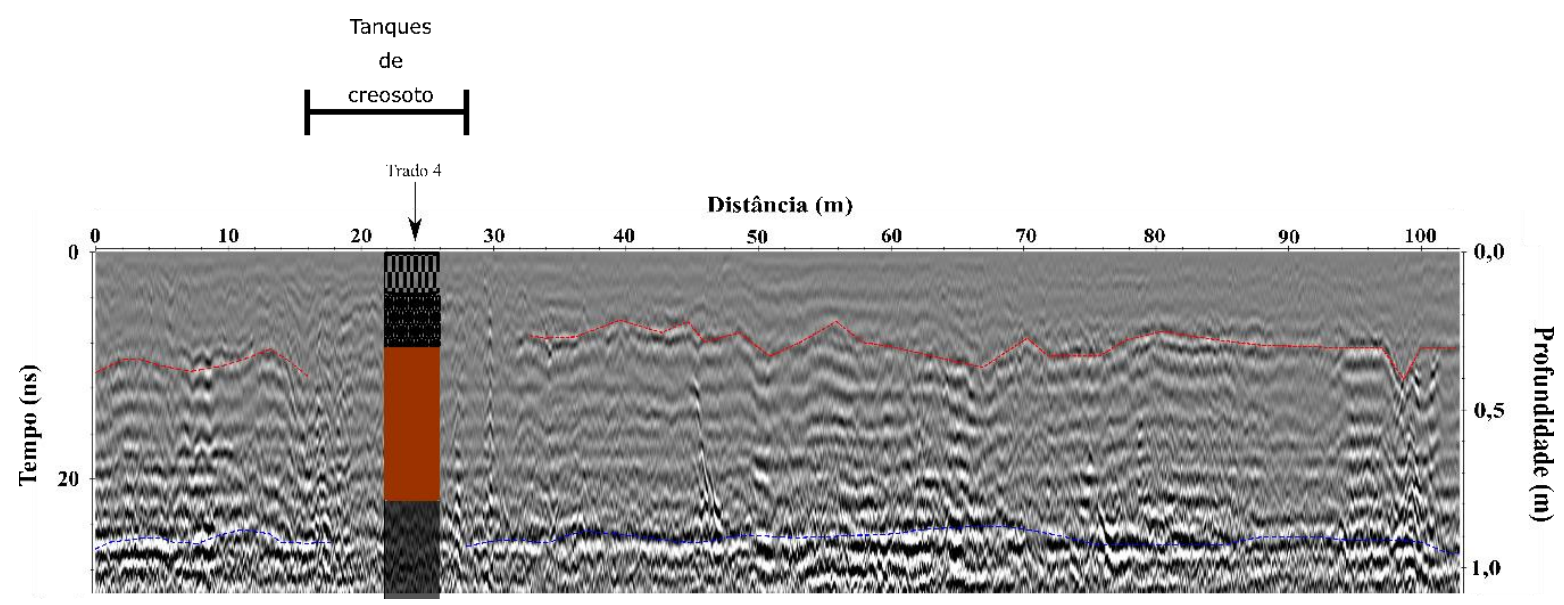

Figura 59. Perfil GPR de $900 \mathrm{MHz}$ sobre a linha lateral. 
Dois perfis das antenas de $200 \mathrm{MHz}$ e $900 \mathrm{MHz}$ foram submetidos a análise espectral, sendo eles o perfil da linha background e o perfil da linha lateral (ver Figura 33). Os resultados da aplicação do algoritmo de análise espectral são apresentados nas Figuras 60 e 61.

A Figura 60 mostra o resultado da aplicação do algoritmo de análise espectral sobre os dados da antena de $200 \mathrm{MHz}$. Na Figura 60a é possível notar uma distribuição uniforme das amplitues em torno da FC de operação de $200 \mathrm{MHz}$. As amplitudes decaem para frequências acima e abaixo de $200 \mathrm{MHz}$, sendo que em frequências próximas de $200 \mathrm{MHz}$ as amplitudes são de aproximadamente 0,4 a 0,6. Na Figura 60b, a posição dos antigos tanques de creosoto estão entre 20 e 40 metros ao longo do perfil. Exatamente nessas posições, as amplitudes das frequências próximas a $200 \mathrm{MHz}$ diminuem para aproximadamente 0,15 . Isso indica que a presença do contaminante faz com que as amplitudes das frequências próximas a FC de operação da antena diminuam. Este resultado era o esperado de acordo com o experimento feito em laboratório.

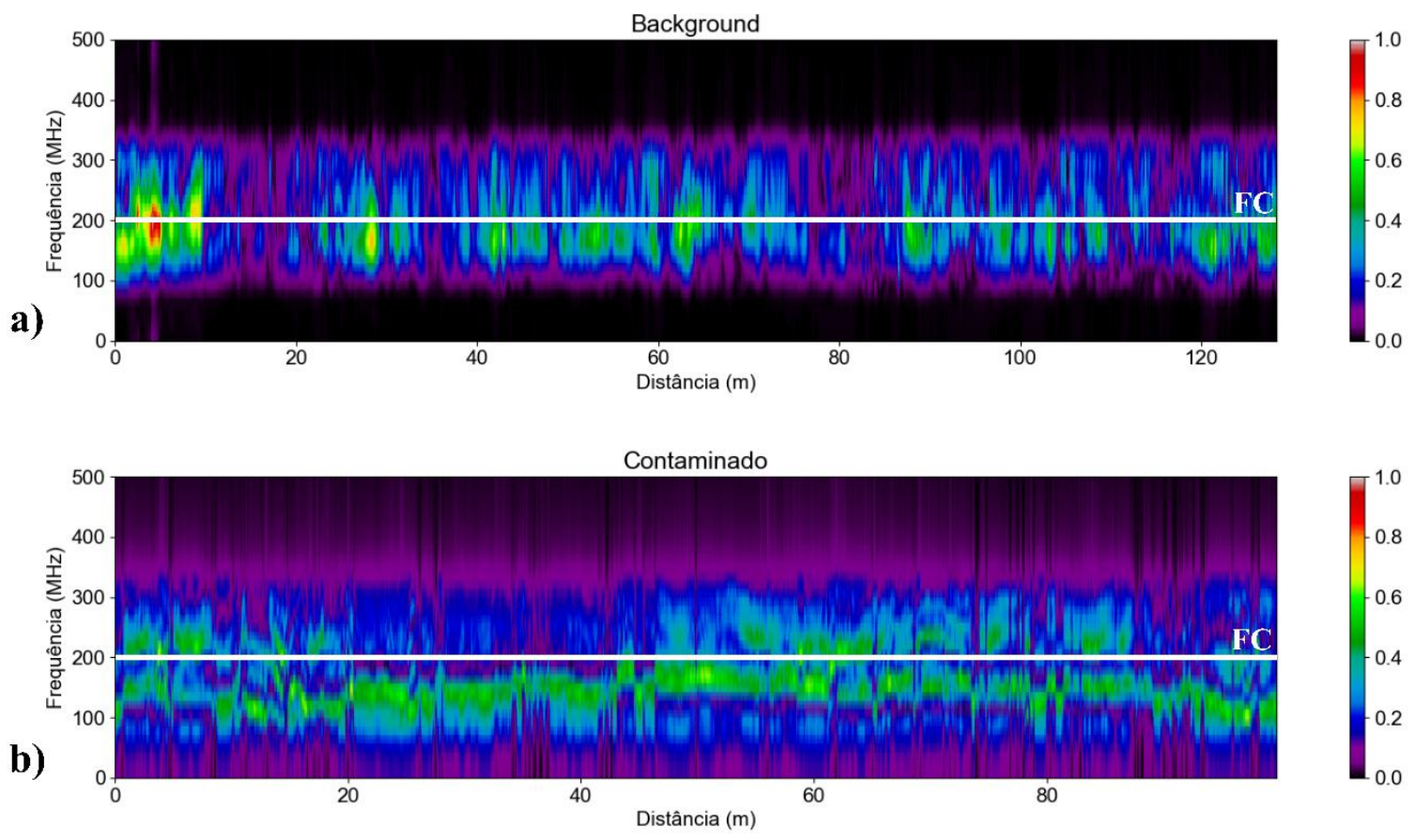

Figura 60. Espectrograma dos dados de frequência central (FC) 200 MHz. a) Linha background. b) Linha lateral. 
A Figura 61 mostra o resultado da aplicação do algoritmo de análise espectral sobre os dados da antena de $900 \mathrm{MHz}$. Na Figura 61a é possível notar uma distribuição uniforme das amplitudes em torno de frequências próximas a $500 \mathrm{MHz}$. Isso mostra que neste caso a FC foi subestimada pelo algoritmo assim como observado na Figura 46. As amplitudes neste caso estão próximas a 0,5. Na Figura 61 b vemos que a uma diminuição da amplitude, até 0,2, é observada em todo o perfil, sendo da mesma forma subestimada a FC de operação. É de se esperar uma diminuição das amplitudes no perfil contaminado com relação ao não contaminado, porém neste caso observa-se uma diminuição em todo o perfil e não somente na parte contaminada. Este fato pode indicar uma limitação no algoritmo quando aplicado a frequência de $900 \mathrm{MHz}$. Mais estudos são necessários, porém estão além dos objetivos desta pesquisa.

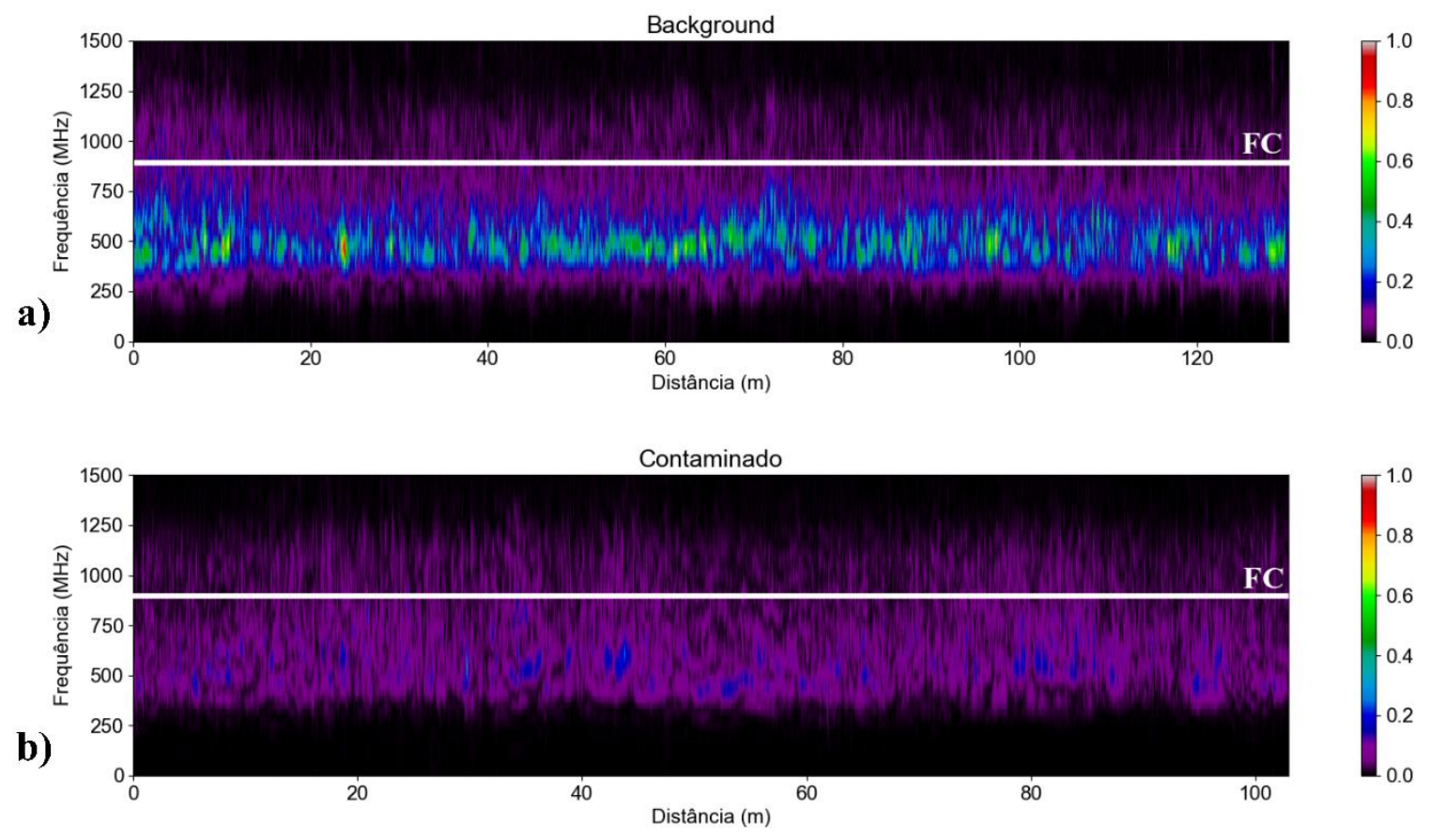

Figura 61. Espectrograma dos dados de frequência central (FC) 200 MHz. a) Linha background. b) Linha lateral.

As linhas de aquisição GPR sobre o grid centrado na posição de uma das antigas autoclaves foram interpoladas para gerar um modelo pseudo-3D. É apresentado um corte horizontal na profundidade de $20 \mathrm{~cm}$ do modelo pseudo-3D (Figura 62). É possível observar uma anomalia de mais alta amplitude (circulada em vermelho) relacionada ao acumulo do contaminante sobre a 
interface entre o aterro e o solo argiloso vermelho. Nas bordas dessa anomalia de mais alta amplitude é possível observar um zona de sombra que está relacionada a uma região mais condutiva da pluma de contaminação.

Para melhorar a visualização dos dados GPR pseudo-3D de $900 \mathrm{MHz}$, foi aplicada a transformada de Hilbert nos dados da Figura 62. A Figura 63 mostra o resultado da aplicação desta transformada. Observa-se que, as áreas delimitadas em azul correspondem a regiões caracterizadas por zonas de sombras e que provavelmente estão relacionadas com a pluma de creosoto biodegradada. As resistividades mais baixas eram esperadas nas bordas dessa pluma, uma vez que as amostras do furo Trado 2 apresentaram baixas resistividades devido a presença do contaminante, provavelmente biodegradado. A área delimitada em vermelho mostra as reflexões na pluma de creosoto em seu estado natural, ou seja, resistiva e sem evidência de biodegradação. Apesar das Figuras 62 e 63 tratarem de cortes na horizontal com $20 \mathrm{~cm}$ de profundidade, este comportamento foi observado até profundidades de aproximadamente 1 metro de profundidade.

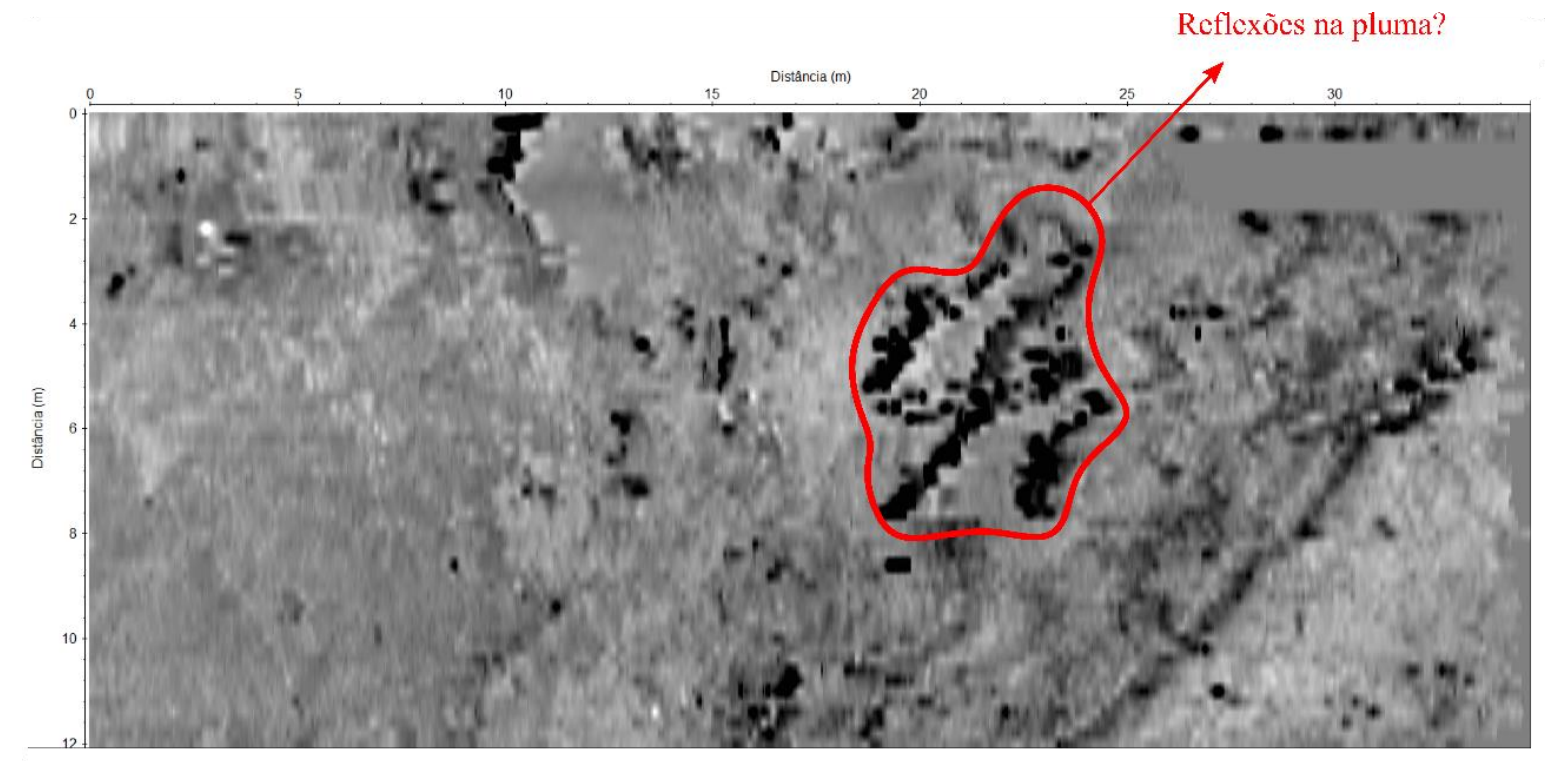

Figura 62. Corte a $20 \mathrm{~cm}$ de profundidade do modelo GPR pseudo-3D de $900 \mathrm{MHz}$ resultado da interpolação das linhas. 


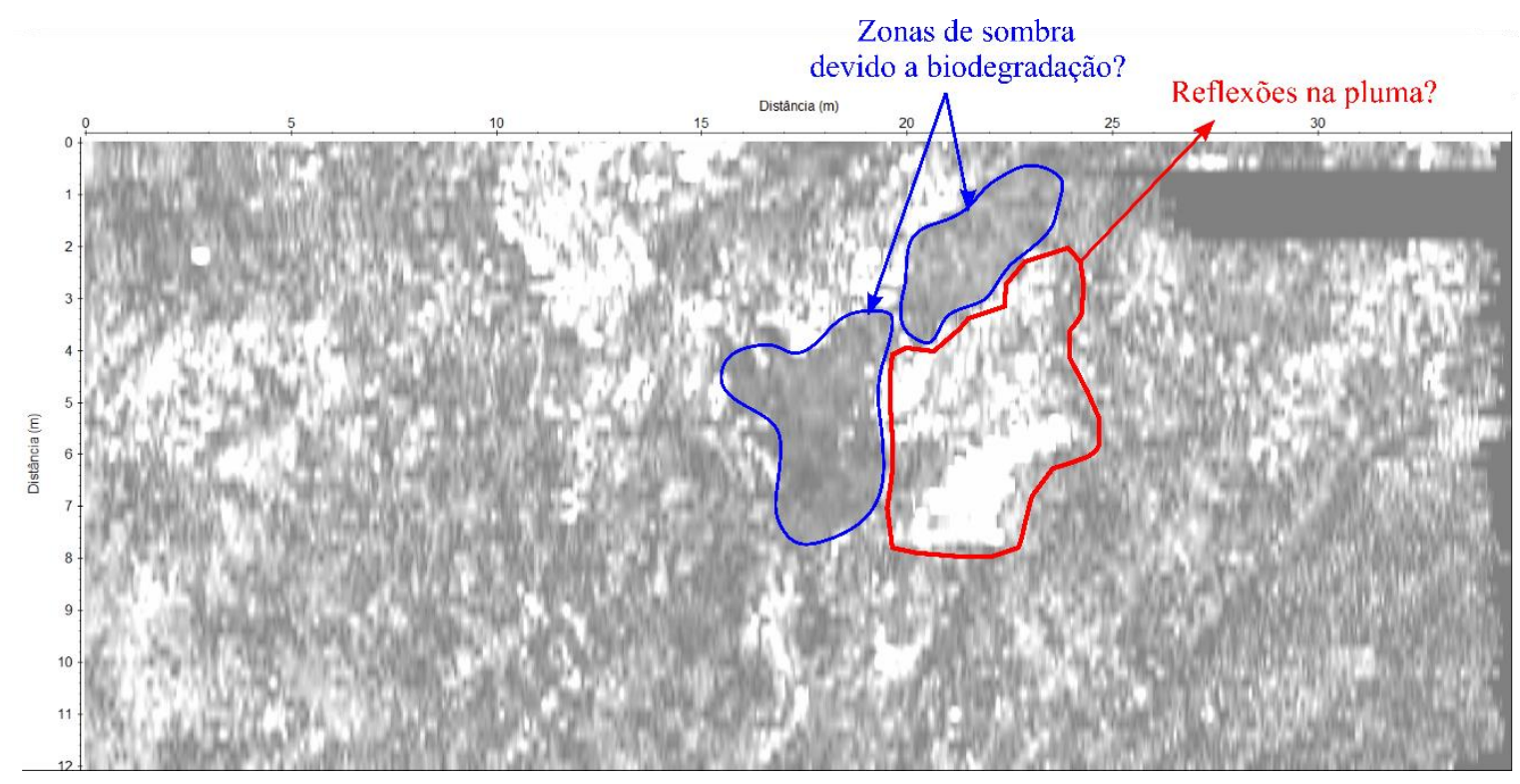

Figura 63. Corte a $20 \mathrm{~cm}$ de profundidade do modelo GPR pseudo-3D de $900 \mathrm{MHz}$ com transformada de Hilbert (Envelope).

Com o processamento dos perfis de aquisições CMP é possível gerar um mapa de velocidades de propagação de ondas EM. Através da expressão da equação (3.26) é possível então calcular valores de constante dielétrica para se obter por fim um modelo pseudo-3D de constante dielétrica. As Figuras 64 e 65 mostram os resultados da interpolação dos valores de constante dielétrica gerando modelos pseudo-3D a partir das aquisições das CMP's.

A Figura 64 mostra o modelo pseudo-3D de constante dielétrica. Nas posições das antigas auto-claves é possível observar anomalias de baixa constante dielétrica, o que é de se esperar já que hidrocarbonetos são caracterizados por constantes dielétricas baixas. Isso mostra a capacidade deste método de processamento em delimitar áreas de interesse. A Figura 65, por sua vez, mostra uma superfície delimitando o valor de constante dielétrica de 20, assim é possível se calcular um volume de solo contaminado caracterizado pela constante dielétrica abaixo desse valor. Baseado nestes dados o volume de solo contaminado foi de $175 \mathrm{~m}^{3}$. 


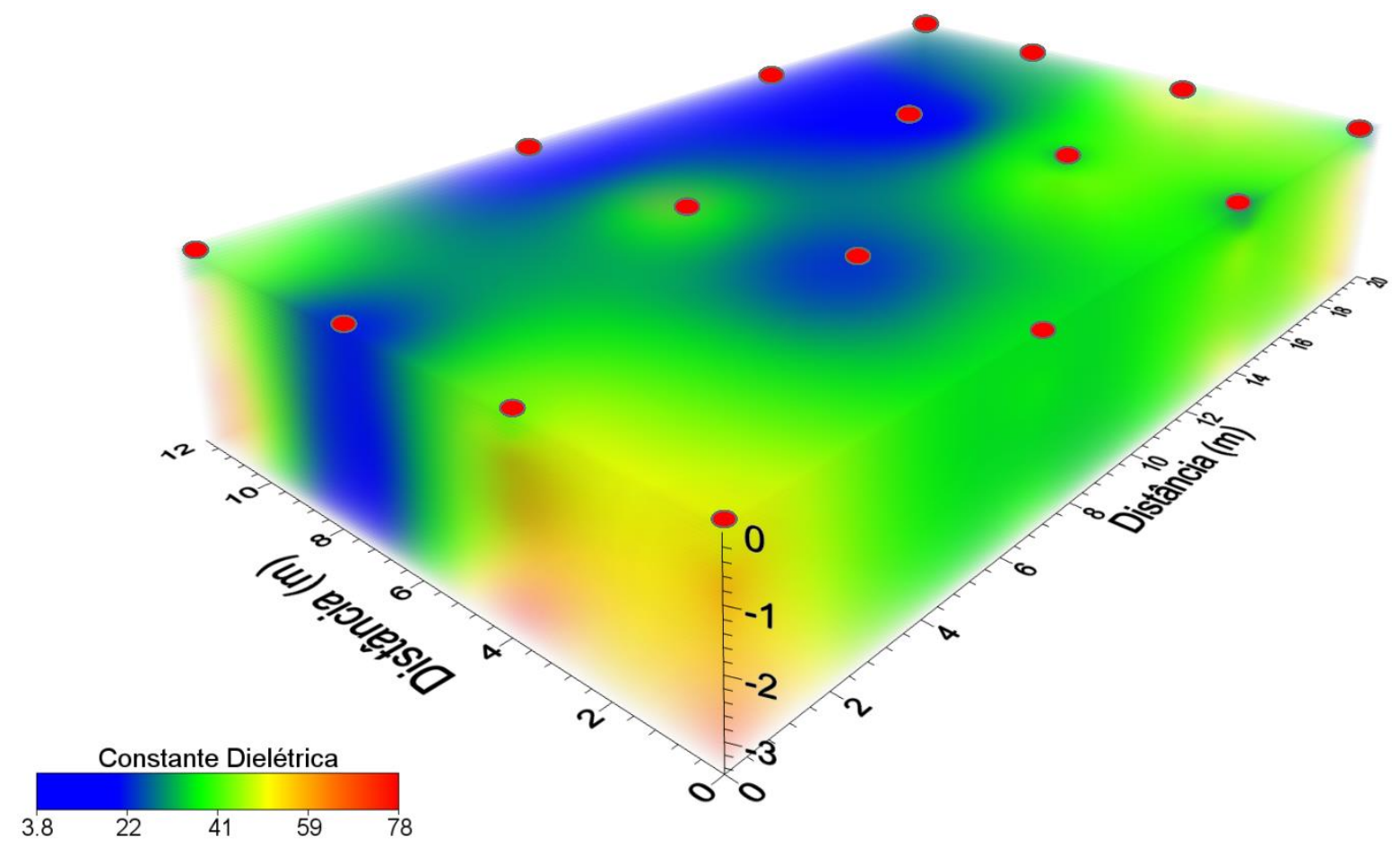

Figura 64. Modelo pseudo-3D de constante dielétrica a partir de processamento CMP. Círculos vermelhos representam as posições das aquisições CMP.

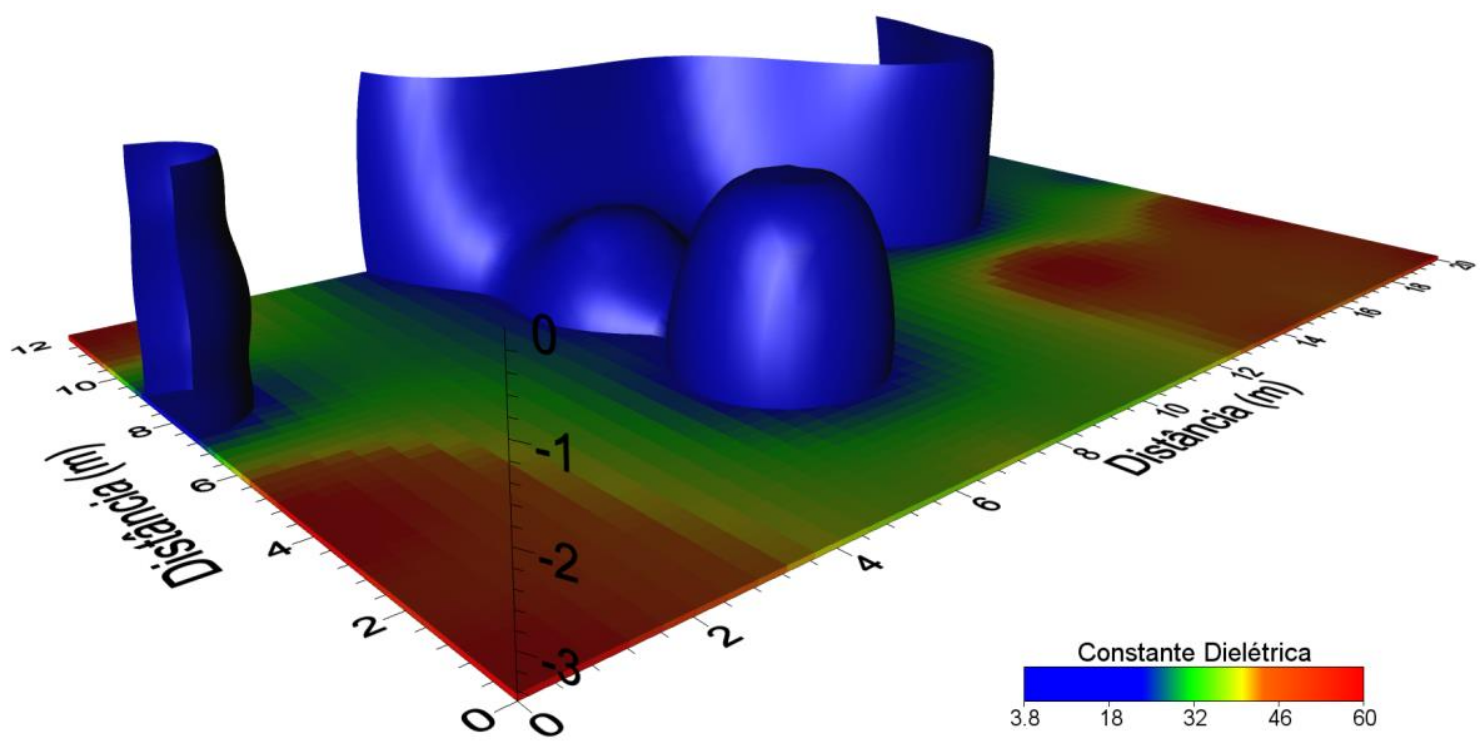

Figura 65. Modelo pseudo-3D de isovalor de constante dielétrica de 20 obtido através do processamento de dados CMP. O volume limitado pelas superfícies é de $175 \mathrm{~m}^{3}$. 


\subsection{ELETRORRESISTIVIDADE (ER)}

A seguir são apresentados os resultados das aquisições com o método ER. As escalas de cores de todos os perfis são as mesmas para facilitar a visualização e interpretação, isso faz com que uma cor que é observada em um perfil tenha o mesmo valor de resistividade dessa cor observada em outro perfil.

A Figura 66 apresenta o perfil da tomografia elétrica da linha de background. De acordo com este resultado os valores naturais para a distribuição de resistividade da área estão entre 60 e 300 Ohm.m. A posição do lençol freático foi inserida com base nas informações das perfurações realizadas na área de estudos. O perfil mostra valores de resistividade um pouco abaixo do esperado de acordo com as medidas de resistividade feitas em laboratório com as amostras do furo Trado 1. Pela Tabela 4, as camadas mais superficiais apresentam resistividades mais altas que os valores observados no perfil. Em contrapartida, as amostras de camadas mais profundas apresentaram resistividades mais baixas do que as observadas no perfil. Isto ocorre pois o processo de geração do perfil (inversão) busca suavizar os contrastes abruptos de resistividade das camadas, gerando assim um modelo que apresenta resistividades intermediárias entre os valores reais mais discrepantes.

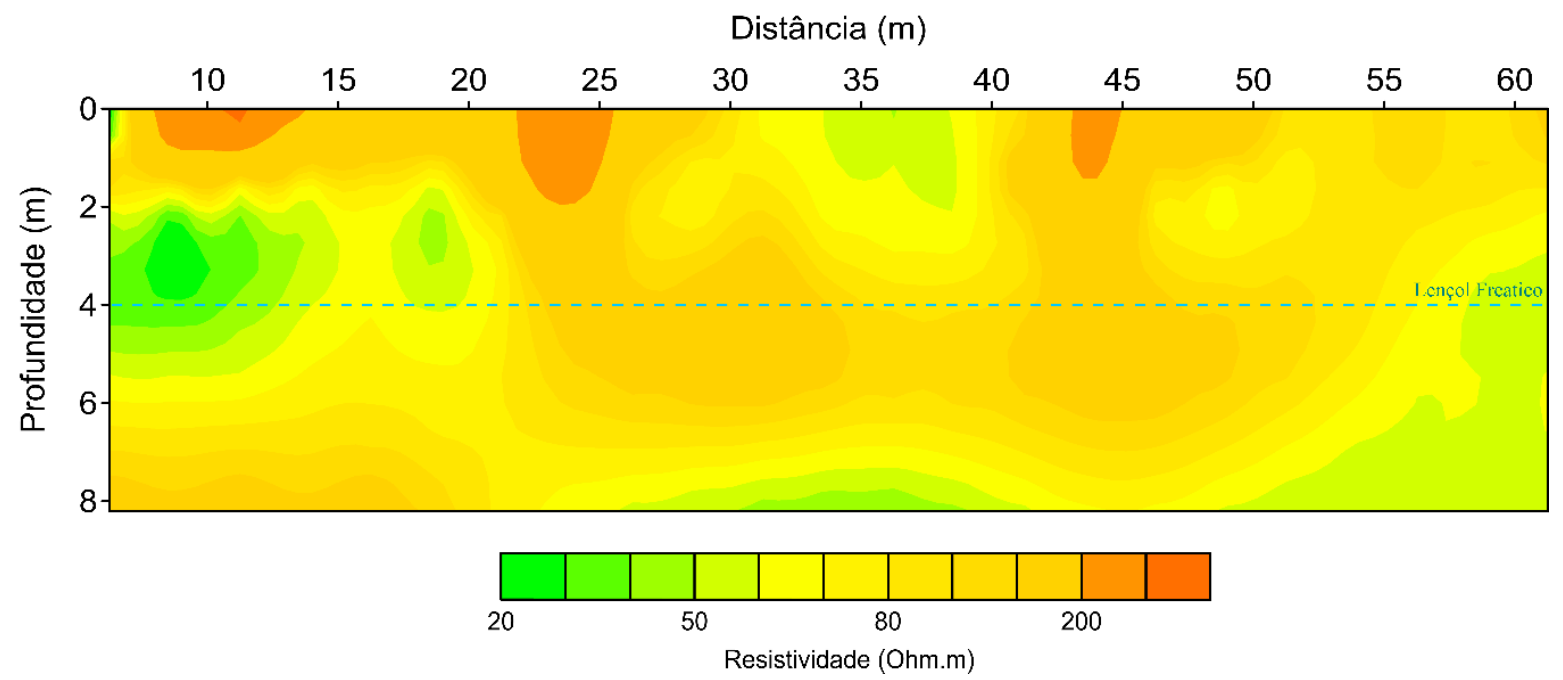

Figura 66. Perfil tomografia elétrica obtida com o método ER sobre a linha de background.

A Figura 67 apresenta o perfil de tomografia elétrica da linha central. Nota-se a presença de anomalias de mais altas resistividades e de anomalias com resistividades mais baixas que os 
valores de background. Esse resultado está de acordo com o experimento de laboratório feito com as amostras de solo da área de estudos, onde para as amostras do furo Trado 2 são observadas resistividades mais baixas e para as amostras com maior concentração de creosoto natural são observadas altas resistividades. As anomalias observadas são interpretadas pelas diferentes fases do contaminante.

A pluma no centro do perfil, entre as posições de 30 e 40 metros, é interpretada como sendo as fases residual e adsorvida do contaminante. Essas fases não possuem mobilidade e ficam estáticas entre os poros (fase residual) e retidas nas superfícies dos grãos por forças eletrostáticas (fase adsorvida), sendo caracterizadas pelo óleo creosoto em seu estado natural com alta resistividade elétrica. De acordo com os resultados do experimento em laboratório apresentados na Figura 39, a concentração de creosoto nesta pluma está em torno de 22\%. A pluma que está localizada no início do perfil, até a posição de 25 metros, se estende até profundidade maiores que 8 metros. Em sua porção mais rasa, nas posições de 15 a 25 metros, a concentração de creosoto está em torno de $8 \%$. A extensão desta pluma abaixo do nível freático é relacionada a fase dissolvida do contaminante. A fase dissolvida migra de acordo com o fluxo do lençol freático. Ambas as plumas identificadas neste perfil apresentam sinais de biodegradação nas extremidades. A biodegradação faz com que o ambiente contaminado se torne mais condutivo devido a diversos fatores já mencionados (Sauck, 2000; Atekwana et al, 2010). Entretanto, para se confirmar a presença de tal processo é necessário a contagem de bactérias em amostra retiradas do local.

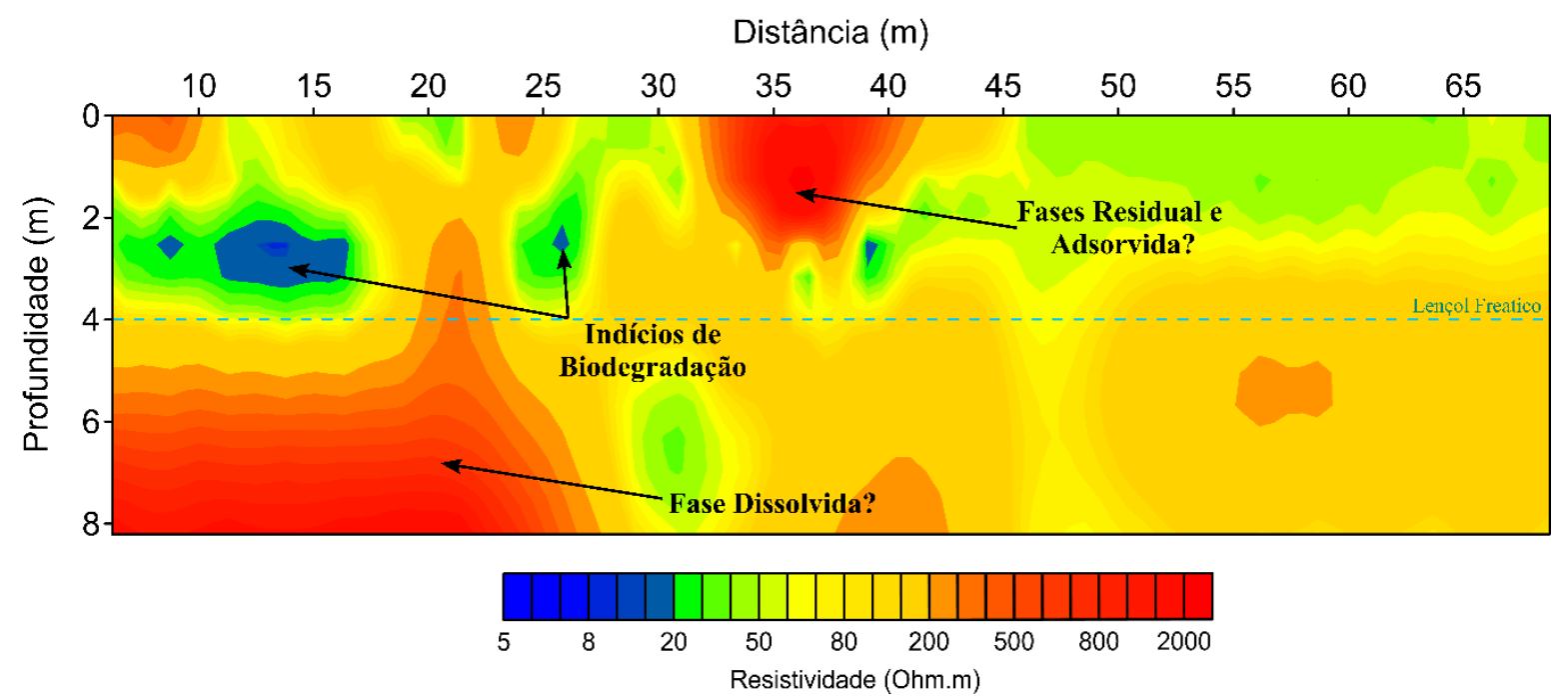

Figura 67. Perfil tomografia elétrica obtida com o método ER sobre a linha central. 
A Figura 68 apresenta o perfil de tomografia elétrica da linha lateral. É observada uma anomalia de alta resistividade no centro do perfil, entre as posições de 30 e $40 \mathrm{~m}$, correspondendo a posição dos antigos tanques de creosoto. Nas extremidades da anomalia de alta resistividade são observadas anomalias com baixas resistividades. Essas anomalias estão relacionadas com a pluma de contaminação, onde na porção mais rasa (até 2 metros de profundidade) se encontram as fases residual e adsorvida mais resistivas do contaminante. Os valores de resistividade em torno de 800 Ohm.m indicam uma concentração de creosoto em torno de $12 \%$ de acordo com a Figura 39. Na porção mais profunda abaixo do nível freático se encontra a fase dissolvida do contaminante, ultrapassando os 8 metros de profundidade. Novamente, as extremidades da pluma sugerem a presença de biodegradação das fases residual e adsorvida. Os resultados reais apresentados nesta figura apresentam uma grande similaridade com a Figura 27 que mostra o resultado de uma modelagem feita com um modelo sintético conceitual de pluma que sofre um processo de biodegradação, portanto, corroborando com a interpretação feita pelo autor.

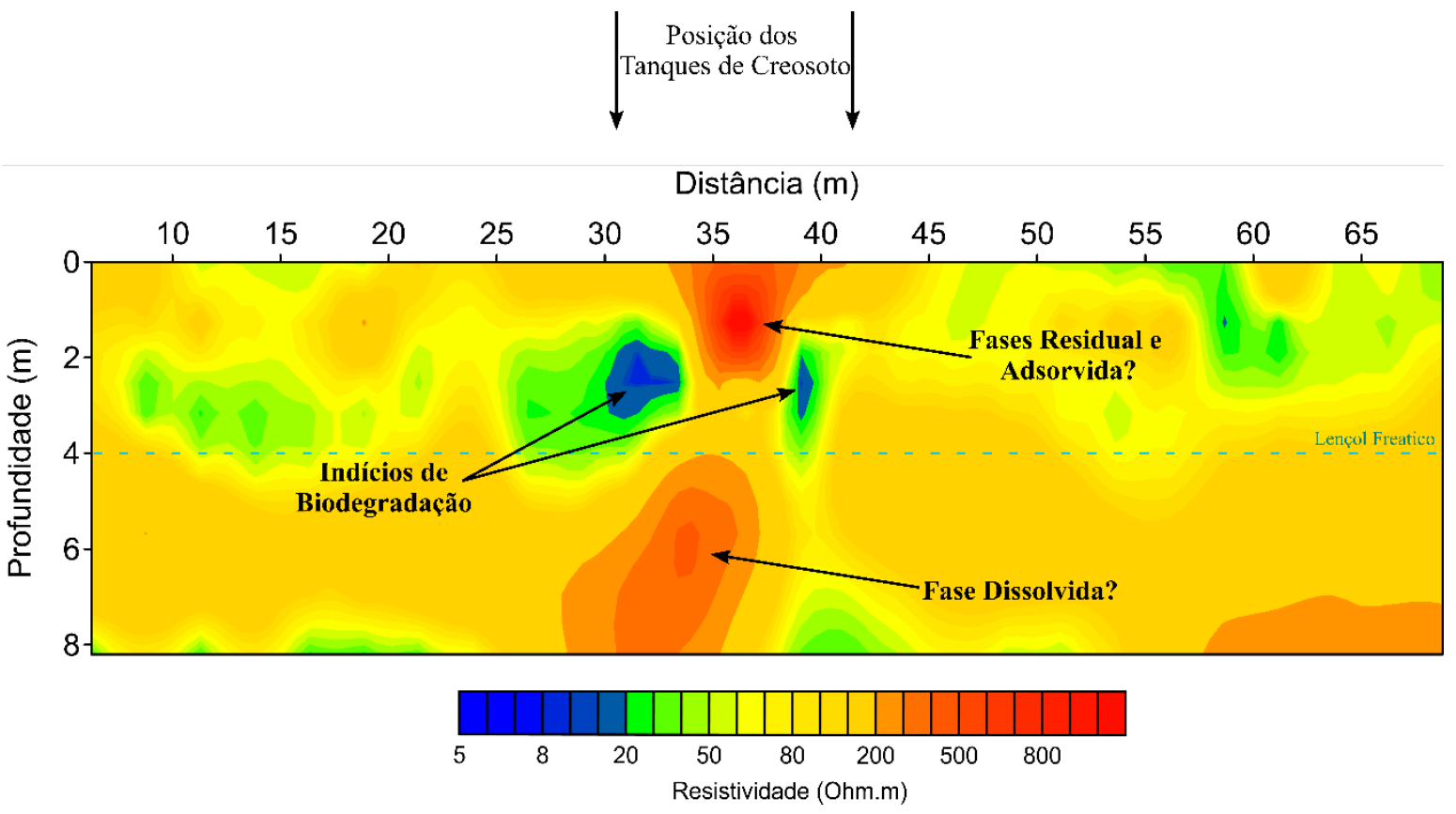

Figura 68. Perfil tomografia elétrica obtida com o método ER sobre a linha lateral. 


\subsection{ELETRORRESISTIVIDADE COM ACOPLAMENTO CAPACITIVO (RC)}

A seguir são apresentados os resultados das aquisições com o método RC. As escalas de cores de todos os perfis, inclusive dos perfis de Eletrorresistividade convencional, são as mesmas para facilitar a visualização e interpretação.

A Figura 69 apresenta o perfil de tomografia elétrica obtido com o equipamento de RC para a linha de background. O resultado mostra que os valores naturais para a área estão entre 40 e 300 Ohm.m. Este resultado está de acordo com os valores obtidos pelo perfil de Eletrorresistividade da Figura 66. De maneira análoga, esses valores estão um pouco abaixo dos valores calculados com base no experimento em laboratório (Tabela 4). A explicação baseada na suavização do modelo pelo processo de inversão também é válida neste caso.

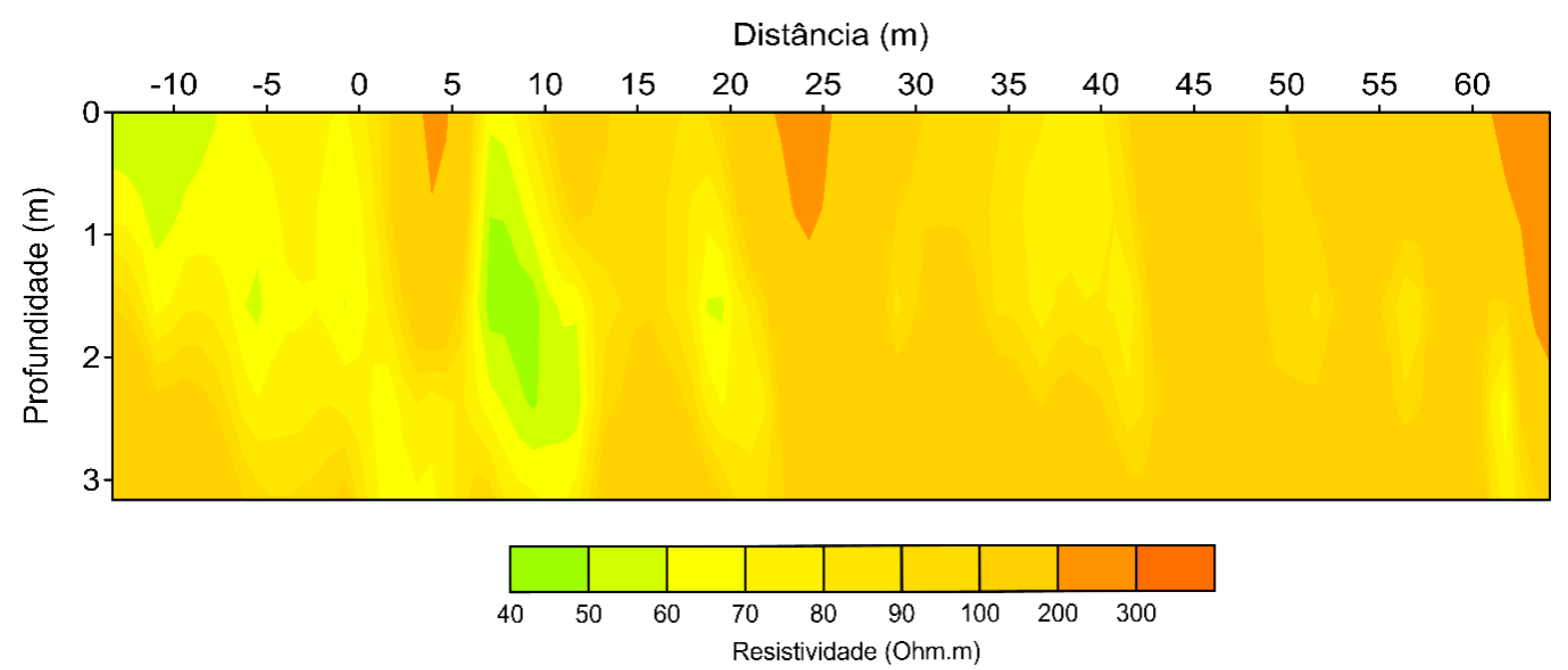

Figura 69. Perfil de tomografia elétrica obtido com o método RC sobre a linha de background.

A Figura 70 apresenta o perfil de tomografia elétrica obtido com o equipamento de RC para a linha de central. São observados dois conjuntos de anomalias de altas resistividades. A primeira, entre as posições -10 e 5 metros ao longo do perfil, se estende além do nível d'água em 4 metros de profundidade. Essa primeira anomalia foi relacionada as fases residual e adsorvida do contaminante, tendo uma concentração de aproximadamente $10 \%$. A segunda, entre as posições 25 e 40 metros ao longo do perfil, também se estende até ultrapassar o nível d'água. Essa segunda anomalia foi relacionada as fases residual e adsorvida do contaminante, tendo uma concentração de aproximadamente 5\%. Ambas as anomalias de alta resistividade apresentam sinais de 
biodegradação nas extremidades, semelhantes aos resultados dos perfis de tomografia elétrica observados nas Figuras 70 e 71.

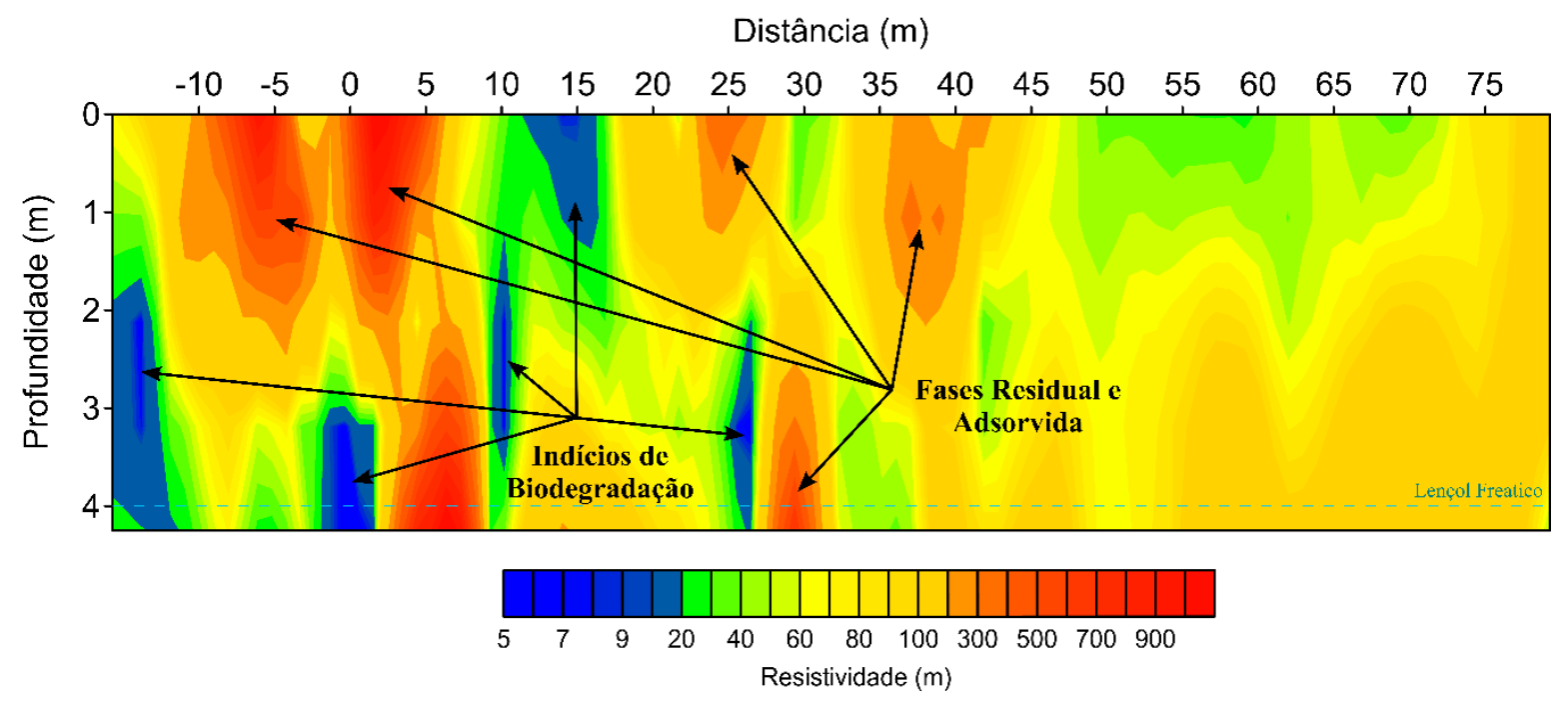

Figura 70. Perfil de tomografia elétrica obtido com o método RC sobre a linha central.

A Figura 71 apresenta o perfil de tomografia elétrica obtido com o equipamento de RC para a linha de lateral. É observada uma anomalia de alta resistividade no centro do perfil, entre 25 e 40 metros, correspondendo a posição dos antigos tanques de creosoto. Esta anomalia está relacionada com a pluma de contaminação. Duas anomalias mais condutivas também são claramente observadas, uma mais rasa na posição de 33 metros e outra mais profunda na posição de 23 metros, adentrando o nível d'água, na extremidade esquerda da pluma mais resistiva. 


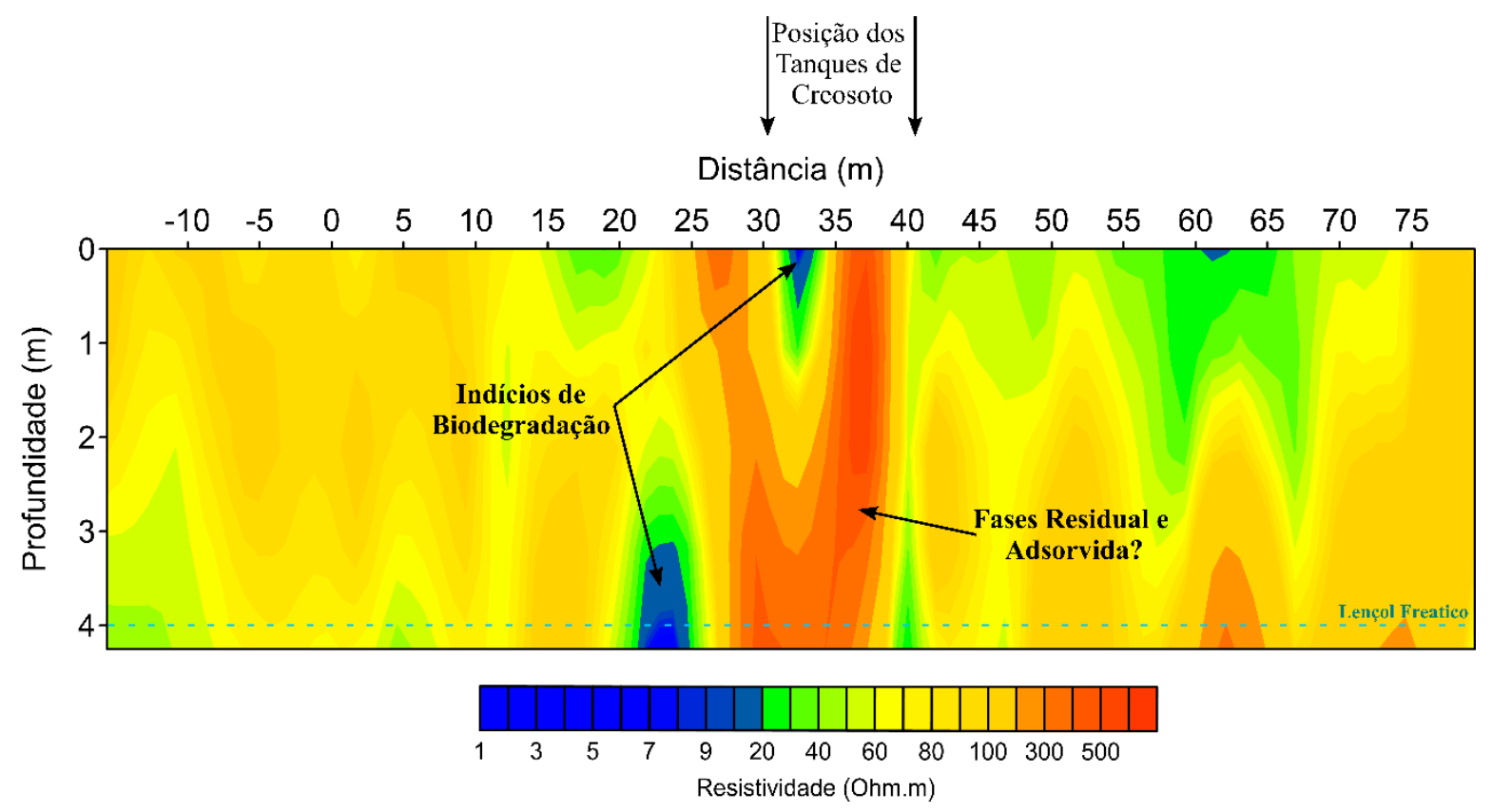

Figura 71. Perfil de tomografia elétrica obtido com o método RC sobre a linha lateral.

Os resultados das inversões dos perfis RC das linhas adquiridas no grid foram interpolados gerando um modelo de resistividade elétrica pseudo-3D (Figura 72). Analisando o histograma de valores de resistividade que compõem o modelo, foi definido o valor de 5000 Ohm.m para o limite superior da escala. Apesar deste limite, os maiores valores de resistividade observados são de mais de 12000 Ohm.m. Nota-se no modelo pseudo-3D que existem duas plumas com alta resistividade na área da antiga auto-clave. As resistividades no centro de uma das plumas chegam 9.000 Ohm.m, o que corresponde a uma concentração de contaminante muito alta de mais de $38 \%$. As plumas ultrapassam o limite de 4 metros de profundidade do modelo, o que mostra que o contaminante ultrapassa o nível d'agua. A pluma com maior extensão tem seu centro localizado na posição de $(17,8)$. O centro da pluma correspondente a posição da antiga autoclave está na posição $(25,8)$. Considerando um valor de resistividade de 1000 Ohm.m, as superfícies delimitadas por esse valor englobam um volume de $80 \mathrm{~m}^{3}$ (Figura 73). Este é considerado o volume total estimado de solo contaminado somente dentro da área englobada pelo modelo. 


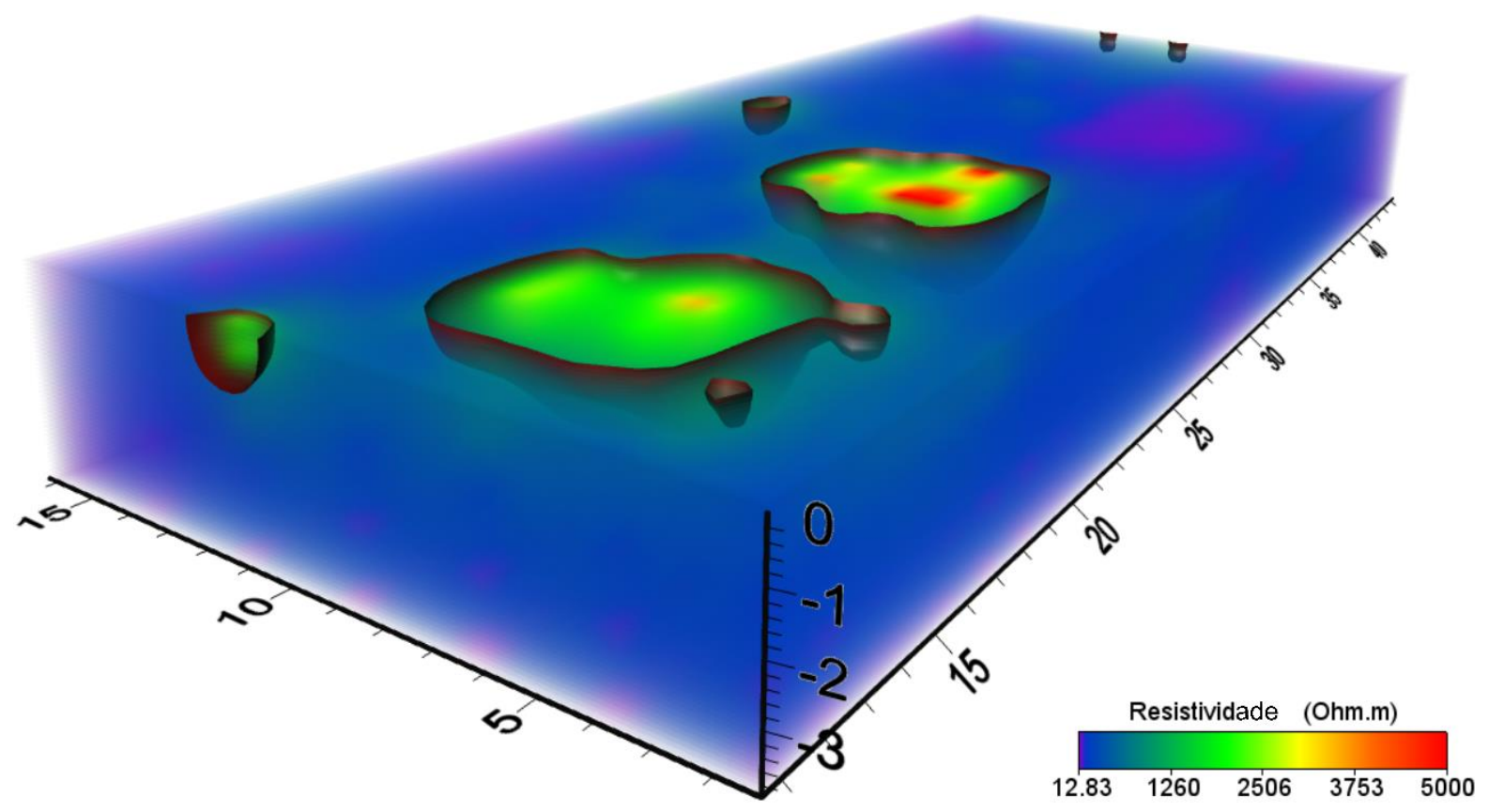

Figura 72. Modelo de resistividade elétrica pseudo-3D obtido com a interpolação dos modelos $2 \mathrm{D}$ de Eletrorresisividade Capacitiva (RC).

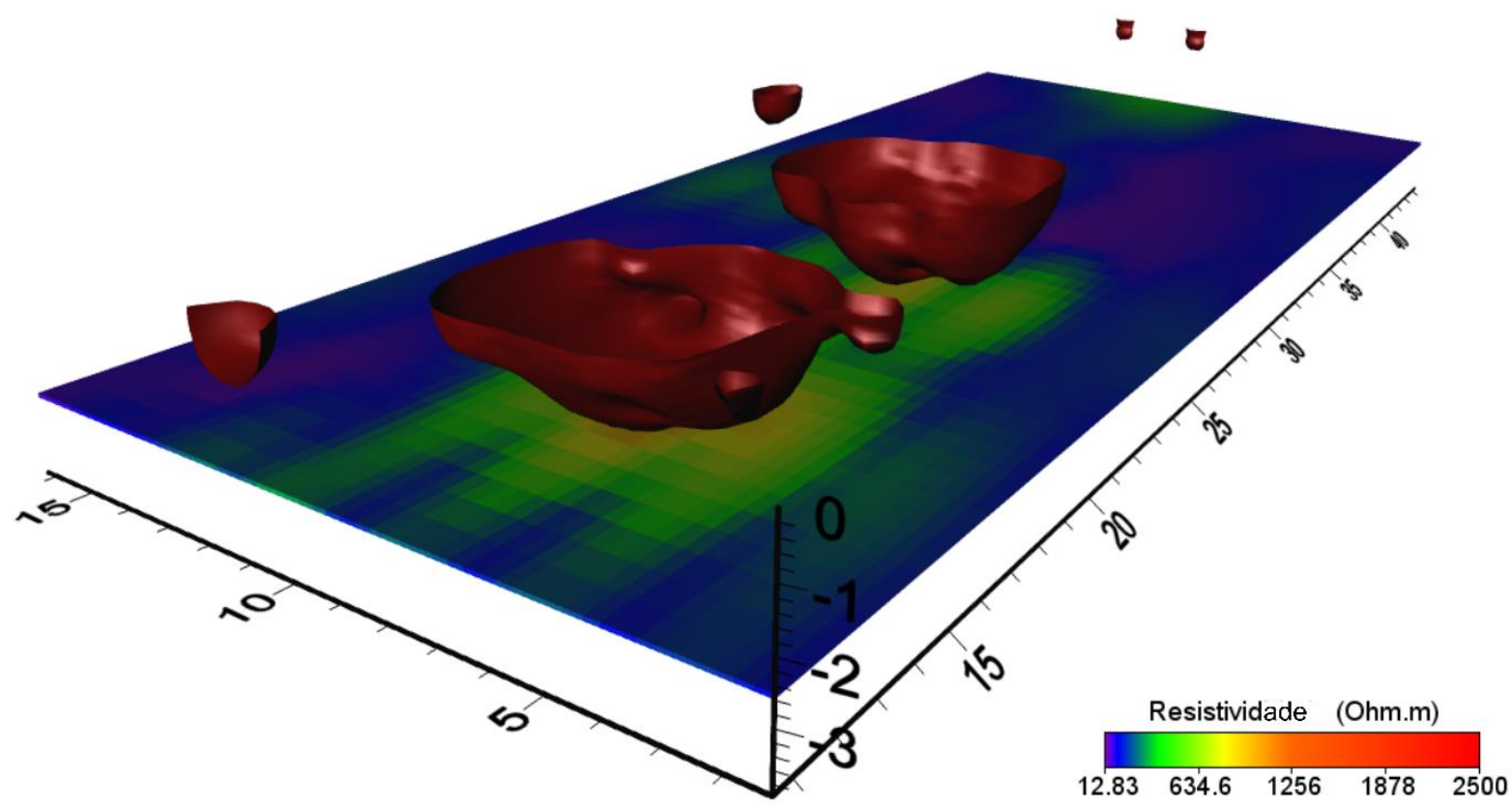

Figura 73. Modelo pseudo-3D de isovalor 1000 Ohm.m obtido com interpolação dos perfis de Eletrorresisividade Capacitiva (RC). O volume limitado pelas superfícies é de $80 \mathrm{~m}^{3}$. 


\section{CAPÍTULO 6}

\section{DISCUSSÃ̃}

\subsection{EXPERIMENTOS EM LABORATÓRIO}

\subsubsection{Medidas de Resistividade das Amostras de Solos}

As medidas em laboratório da resistividade elétrica das amostras coletadas em campo assim como o experimento de aumento da concentração de óleo creosoto foram de extrema importância para entender os resultados da utilização dos métodos geofísicos (GPR, ER e RC) sobre a área de estudos.

Com a análise da Tabela 4, nota-se que os solos contaminados coletados na área de estudos apresentaram menores resistividades se comparado aos solos não contaminados. Isso era de se esperar uma vez que processos de biodegradação são naturais de áreas contaminadas por décadas (long-term contaminated sites). Esses processos alteram as propriedades eletromagnéticas naturais para a mistura solo e contaminante. Assim, regiões onde teriam características resistivas passam a ter características mais condutivas. Os processos de biodegradação que levam a isso são muitos e podem ser encontrados em trabalhos listados nas referências (Sauck, 2000; Atekwana et al, 2000; Atekwana \& Atekwana, 2010).

O experimento de aumento da concentração de creosoto nas amostras mostra que as características geoelétricas naturais para a mistura de contaminante mais solo são altamente resistivas. Isto fica evidente nos dados observados nas Figuras 42 a 44 onde é possível observar um aumento rápido dos valores de resistividade conforme a concentração de contaminante aumenta nas amostras. Foi constatado um limite experimental de medição diferente para os três diferentes tipos de solos. O solo argiloso vermelho, por exemplo, teve seu limite de leitura no resistivímetro para concentrações em torno de $36 \%$, enquanto o solo argiloso cinza intermediário teve o limite para concentrações em torno de $18 \%$. A areia por sua vez teve um limite em torno de $12 \%$. 


\subsubsection{Resultados das Aquisições e Análise Espectral GPR}

Os resultados do experimento de aquisições GPR e análise espectral dos dados foram muito importantes para se avaliar a capacidade do método na caracterização da contaminação em situações reais de campo. Com esses resultados foi possível observar tanto as características da contaminação no domínio do tempo (radargrama) quanto no domínio da frequência (espectrograma). Este experimento criou uma referência para se interpretar os resultados reais da análise espectral pois permite avaliar o impacto da contaminação no espectro do sinal em ambiente controlado.

Para os dados no domínio do tempo foi possível observar tanto na argila quanto na areia a caracterização da presença do contaminante. No caso do experimento na caixa de argila foi observado que a presença do contaminante pode ser notada pela sutil reflexão no centro do perfil da Figura 43. Esta reflexão tem amplitude parecida com a reflexão encontrada no centro do perfil da Figura 42. Isto mostra que uma heterogeneidade no solo pode também levar a interpretações equivocadas devido a semelhanças das anomalias geradas pelo contaminante e por heterogeneidades naturais do solo. No caso do experimento na caixa de areia foi observado que a presença do contaminante também pode ser notada por uma reflexão no centro do perfil da Figura 45. Esta reflexão por sua vez é mais evidente que a reflexão encontrada na contaminação da argila. Isto mostra que um ambiente arenoso mais homogêneo pode caracterizar um meio mais propicio para a caracterização do contaminante. Se comparado ao solo argiloso utilizado para o experimento, este solo arenoso é muito mais selecionado e proporcionou uma ótima caracterização do contaminante enterrado.

Para os dados no domínio da frequência também foi possível observar tanto na argila quanto na areia a caracterização da presença do contaminante. No caso do experimento na caixa de argila foi possível notar que a FC de operação em $2600 \mathrm{MHz}$ foi subestimada uma vez que as maiores amplitudes estão em frequências mais baixas, em torno de $1500 \mathrm{MHz}$. Isto é esperado principalmente para antenas de mais altas frequências como explicado pelo pesquisador Dr. Vinícius Rafael Neris dos Santos em seu trabalho de pesquisa (Santos, 2014). Foi observado neste caso que na posição central do perfil, na Figura 46a, existe uma anomalia no espectrograma com uma amplitude de aproximadamente 0,3 a 0,4 associada a frequências entre 1000 e $2000 \mathrm{MHz}$. No caso da Figura 46b, observou-se que na mesma região a anomalia diminui de amplitude, para amplitudes de aproximadamente 0,1 a 0,2 . Isto mostra que a presença do contaminante faz com 
que as amplitudes diminuam na região da FC de operação, levando em conta que a FC é subestimada na transformada STFT (Short Time Fourier Transform) (Santos, 2014).

No caso do experimento na caixa de areia foi possível notar um ruído de baixa frequência nos dados caracterizados por altas amplitudes associadas a frequências próximas de zero. Apesar disso, nota-se que a presença do contaminante faz com que as amplitudes na região contaminada diminuam com relação a FC de operação, conforme observado na Figura 47. A Figura 47a mostra a distribuição de amplitudes para a areia sem contaminação. Nota-se que as amplitudes se distribuem de forma homogênea ao longo do perfil, sendo observado o ruído de baixa frequência. No caso da Figura 47b nota-se que na posição do contaminante as amplitudes não mais se distribuem uniformemente, tendo uma diminuição da mesma para a FC de operação. Isto mostra novamente que o impacto do contaminante é de diminuir as amplitudes para a FC de operação. Ao fim do experimento foi possível constatar a capacidade do método GPR de caracterizar uma contaminação por creosoto.

\subsection{GROUND PENETRATING RADAR (GPR)}

O GPR foi uma metodologia importante nesta pesquisa uma vez que conseguiu caracterizar com boa resolução a estratigrafia rasa da área de estudo. Além disso, os resultados mostram que o método foi capaz de detectar também a contaminação, sendo, para cada linha, a contaminação caracterizada por diferentes aspectos do sinal.

A linha de background serviu como uma referência para a área de estudo e principalmente para a caracterização da estratigrafia rasa da área. O emprego das diferentes frequências (200, 270, 400 e $900 \mathrm{MHz}$ ) permitiu a caracterização da estratigrafia, com cada uma das frequências podendo atingir diferentes profundidades como era esperado. Foi possível identificar principalmente três interfaces estratigráficas caracterizando quatro camadas. A primeira parte mais rasa corresponde a camada de paralelepípedo. A primeira camada observada, em torno de $30 \mathrm{~cm}$ de profundidade, corresponde a interface entre o aterro e o solo argiloso vermelho. A segunda camada observada, em torno de 1,0 metro de profundidade, corresponde a interface entre o solo argiloso vermelho e o solo argiloso cinza escuro. A terceira camada observada, em torno de 1,7 metros de profundidade, corresponde a interface entre o solo argiloso cinza escuro e o solo argiloso preto. Após a camada de solo argiloso preto o sinal é atenuado devido a maior condutividade desta camada e nem mesmo a antena de $200 \mathrm{MHz}$ conseguiu definir mais camadas abaixo deste solo. 
A linha central está localizada nas posições das antigas autoclaves onde a contaminação foi confirmada. Neste caso os resultados GPR mostram diferentes sinais que podem estar associados a contaminação e assim permitindo a sua caracterização. $O$ acúmulo de contaminante sobre uma interface com condutividade hidráulica mais baixa faz com que o contraste de permissividade dielétrica entre as argilas da área seja maior, proporcionando assim uma reflexão com maior amplitude. Este tipo de sinal é observado em todos os perfis desta linha. Além disso, o óleo creosoto em seu estado intacto, ou seja, natural, é altamente resistivo, permitindo uma maior penetração do sinal onde a concentração de creosoto é maior. Este aspecto é encontrado na Figura 54 onde se tem uma maior penetração do sinal na região associada a antiga autoclave.

A linha lateral está localizada exatamente sobre a posição dos antigos tanques de creosoto onde a contaminação também foi confirmada. Neste caso os resultados GPR foram importantes, caracterizando de forma nítida a região contaminada. A contaminação foi caracterizada por uma zona sem reflexões com relação a segunda interface. A expressão "zona sem reflexões" está sendo utilizada para caracterizar a invisibilidade de uma reflexão devido a presença do creosoto que faz com a interface entre duas argilas seja imperceptível devido a homogeneização do valor de permissividade dielétrica de uma camada com relação a outra.

A análise do espectro de amplitude através da aplicação da STFT se mostrou eficiente na caracterização da contaminação nos dados reais. A contaminação na linha lateral foi caracterizada inicialmente pelo radargrama, porém a análise espectral confirmou os resultados. Foi possível observar a diminuição esperada das amplitudes com relação a FC de operação. Isto foi observado com clareza principalmente para a antena de $200 \mathrm{MHz}$ na Figura 60 e está de acordo com o experimento em laboratório de análise espectral.

No caso do modelo GPR pseudo-3D foi possível observar tanto zonas de reflexões com maiores amplitudes quanto zonas de sombra caracterizando regiões de mais alta condutividade. As reflexões estão associadas a presença do contaminante depositados nas argilas da área de estudos. As zonas de sombra por sua vez estão associadas a regiões com biodegradação onde a condutividade aumenta, como já era esperado.

Com os levantamentos CMP foi possível a geração de um modelo pseudo-3D tanto de velocidades quanto de constante dielétrica. Nesta pesquisa foi apresentado apenas o modelo de constante dielétrica uma vez que os modelos são conceitualmente iguais, já que a relação entre eles é dada pela equação (3.26). Na Figura 64 é possível notar que existe uma região caracterizada por 
constante dielétrica mais baixa que está localizada sobre as posições das antigas auto-claves onde foi constatada a contaminação. Este resultado mostra a capacidade deste método de processamento em caracterizar o solo contaminado através da constante dielétrica. Na Figura 65 tem-se uma isosuperfície de constante dielétrica de 20 para caracterizar o volume de solo contaminado baseado nesta superfície. Considerando como sendo o solo contaminado valores de constante dielétrica abaixo deste valor temos um volume de $80 \mathrm{~m}^{3}$ de solo contaminado apenas nesta região dentro do modelo de aquisição CMP.

\subsection{ELETRORRESISTIVIDADE (ER)}

O emprego do método ER juntamente com os experimentos em laboratório e ainda o emprego do método RC foram de extrema importância para a caracterização do contaminante. A utilização conjunta dos dados de laboratório permitiu, além de caracterizar as plumas de contaminação, também estimar a concentração de creosoto em cada pluma.

A linha de background (Figura 66) foi caracterizada por valores de resistividade entre 50 e 300 Ohm.m, definindo então os valores naturais para a área de estudo. A questão da diferença entre os valores apresentados na Tabela 4 medidos nas amostras em laboratório e os valores obtidos pelo método ER já foi comentado sendo associado ao processo de inversão geofísica. A linha central (Figura 67) apresentou plumas bem definidas de alta resistividades. As anomalias caracterizadas por menores valores de resistividades elétricas observadas associadas as plumas sugerem a existência de processos de biodegradação que ocorrem nas extremidades das plumas.

A linha lateral (Figura 68) apresentou um excelente resultado que tem uma ótima correspondência com o resultado sintético da modelagem utilizando o modelo conceitual de pluma de contaminação que sofre biodegradação (Figura 27). A análise somente dos dados geofísicos do método ER pode levar a interpretações equivocadas de que as anomalias de resistividades mais baixas poderiam ser decorrentes de pontos espúrios ou ruídos nos dados e que deveriam ser removidos. Porém baseado na modelagem e nas medidas de resistividade das amostras (Tabela 4) nota-se que as anomalias devem ser mantidas pois tratam-se de valores reais de resistividades elétricas das plumas. 


\subsection{ELETRORRESISTIVIDADE COM ACOPLAMENTO CAPACITIVO (RC)}

A aplicação deste método permitiu uma rápida aquisição de uma grande quantidade de dados permitindo principalmente a geração de um modelo de resistividade elétrica pseudo-3D. Além disso permitiu a confirmação dos dados observados na aplicação do método ER, apesar do método RC ter uma menor profundidade de investigação.

A linha de background (Figura 69) pode ser analisada em conjunto com os resultados da linha de background do método ER. O resultado mostra que os valores naturais para a área estão entre 40 e 300 Ohm.m, o que está de acordo com o observado para o resultado do método ER (Figura 66). A linha central (Figura 70) mostra que este método também é capaz de caracterizar as plumas de contaminação. Assim como no caso do método ER, neste caso também foi possível observar anomalias de mais baixas resistividades que são associadas ao contaminante biodegradado.

A linha lateral tem um resultado também adequado se comparado ao perfil da Figura 68. Também foi possível delimitar a pluma de contaminação resistiva assim como suas anomalias mais condutivas. Apesar do emprego do método RC proporcionar uma profundidade de investigação mais limitada, com este método foi possível a caracterização das plumas.

O modelo de resistividade elétrica pseudo-3D foi construído para se avaliar de forma geral a capacidade do método em delimitar as plumas de contaminação. A Figura 72 mostra que existem não somente uma pluma na área que engloba o modelo, mas sim duas plumas principais. Isto está de acordo com os resultados da linha central tanto do método RC quanto do método ER. Com o auxílio do experimento em laboratório de aumento da concentração de creosoto em amostras de solos foi possível delimitar a resistividade de 1000 Ohm.m como sendo característica de solo contaminado. Assim, fixando esse valor foi calculado uma isosuperfície e assim calculou-se o volume de solo contaminado através deste método. A Figura 73 mostra que para um isovalor de 1000 Ohm.m o volume de solo contaminado é de $80 \mathrm{~m}^{3}$. 


\section{CAPÍTULO 7}

\section{CONCLUSÕES}

O emprego dos métodos geofísicos GPR, Eletrorresistividade (ER) e Eletrorresistividade com Acoplamento Capacitivo (RC) permitiram a detecção e a caracterização de uma contaminação por hidrocarboneto creosoto. Os experimentos em laboratório foram imprescindíveis para validar uma boa interpretação dos resultados dos métodos geofísicos. Os experimentos de medida de resistividade das amostras e de saturação com óleo creosoto foram de extrema importância para a interpretação dos resultados dos três métodos geofísicos. O experimento em laboratório das aquisições GPR também foram importantes para a interpretação dos resultados GPR da área de estudos.

A metodologia GPR foi capaz de detectar a presença do contaminante na área de estudos. A aquisição sobre a linha de background proporcionou a caracterização estratigráfica da área que foi confirmada com as perfurações. A aquisição sobre a linha central mostrou que o acúmulo de contaminante sobre as camadas de argila geram tanto reflexões como zonas onde se observa maior penetração do sinal. A aquisição sobre a linha lateral mostrou que a presença do contaminante pode gerar zonas sem reflexão com respeito a interfaces entre as argilas. O modelo GPR pseudo-3D foi capaz de detectar e estimar a forma e extensão de uma das plumas. Além disso, o modelo pseudo3D mostrou que a presença do contaminante gera ainda zonas de reflexões e zonas de sombra.

A análise espectral dos sinais GPR foram capazes de auxiliar na detecção das plumas de contaminação, embora sejam necessários mais estudos acerca desta metodologia. As aquisições CMP proporcionaram a geração de um modelo pseudo-3D de constante dielétrica que foi capaz de delimitar as áreas com contaminação e também permitiu se estimar um volume de solo contaminado baseado em valores de constante dielétrica.

A metodologia ER foi capaz de identificar e estimar as dimensões das plumas de contaminação. Apesar das dificuldades durante aquisições sobre a área devido às limitações do terreno, os resultados foram excelentes e estão de acordo com a modelagem feita utilizando um modelo conceitual de pluma de contaminação com processo de biodegradação. A linha de background foi utilizada para se criar valores naturais de referências da área de estudos. As linhas 
central e lateral apresentaram bons resultados mostrando a capacidade do método em mapear plumas de contaminação.

A metodologia RC também foi capaz de identificar e estimar as dimensões das plumas de contaminação. Para terrenos com cobertura de concreto e paralelepípedo, como foi o caso, este método configura a forma ideal de se obter a distribuição de resistividade elétrica de subsuperfície. O que se deve levar em consideração é a menor profundidade de investigação se comparado ao método ER. A forma ágil e possibilidade da coleta de grande quantidade de dados a serem adquiridos que foi proporcionado pelo emprego deste método possibilitou a geração de um modelo de resistividade elétrica pseudo-3D o qual foi possível determinar o volume de solo contaminado.

Por fim, recomenda-se a análise em laboratório das amostras de solos a fim de se confirmar a existência de processos de biodegradação. Esta análise consiste na detecção, classificação e contagem de bactérias capazes de se alimentar de hidrocarbonetos. Recomenda-se ainda um levantamento RC em todo o setor de tratamento químico a fim de se construir um modelo pseudo3D para a localização e estimativa de volume de todas as plumas de contaminação na área de estudos. 


\section{Referências}

Almeida, E. R. 2016. Análise da tomografia de micro-ondas em dados GPR sob condições controladas: aplicações em arqueologia e estudos forenses. Tese de Doutorado. Instituto de Astronomia, Geofísica e Ciências Atmosféricas. Universidade de São Paulo.

Annan, A. P., Davis, J. L., 1976. Impulse radar sounding in permafrost. Radio Science, v. 11, n. 4, p. 383-394.

Annan, A. P., Davis, J. L., Gendzwill, D. 1988. Radar sounding in potash mines, Saskatchewan, Canada. Geophysics, v. 53, n. 12, p. 1556-1564.

Annan, A. P. 1992. Ground penetration radar workshop notes. Sensors \& Software, Inc., Internal Report, p. 130.

Annan, A. P. \& Cosway, S.W. 1992. Ground penetration radar survey design. Synposium on the application of geophysics to engineering and environmental problems, 5ft, 1992, Oakbrook, Illinois. Proceedings, Oakbrook, SAGEEP, v.2, p.329-352.

Annan, A. P. 1996. Transmission dispersion and GPR. JEEG, Vol. 0, January 1996, pp. 125-136.

Annan, A. P. 2003. Ground penetrating radar: Principles, procedures \& applications. Sensors \& Software Inc. Technical Paper.

Aranha, R. A. M., Magalhães, V.M., Mendes, P., et al. 2020. Characterization and Partitioning Behavior of Creosote in Different Matrices: Soil, Water, and Air. Water Air Soil Pollut 231, 402. doi.org/10.1007/s11270-020-04772-y

Atekwana, E. A., Sauck, W. A., Werkema, D. D. J. 2000. Investigations of geoelectrical signatures at a hydrocarbon contaminated site. Journal of Applied Geophysics. 442000 167-180.

Atekwana, E. A., Atekwana, E. A. 2010. Geophysical Signatures of Microbial Activity at Hydrocarbon Contaminated Sites: A Review. Survey Geophysics. 31:247-283. doi.org/10.1007/s10712-009-9089-8.

Barker, R. D. 1989. Depth of investigation of colinear summetrical four-electride arrays. Geophysics. Vol. 54: 1031 - 1037.

Bertolla, L., Porsani, J. L., Soldovieri, F., Catapano, I. 2014. GPR-4D monitoring a controlled LNAPL spill in a masonry tank at USP, Brazil. Journal of Applied Geophysics, v. 103, p. 237-244.

Borges, W. R. 2002. Investigações Geofísicas na Borda da Bacia Sedimentar de São Paulo, utilizando-se GPR e eletrorresistividade. Dissertação de Mestrado. Instituto de Astronomia, Geofísica e Ciências Atmosféricas, IAG/USP, 153p.

Borges, W. R. et al. 2010. Aplicação de geofísica forense na busca de vestígios de pessoas desaparecidas na guerrilha do Araguaia. IV Simpósio Brasileiro de Geofísica. Brasília, p. 1-7. 
Braga, A. C de O. 1997. Métodos Geoelétricos aplicados na caracterização geológica e geotécnica Formações Rio Claro e Corumbataí, no município de Rio Claro SP, Rio Claro, SP. Tese de Doutorado, Instituto de Geociências e Ciências Exatas, UNESP, Campus de Rio Claro SP, 169p.

Campbell, D.L., Lucius, J.E., Ellefsen, K.J., Deszcz-Pan, M. 1996. Monitoring of a controlled LNAPL spill using ground penetrating radar. Proceedings of the Symposium on the Application of Geophysics to Engineering and Environmental Problems SAGEEP '96, Ž . Keystone, CO, pp. 511-517.

Carcione, J. M., Marcak, H., Seriani, G., Padoan, G. 2000. GPR modeling study in a contaminated área of krzywa Air Base (Poland). Society of Exploration Geophysicits. Institute of Geophysics, University of Mining and metallurgy, Al, Mackiewieza 30, 30-059 kraków, Poland.

Castro, L. D., Branco, R.M.G.C. 2003. 4-D ground penetrating radar monitoring of a hydrocarbon leakage site in Fortaleza (Brazil) during its remediation process: a case history. Jounrnal of Applied Geophysics 54:127-144

Cavenaghi, V. L. S. 2017. Caracterização geoelétrica de alvos rasos no sítio controlado de geofísica rasa II - IAG/USP através do uso de resistividade capacitiva. Dissertação de Mestrado. Instituto de Astronomia, Geofísica e Ciências Atmosféricas. Universidade de São Paulo.

Craig, B. 1998. Predicting the Conductivity of Water-in-Oil Solutions as a Means to Estimate Corrosiveness. NACE international, MetCorr, 4600 S. Ulster St., Suite 700, Denver, CO 80237.

Cutrim, O. A. 1999. Hidrogeologia, Demanda e Consumo de Água em Rondonópolis-MT: Subsídios para o Desenvolvimento Urbano Sustentável. Tese de Doutorado, Instituto de Biociências, UFMT, 215p.

Daniels, J. J., Roberts. R., Vendi, M. 1992. Site Studies of Ground Penetrating Radar for Monitoring Petroleum Product Contaminants. Proceedings of the Symposium on the Application of Geophysics to Engineering and Environmental Problems.

Daniels, D. J. 2004. Ground Penetrating Radar 2nd Edition. Institution of Electrical Engineers, London, United Kingdom.

Elis, V.R. 1999. Avaliação da aplicabilidade de métodos elétricos de prospecção geofísica no estudo de áreas utilizadas para disposição de resíduos, Tese de Doutorado, Instituto de Geociências e Ciências Exatas, UNESP, Campus de Rio Claro - SP, 264 p.

Evans, S. 1967. Progress report on radio echo sounding. The polar record, v. 13, n. 85, p. 413-420.

Freitas, L. G., Gandolfo, O. C. B. 2015. Integração de métodos geofísicos com a sonda MIP para caracterização estratigráfica de uma área contaminada. Conference: $15^{\circ}$ Congresso Brasileiro de Geologia de Engenharia e Ambiental.

Geotomo. 2002. RES2DMOD. Ver. 3.01. Rapid 2D resistivity forward modelling using the finite difference and finite-element methods. User's Manual. 15p. 
Geotomo. 2003. RES2DINV Version 3.53. for Windows 98/ME/2000/NT/XP. Rapid 3D resistivity; Ip inversion using the least-squares method. User's Manual, 66p.

Giannakis, I., Giannopoulos, A., Warren, C. 2020. A machine learning scheme for estimating the diameter of reinforcing bars using ground penetrating radar. IEEE geoscience and remote sensing letters. 1545-598X.

Hamran, S. E.; Berger, T.; Brovoll, S.; Damsgård, L.; Helleren, Ø.; Øyan, M. J.; Amundsen, H. E.; Carter, L.; Ghent, R. 2015. "RIMFAX: A GPR for the Mars 2020 rover mission". 2015 8th International Workshop on Advanced Ground Penetrating Radar (IWAGPR): 1-4. doi:10.1109/IWAGPR.2015.7292690. ISBN 978-1-4799-6495-6.

Kearey, P., Brooks, M., Hill, I. 2002. An introduction to geophysical exploration. Backwell Science ltd. ISBN 978-0-632-04929-5.

Kenyon, J. L. 1977. Ground-Penetrating Radar and Its Application to a Historical Archaeological Site. Historical Archaeology, v. 11, pp. 48-55.

Kress, W.H., and Teeple, A.P. 2005, Two-Dimensional Resistivity Investigation of the North Cavalcade Street Site, Houston, Texas, August 2003: U.S. Geological Survey Scientific Investigations Report 2005-5205, 32 p.

Kuppusamy, S., Maddela, N. R., Megharaj, M., Venkateswarlu, K. 2020. Total Petroleum Hydrocarbons Environmental Fate, Toxicity, and Remediation. Springer Nature Switzerland.

Lago, A. L. 2009. Investigação geofísica 2D e 3D com aplicação em meio ambiente: estudo sobre uma área de disposição de resíduos de óleo lubrificante no município de Ribeirão Preto-SP. Tese de Doutorado. Instituto de Astronomia, Geofísica e Ciências Atmosféricas. Universidade de São Paulo.

Lee, L. J.H., Chung, C.W., Ma. Y.C., Wang, G.S., Chen, P.C., Hwang, Y.H., Wang, J.D. 2003. Increased mortality odds ratio of male liver cancer in a community contaminated by chlorinated hydrocarbons in groundwater.

Loke, M.H., 1998. RES2Dinv ver. 3.3. for Windows 3.1 and 95 Rapid 2D resistivity and IP inversion using the least-squares method. Geotomo Software User's Manual, Penang, Malaysia, 35p. LOKE, M.H., 1999. Electrical Imaging Surveys for Environment and Engineering Studies: Aprectical guide to 2D and 3D surveys. Malaysia.

Loke, M. H., Barker, R. D. 1996. Practical techniques for 3D resistivity surveys and data inversion. Geophysical Prospecting, Vol. 44: 499-523.

Nash, M. S., Atekwana, E., Sauck, W. A. 1997. Geophysical investigation of anomalous conductivity at a hydrocarbon contaminated site. Proceedings of the symposium on the Application of Geophysics to Engineering and Environmental Problems. 
Netto, L. G., Barbosa, A. M., et al. 2020. Application of invasive and non-invasive methods of geo-environmental investigation for determination of the contamination behavior by organic compounds. Journal of Applied Geophysics 178, 104049.

Ortega, R. A. 2007. Localização e delineamento de plumas de contaminação por hidrocarbonetos através dos métodos GPR e Eletrorresistividade. Dissertação de Mestrado. Instituto de Astronomia, Geofísica e Ciências Atmosféricas. Universidade de São Paulo.

Orellana, E. 1972. Prospeccion Geoelétrica en corriente continua. Madrid, Ed. Paraninfo, Biblioteca Técnica Philips, 523p.

Porcello, L. J., Jordan, R. L., Zelenka, J. S., Adams, G. F., Phillips, R. J., Brown, W. E., Ward, S. H., Jackson, P. L. 1974. The Apollo lunar sounder radar system. Proceedings of the IEEE, v. 62, n. 6, p. 769-783.

Porsani, J. L. 1999. Ground Penetrating Radar (GPR): Proposta metodológica de emprego em estudos geológico-geotécnicos nas regiões de Rio Claro e Descalvado - SP. Tese de Doutorado. Instituto de Geociências de Ciências Exatas, Universidade Estadual Paulista, Rio Claro.

Porsani, J. L., Sauck, W. 2007. Ground-penetrating radar profiles over multiple steel tanks: artifact through effective data processing. Geophysics, v. 72, p. J77-J83.

Porsani, J. L., Jesus, F. A. N., Stangari, M. C. 2019. GPR survey on an irton mining area after the collapse of the tailings dam I at the córrego do Feijão mine in brumadinho- MG, Brazil Remote Sensing, 11, 860. doi.org/10.3390/rs11070860.

Roy, A., Apparao, A. 1971. Depth of investigation in direct current methods. Geophysics, Vol. 36(5), 943-959.

Rubin, L. A., Fowler, J. C. 1978. Ground-probing radar for delineation of rock features. Engineering geology, v. 12, p. 163-170.

Sandmeier, K. J. 2012. ReflexWin 7.0 - Windows ${ }^{\text {TM }}$ 9x/NT/2000/XP/7 - program for processing of Seismic, Acoustic or Electromagnetic Reflection, Refraction, and Transmission Data. Karlsruhe, Germany.

Santos, V. R. N. 2014. Detecção e classificação automática de interferências do subsolo com GPR utilizando redes neurais artificiais: estudo no SCGR do IAG/USP. Tese de Doutorado, Instituto de Astronomia, Geofísica e Ciências Atmosféricas. Universidade de São Paulo.

Sauck, W. A. 2000. A model for the resistivity structure of LNAPL plumes and their environs in sandy sediments. Journal of Applied Geophysics 442000 151-165.

Strattong, J. A. 1941. Electromagnetic Theory. McGraw Hill Book Company, New York, 615p.

Telford, W. M.; Geldart, L. P. \& Sheriff, R. E. 1990. Applied Geophysics. Second Edition, Cambridge University Press, United Kingdom, 770p.

Ustra, A. T. 2008. Utilização dos métodos eletroresistividade e polarização induzida com aquisição de dados 3D para caracterização geoambiental de uma área à jusante do aterro de resíduos sólidos 
urbanos de Bauru - SP. Dissertação de Mestrado Instituto de Astronomia, Geofísica e Ciências Atmosféricas. Universidade de São Paulo. 